\title{
ÁCAROS DE PALMEIRAS (ARECACEAE) EM ÁREAS DOS ESTADOS DE SÃO PAULO E PERNAMBUCO
}

\section{MANOEL GUEDES CORRÊA GONDIM JUNIOR}

Engenheiro Agrônomo

Orientador: Prof. Dr. GILBERTO JOSÉ DE MORAES

Tese apresentada à Escola Superior de Agricultura

'Luiz de Queiroz", Universidade de São Paulo, para obtenção do título de Doutor em Agronomia, Área de Concentração: Entomologia.

\section{PIRACICABA}

Estado de São Paulo - Brasil

Maio - 2000 
Gondim Jr., Manoel Guedes Corrêa

Ácaros de palmeiras (Arecaceae) em áreas dos Estados de São Paulo e Pernambuco / Manoel Guedes Corrêa Gondim Junior. - - Piracicaba, 2000.

161p. : il.

Tese (doutorado) - Escola Superior de Agricultura Luiz de Queiroz, 2000. Bibliografia.

1. Fitossanidade 2. Palmeira 3. Praga 4. Relação planta-ácaro I. Título 


\section{AGRADECIMENTOS}

Ao Prof. Gilberto J. de Moraes, pela orientação, confiança e respeito demonstrado durante nosso convívio.

Aos Profs. do Departamento de Entomologia, Fitopatologia e Zoologia Agrícola (ESALQ/USP), pela ajuda, colaboração no desenvolvimento deste trabalho e nas disciplinas no decorrer do curso de pós-graduação.

Ao Prof. Carlos H.W. Flechtmann, pela colaboração na realização deste trabalho.

A todos os colegas do curso de pós-graduação, em especial à equipe do Setor de Zoologia (Andréa, Anibal, Antônio Carlos, Aloysea, Cláudia, Cristiane, Jeferson, Juarez, Lázaro, Renata e Zacarias) e Entomologia (Américo, Eduardo, Everaldo, Luciana e Udinete), pela amizade e companheirismo.

Aos Profs. Ricardo R. Rodrigues e Vinícus V. Souza e a Técnica Tereza, do Departamento de Botânica (ESALQ/USP), pela ajuda na identificação das espécies de palmeiras avaliadas ao longo do trabalho de tese.

Aos Profs. Eliot W. Kitagima e Bruno Leite e a Técnica Silvania Machado, do Núcleo de Apoio à Pesquisa (ESALQ/USP), pela colaboração e suporte na realização das fotografias em microscópio eletrônico.

Ao Dr. Andre L. Lourenção e ao Instituto Agronômico de Campinas, pela colaboração e suporte nas atividades de coleta para a realização deste trabalho.

A Coordenadoria para Aperfeiçoamento de Pessoal de Ensino Superior, BIOTAFAPESP e PRONEX, pelo suporte financeiro. 
A Universidade Federal Rural de Pernambuco, pelo incentivo e apoio na realização do curso de pós-graduação.

A toda a minha familia, em especial a minha esposa e filhas, que sempre me incentivaram no meu trabalho.

Este trabalho faz parte do Programa BIOTA/FAPESP - O Instituto Virtual da Biodiversidade (www.biotasp.org.br). 
A minha esposa Cláudia Patrícia e minhas filhas Ana Beatriz e Ana Luiza, pelo companheirismo, amizade, amor e dedicação 


\section{SUMÁRIO}

Página

LISTA DE FIGURAS ........................................................................... ix

LISTA DE TABELAS .......................................................................... xii

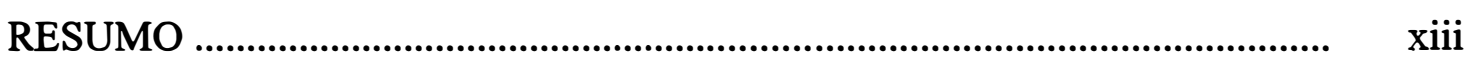

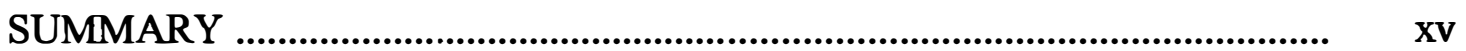

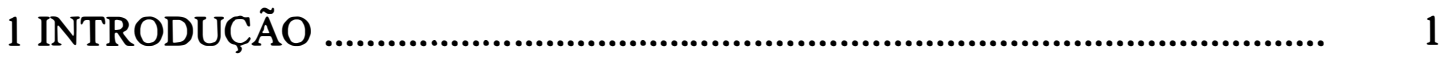

2 REVISÃO DE LITERATURA

2.1 Palmeiras no Brasil ........................................................................ 3

2.2 Estudos de biodiversidade ................................................................. 5

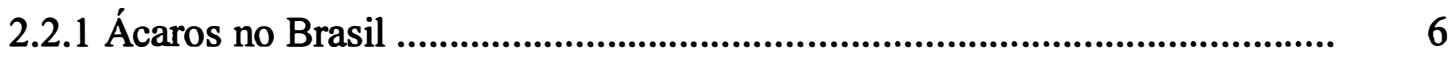

2.2.2 Ácaros em arecáceas no Brasil .............................................................. 7

2.2.3 Eriophyoidea em Arecaceae .................................................................... 8

2.2.4 Aspectos bioecológicos de Eriophyoidea ............................................. 9

2.2.5 Família Phytoseiidae ........................................................................ 10

3 ÁCAROS (ARTHROPODA: ACARI) ASSOCIADOS A PALMEIRAS (ARECACEAE) EM ÁREAS DOS ESTADOS DE SÃO PAULO E

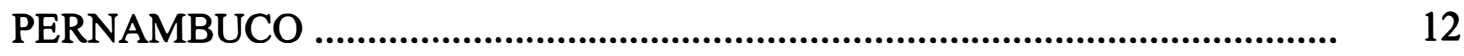

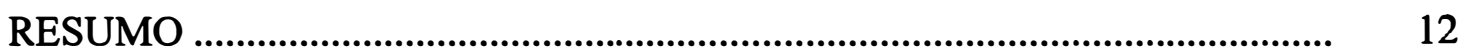

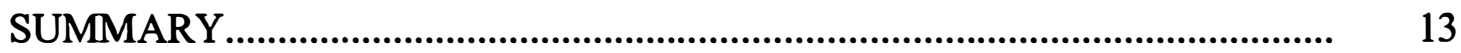

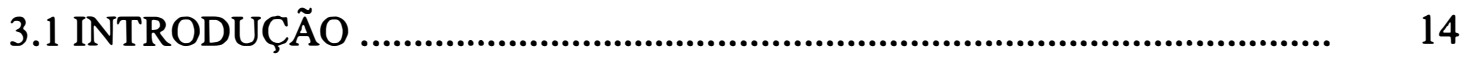

3.2 MATERIAL E MÉTODOS .................................................................... 14

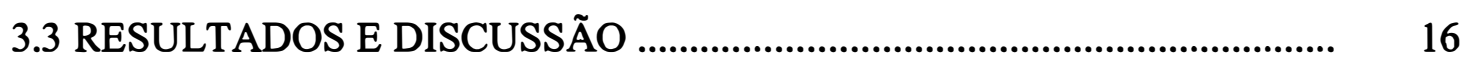

3.4 CONCLUSÕES ............................................................................... 34

4 QUATRO NOVAS ESPÉCIES DE ERIOPHYOIDEA (ARTHROPODA: ACARI) ASSOCIADOS A PALMEIRAS (ARECACEAE) EM ÁREAS DOS ESTADOS DE SÃO PAULO E PERNAMBUCO .......................................... 35

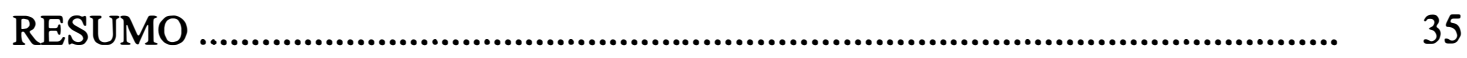


SUMMARY 36

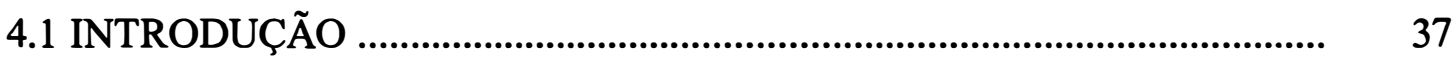

4.2 MATERIAL E MÉTODOS .................................................................... 38

4.3 RESULTADOS E DISCUSSÃO .............................................................. 40

5 FITOSEÍDEOS (ACARI: PHYTOSEIIDAE) ASSOCIADOS A PALMEIRAS (ARECACEAE) EM ÁREAS DOS ESTADOS DE SÃO PAULO E PERNAMBUCO ............................................................................

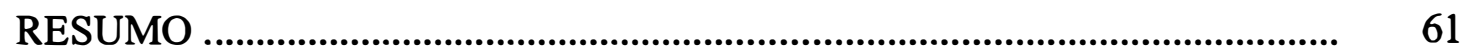

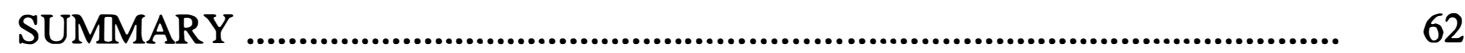

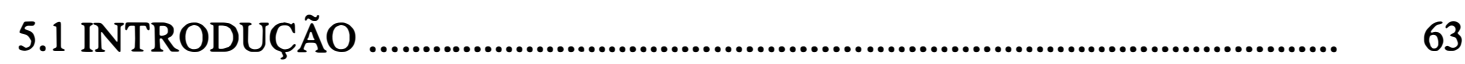

5.2 MATERIAL E MÉTODOS .................................................................... 63

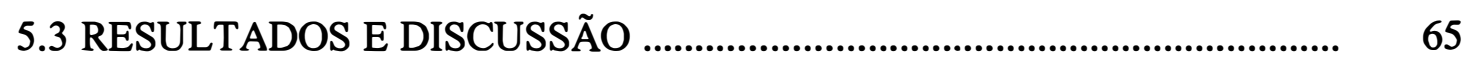

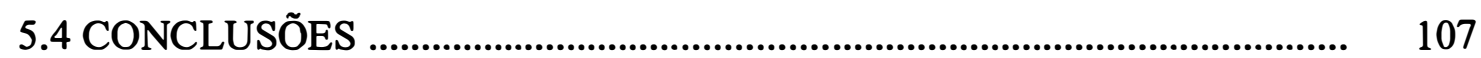

6 DESCRIÇÃO DE UMA NOVA ESPÉCIE DO GÊNERO Cocoseius (ACARI: PHYTOSEIIDAE) E REDESCRIÇÃO DO GÊNERO ........................ 108

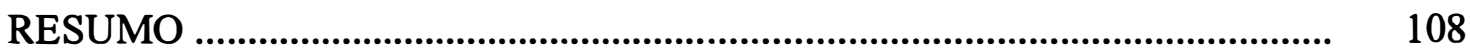

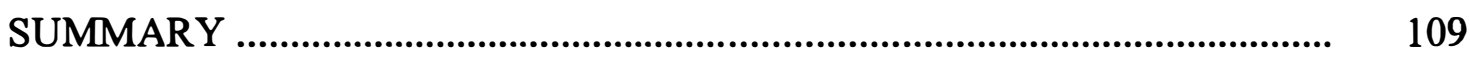

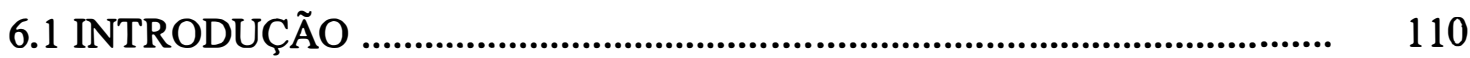

6.2 MATERIAL E MÉTODOS …................................................................ 110

6.3 RESULTADOS E DISCUSSÃO .......................................................... 110

7 CICLO DE VIDA DE Retracrus johnstoni (ACARI: PHYTOPTIDAE) ........ 117

RESUMO ............................................................................................. 117

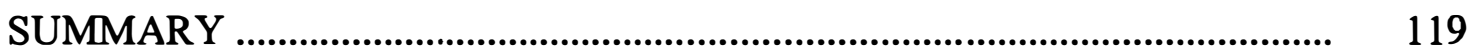

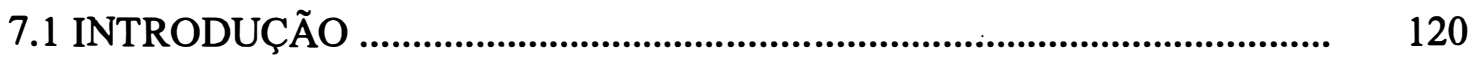

7.2 MATERIAL E MÉTODOS ................................................................. 121

7.3 RESULTADOS E DISCUSSÃO …......................................................... 123

7.4 CONCLUSÃO

8 COMPATIBILIDADE REPRODUTIVA DE DUAS POPULAÇÕES DE Iphiseiodes zuluagai (ACARI: PHYTOSEIIDAE) ............................................. 132 
Página

RESUMO

132

SUMMARY

8.1 INTRODUÇÃO

134

8.2 MATERI AL E MÉTODOS 135

8.3 RESULTADOS E DISCUSSÃO 136

8.4 CONCLUSÃO . 139 REFERÊNCIAS BIBLIOGRÁFICAS 


\section{LISTA DE FIGURAS}

\section{Página}

1 Notostrix butiae sp. n. D - Dorso; AC - Área coxigenital; AL - Vista anterolateral; P1 - Perna I; P2 - Perna II; GM - Área genital do macho; IGF Estruturas genitais internas da fêmea; ED - Empódio da perna I (vista dorsal); EV - Empódio da perna I (vista ventral)

2 Notostrix butiae sp. n. A - Vista lateral da fềmea; B - Vista ventral da fềmea; C - Vista do hipostômio e coxisterno; D - Epigínio; E - Área coxigenital do macho; F - Empódio da perna I (dorso); G - Empódio da perna I (ventre) .......

3 Notostrix nasutiformes sp. n. D - Dorso; AC - Área coxigenital; AL - Vista anterolateral; P1 - Perna I; P2 - Perna II; IGF - Estruturas internas da fềmea; GM - Área genital do macho; ED - Empódio (dorsal); EV - Empódio (ventral)

4 Notostrix nasutiformes sp. n. A - Vista dorsal; B - Área coxigenital da fêmea; C - Ornamentação do coxisterno; D - Epigínio; E - Empódio da perna I (ventral); F - Empódio da perna I (dorsal).............................................................

5 Knorella geonomae sp. n. D - Dorso; AC - Área coxigenital; AL - Vista anterolateral; P1 - Perna I; P2 - Perna II; E - Empódio; GM - Área genital do macho; IGF - Estruturas internas da genitália feminina..

6 Knorella geonomae sp. n. A - Vista dorsal; B - Epigínio; C - Área lateral do coxisterno; E - Ventre do opistossoma; F - tarso I.

7 Propilus syagris sp. n. D - Dorso; ACF - Área coxisternal da fêmea; ACM Área coxisternal do macho; P1 - Perna I; P2 - Perna II; ED - Empódio (vista dorsal); EV - Empódio (vista ventral); EGF - Estruturas genitais internas da fềmea; GM - Área genital do macho

8 Propilus syagris sp. n. A - Vista dorsal; B - Omamentação do escudo prodorsal; C - Vista anterolateral do escudo prodorsal; D - vista ventral do opistossoma; E - Área coxigenital; F - Tarso I 
Página

9-12 Amblyseius euterpes sp. n. 9, placa dorsal; 10, placas ventrais; 11, genu, tíbia e pré-tarso da perna IV; 12 , cérvix da espermateca

13-17 Amblyseius geonomae sp. n. 13, placa dorsal; 14, placas ventrais; 15, genu, tíbia e pré-tarso da perna IV; 16 , cérvix da espermateca; 17 , quelícera

18-22 Amblyseius igarassuensis sp. n. 18, placa dorsal; 19, placas ventrais; 20, genu, tíbia e pré-tarso da perna IV; 21 , cérvix da espermateca; 22 , quelícera

23-27 Iphiseiodes setillus sp. n. 23, placa dorsal; 24, placas ventrais; 25, genu, tíbia e pré-tarso da perna IV; 26, cérvix da espermateca; 27, quelícera

28-32 Neoseiulus recifensis sp. n. 28, placa dorsal; 29, placas ventrais; 30, genu, tíbia e pré-tarso da perna IV; 31 , cérvix da espermateca; 32 , quelícera .......

33-36 Neoseiulus veigai sp. n. 33, placa dorsal; 34, placas ventrais; 35, genu, tíbia e pré-tarso; 36 , cérvix da espermateca

37-40 Paraamblyseius multicircularis sp. n. 37, placa dorsal; 38, placas ventrais; 39, genu, tíbia e pré-tarso da perna IV; 40 , cérvix da espermateca

41-45 Typhlodromips ariri sp. n. 41, placa dorsal; 42, placas ventrais; 43, genu, tíbia e pré-tarso da perna IV; 44 , cérvix da espermateca; 45 , quelíceras .

46-52 Typhlodromips cananeaensis sp. n. 46, placa dorsal da fềmea; 47, placas ventrais da fềmea; 48 , genu, tíbia e pré-tarso da fềmea; 49 , cérvix da espermateca; 50, quelíceras da fềmea; 51 , placa ventrianal do macho; 52 , espermadáctilo

53-57 Typhlodromips jucara sp. n. 53, placa dorsal; 54, placas ventrais; 55, genu, tíbia e pré-tarso; 56 , cérvix da espermateca; 57 , quelíceras.

58-59 Cocoseius palmarum sp. $\mathrm{n}$. (larva). 58, vista dorsal; 59, vista ventral

60-61 Cocoseius palmarum sp. n. (protoninfa). 60, vista dorsal; 61, vista ventral .

62-63 Cocoseius palmarum sp. n. (deutoninfa). 62, vista dorsal; 63, vista ventral .

64-68 Cocoseius palmarum sp. n. (fềmea). 64, vista dorsal; 65, vista ventral; 66 , Genu, tíbia e tarso da perna IV; 67, espermateca; 68, quelícera 
Página

69 Criação de Retracrus johnstoni em laboratório a 25,8土2,00C; $56 \pm 5 \%$ de umidade relativa 14 horas de fotofase

70 Retracrus johnstoni. A, ovo sem cera; B, ovo com cera; C, ninfa I; D, ninfa II; $\mathrm{E}$, exúvia; $\mathrm{F}$, adulto. 126

71 Espermatóforo de Retracrus johnstoni

72 Sintomas provocados por Retracrus johnstoni a face abaxial da folha de Syagrus romanzoffiana

73 Sintomas provocados por Retracrus johnstoni a face superior da folha de Syagrus romanzoffiana 129

74 Colônia de Retracrus johnstoni em Syagrus romanzoffiana 


\section{LISTA DE TABELAS}

Página

1 Duração dos estágios de desenvolvimento e reprodução, em dias, e fecundidade de Retracrus johnstoni em Syagrus romanzoffiana a $25,8 \pm 2,0^{\circ} \mathrm{C}, 56 \pm 5 \%$ de umidade relativa e 14 horas de fotofase

2 Médias dos parâmetros morfológicos, expressos em micrômetros, de fềmeas de 2 populações identificadas como Iphiseiodes zuluagai, coletadas em Citrus sp. e Arecaceae no Estado de São Paulo. 1999.

3 Cruzamentos e retrocruzamentos entre duas populações identificadas como Iphiseiodes zuluagai, coletadas em Citrus sp. e Arecaceae no Estado de São Paulo. 1999. 


\title{
ÁCAROS DE PALMEIRAS (ARECACEAE) EM ÁREAS DOS ESTADOS DE SÃO PAULO E PERNAMBUCO
}

\author{
Autor: MANOEL GUEDES CORREAA GONDIM JUNIOR \\ Orientador: Prof. Dr. GILBERTO JOSÉ DE MORAES
}

\section{RESUMO}

As espécies de ácaros em palmeiras em áreas dos Estados de São Paulo e Pernambuco foram avaliadas neste estudo. O número de espécies foi elevado, principalmente da superfamília Eriophyoidea e família Phytoseiidae. Doze espécies da superfamília Eriophyoidea são relatadas, sendo 4 espécies novas para a ciência e 2 novos relatos para o Brasil. Retracrus johnstoni Keifer, um eriofídeo da família Phytoptidae, apresentou a maior distribuição e número de plantas hospedeiras. Este foi também encontrado em altas populações em Syagrus romanzoffiana (Cham.) Glassman em Piracicaba, Estado de São Paulo e tem sido mencionado na literatura como importante praga de Arecaceae. A biologia deste ácaro foi estudada a $25,8 \pm 2,0^{\circ} \mathrm{C}, 56 \pm 5 \%$ umidade relativa e $14 \mathrm{~h}$ de fotofase. Os parâmetros obtidos foram: desenvolvimento de ovo a adulto de 20,5 dias, longevidade de 19,1 dias, fecundidade de 5,4 ovos/fềmea e razão sexual de 2 fềmeas para 1 macho. Os sintomas causados por $R$. johnstoni foram descritos, e a morfologia de cada estágio de desenvolvimento e do espermatóforo foram estudados através de microscopia eletrônica de varredura. Quarenta e quatro espécies de fitoseídeos foram identificadas, sendo 11 novas para a ciência e 3 novos relatos para o Brasil. Iphiseiodes zuluagai Denmark \& Muma, foi o fitoseídeo mais comum e abundante. Devido a ocorrência comum deste ácaro em várias culturas, a 
compatibilidade reprodutiva entre populações coletadas em S. romanzoffiana e Citrus sp., ambas identificadas como I. zuluagai, foi estudada. Ácaros de ambas populações foram cruzados livremente e produziram um número normal de descendentes, indicando que eles são compatíveis reprodutivamente, e que a vegetação nativa pode funcionar como reservatório de $I$. zuluagai para plantas cultivadas comercialmente. $\mathrm{O}$ gênero Cocoseius foi redescrito. Outros grupos de ácaros são mencionados como as famílias Ascidae, Bdellidae, Cheyletidae, Cunaxidae, Eupodidae, Neophyllobiidae, Raphygnathidae, Stigmaeidae, Tarsonemidae, Tenuipalpidae, Tetranychidae e Tydeidae. 


\title{
MITES OF THE PALM TREES (ARECACEAE) ON AREAS OF THE STATES OF SÃO PAULO AND PERNAMBUCO
}

\author{
Author: MANOEL GUEDES CORRÊA GONDIM JUNIOR \\ Adviser: Prof. Dr. GILBERTO JOSÉ DE MORAES
}

\section{SUMMARY}

The mite species on palm threes in areas of the States of São Paulo and Pernambuco were evaluated in this study. The number of species was high, mainly in the superfamily Eriophyoidea and the family Phytoseiidae. Twelve species of the superfamily Eriophyoidea were found, 4 of which are new to science and 2 are found for the first time in Brazil. Retracrus johnstoni Keifer, an eriophyoid of the family Phytoptidae, showed the widest distribution and the highest number of host plants. It was found in high populations on Syagrus romanzoffiana (Cham.) Glassman in Piracicaba, State of São Paulo and it has been mentioned in the literature as an important pest of Arecaceae. The biology of this species was studied at $25,8 \pm 2,0^{\circ} \mathrm{C}, 56 \pm 5 \%$ relative humidity and $14 \mathrm{~h}$ of photophase. The following parameters were obtaind: development from egg to adult 20.5 days, longevity 19.1 days, fecundity 5.4 eggs/female and sexual rate of 2 females: 1 male. The symptoms caused by $R$. johnstoni mite were described, and the morphology of each developmental stage and the spermatophore was studied under SEM. Forty-four species of Phytoseiidae were identified, 11 of which are new to science and 3 are new records for Brazil. Iphiseiodes zuluagai Denmark \& Muma, was the phytoseiid most widespread and abundant. Because of its common occurrence on several crops, the reproductive compatibility between a populations from 
S. romanzoffiana and a population from Citrus sp., both identified as I. zuluagai, was studied. Mites of both populations crossed freely and produced a normal number of offspring, indicating that they are reproductively compatible, and that the native vegetation could function as a reservoir of $I$. zuluagai to plants grown commercially. The genus Cocoseius was redescribed. Other groups of mites are also mentioned in the families Ascidae, Bdellidae, Cheyletidae, Cunaxidae, Eupodidae, Neophyllobiidae, Raphygnathidae, Stigmaeidae, Tarsonemidae, Tenuipalpidae, Tetranychidae and Tydeidae. 


\section{INTRODUÇÃO}

As palmeiras são plantas monocotiledôneas pertencentes à família Arecaceae. A palavra palma, que denomina vulgarmente as plantas desta família, é originária de povos do Mediterrâneo, que aplicavam-na à tamareira (Phoenix dactilifera L.) (Lorenzi, 1996).

Ácaros são organismos do filo Artropoda, subfilo Chelicerata, classe Arachnida e subclasse Acari. São artrópodos que geralmente apresentam 4 pares de pernas nas fases pós-larvais, corpo não segmentado, apêndices articulados e esqueleto externo (Flechtmann, 1975).

O termo biodiversidade pode ser entendido como variedade de vida, referindo-se à diversidade taxonômica ou de espécies, diversidade de ecossistemas e diversidade genética (Gaston, 1996). O primeiro passo no conhecimento da biodiversidade de qualquer grupo é a determinação das espécies que o constituem. Entretanto, a diversidade de espécies de ácaros em plantas da família Arecaceae ainda é pouco conhecida no Brasil, onde apenas 17 espécies de ácaros já foram relatadas em palmeiras nativas e exóticas. Este número é muito pequeno se considerarmos que mais de 400 espécies de palmeiras são encontradas no Brasil, algumas das quais de grande importância econômica, como o coqueiro (Cocos nucifera L.) e o dendezeiro (Elaeis guineensis N.J. Jacquin).

Apesar de ser a acarologia uma disciplina relativamente recente, aproximadamente 2.000 pessoas hoje se dedicam a este estudo em todo mundo. Apenas no Brasil, cerca de 60 pesquisadores conduzem algum tipo de investigação acarológica. Entretanto, a maioria destes pesquisadores se dedica ao estudo da acarologia aplicada, poucos se interessam pela taxonomia ou outros aspectos de estudos de diversidade acarológica. 
A taxonomia é uma disciplina básica para o estudo de biodiversidade, contudo seguindo uma tendência mundial, poucos pesquisadores brasileiros se dedicam à taxonomia de ácaros (Flechtmann \& Moraes, 1999). Há necessidade de se formar mão de obra capaz de identificar material deste grupo, sob pena de em um futuro muito próximo as pesquisas desenvolvidas no Brasil ficarem totalmente na dependência de pesquisadores de outros países.

Este trabalho teve por objetivo estudar a composição faunística da subclasse Acari em palmeiras nativas e exóticas em áreas dos Estados de São Paulo e Pernambuco, e com isto possibilitar o treinamento e capacitação em taxonomia de ácaros, principalmente da superfamília Eriophyoidea e da família Phytoseiidae. 


\section{REVISÃO DE LITERATURA}

\subsection{Palmeiras no Brasil}

As palmeiras são plantas arbóreas, cuja raiz primária é substituída por raízes secundárias fasciculadas. $O$ estipe é lignificado. As folhas são espiraladas, em nós abreviados, dispostos no ápice do estipe em forma de coroa. Geralmente são pinadas ou em forma de um leque quando adultas, persistindo frequentemente por mais de um ano na planta. As flores são geralmente unissexuadas, regularmente trímeras e actinomorfas. O fruto é uma baga ou drupa (Gemtchujnicov, 1976).

A família Arecaceae contém aproximadamente 2700 espécies (Henderson et al., 1995) distribuídas em 200 gêneros, ocorrendo nas regiões tropicais e subtropicais (Uhl \& Dransfield, 1987). Apesar de não ser a maior família em número de espécies, é sem dúvida uma das que possui maior diversidade morfológica (Evans, 1995), sendo um grupo notável ainda pelo elevado número de espécies de importância econômica (Macarto, 1999).

No Brasil já foram constatadas 284 espécies de arecáceas, sendo 132 nativas e 152 exóticas. Algumas são conhecidas por nomes vulgares que as identificam, mas muitas não os possuem ou se possuem dão origem a uma grande confusão por serem aplicados a plantas totalmente diferentes. São características da flora tropical e a maior ocorrência de gêneros e espécies verifica-se na Ásia, Ilhas do Pacífico e América (Lorenzi, 1996).

A chamada zona dos cocais (pindorama) abrange extensas regiões do norte e nordeste, em direção ao centro do Brasil. Caracteriza-se pelos babaçuais, camaubais, buritizais e, em direção ao oeste os carandasais. As demais regiões do país são uma 
verdadeira colcha de retalhos, salpicada na Amazônia por plantas de buritis, tucumãs, inajás, marajás, jarinas, pupunhas e açaís; no centro pelos jerivás, macaúbas, guarirobas e bacuris; do centro para o sul pelos jerivás, juçaras e butiás; no centro-leste pelos licuris e buris; nos cerrados do centro pelos indaiás do campo; certos trechos da Serra do Mar pelos indaiás do litoral, pindobas, patis, guaricangas, içás e brejaúvas e à beira-mar pelos guriris e tucuns (Lorenzi, 1996).

As espécies de maior importância econômica no Brasil são os palmitos açai (Euterpe oleracea Mart.), juçara (Euterpe edulis Mart.) e pupunha (Bactris gasipaes Kunth); a carnaúba (Copernicia prunifera (Miller) H.E. Moore); o babaçu (Attalea speciosa Mart. ex Spreng.); o dendezeiro (Elaeis guineensis N.J. Jacquin) e o coqueiro (Cocos nucifera L.).

A juçara é uma espécie de ampla distribuição ao longo do litoral brasileiro, ocorrendo naturalmente desde o sul da Bahia até o Rio Grande do Sul, encontrada no extrato mediano da mata (Lorenzi, 1996). É uma planta com diversas aplicações em construções rurais, podendo ser usada também na produção de papel e celulose. Contudo, seu uso mais nobre é na produção de palmito para a alimentação (Furia, 1993).

O açai é uma palmeira encontrada na Amazônia, principalmente nas regiões de baixada (Lorenzi, 1993). O uso desta planta é bastante extenso. A raiz é usada como vermífugo, seu estipe tem grande utilidade nas construções rurais, os frutos são bastante utilizados como alimento e bebida, as folhas como cobertura de casas e o palmito na alimentação humana (Jardim \& Anderson, 1987).

A pupunha é uma planta bastante rústica, melhorada geneticamente e extensamente distribuída. Seu principal produto é o palmito, mas seu estipe, raízes e frutos também têm ampla aplicação à semelhança de outras espécies de palmito (Barbosa, 1993).

O babaçu é encontrado em áreas extensas, desde o Acre até o Maranhão. É a maior fonte de óleo de sementes silvestres para uso doméstico do mundo, sendo utilizado também na perfumaria, saboaria e lubrificação de máquinas (Lorenzi, 1996).

A carnaúba é encontrada desde a Bahia até o Maranhão, principalmente nos Estados do Piauí e Ceará. Possui grande potencial paisagístico e madeira forte. As fibras 
das folhas são muito utilizadas na produção de artesanato. $\mathrm{O}$ principal produto da camaúba é a cera extraída de suas folhas (Lorenzi, 1996).

O dendezeiro é uma palmeira africana, bastante difundida nas regiões tropicais do mundo, respondendo por $12 \%$ de todo óleo vegetal mundialmente produzido. O óleo extraído dos frutos é utilizado na culinária e indústria, sendo o Brasil um dos maiores produtores (Canizo, 1991).

O coqueiro é uma palmeira que ainda não tem sua origem defmida e aceita consensualmente pelos estudiosos do assunto, apesar dos diversos estudos taxonômicos e filogenéticos envolvendo esta espécie. A hipótese mais aceita considera que a planta é originária do sudoeste asiático ou ilhas do Pacífico Sul, tendo se dispersado ao longo do tempo até a África e daí, através de correntes marítimas, até as Américas (Harries, 1978).

A cultura do coqueiro tem considerável importância na alimentação e obtenção de mais de 100 produtos, em mais de 86 países na zona tropical do globo terrestre. Trata-se de uma das mais importantes culturas perenes, apropriada a um sistema autosustentável de exploração, como verificado em vários países do continente asiático, onde é uma importante fonte geradora de divisas e a principal fonte de proteínas e calorias para a população. Do coqueiro, praticamente tudo é utilizado: raiz, estipe, inflorescência, folhas, palmito e principalmente o fruto que, gera diversos produtos, mediante transformações geralmente simples (Cuenca, 1994).

Muitas das demais espécies de palmeiras são mundialmente exploradas comercialmente como omamentais. A família Arecaceae é constituída de plantas imponentes, que embelezam sobremaneira os jardins de casas e parques. Seu aspecto está associado às matas que fascinam as pessoas e transmitem um sentimento de diversidade biológica comum à flora tropical (Lorenzi, 1996).

\subsection{Estudos de biodiversidade}

A biodiversidade refere-se à diversidade de plantas, animais e microorganismos existentes na natureza e suas interações com o ecossistema. Esta tem sido reduzida 
drasticamente devido às atividades agrícolas em extensas áreas. A consequência desta simplificação é a intervenção cada vez mais frequente do homem nestes ambientes, através de práticas que reduzem a população de organismos considerados pragas (Altiere, 1994).

O estudo da biodiversidade envolve a análise das interações entre os vários componentes bióticos do ecossistema, que se mantém naturalmente em equilibrio. $\mathbf{O}$ conhecimento da biodiversidade pode de forma pragmática facilitar o desenvolvimento ou adoção de práticas agrícolas sustentáveis. Pode ainda auxiliar a avaliação do potencial das espécies de se tornarem pragas ou agir como inimigos naturais, e tentar prever o impacto que elas podem causar ao ambiente. Apesar de certas espécies serem consideradas indesejáveis pelo seu comportamento parasitário sobre plantas e animais, a maioria das espécies desempenha papel importante atuando como inimigos naturais de outros ácaros, insetos e plantas daninhas, ou como presas alternativas para diferentes grupos de predadores (Flechtmann \& Moraes, 1999).

Um exemplo do interesse pelo estudo de diversidade de ácaros se refere ao ácaro da necrose do olho do coqueiro, Aceria guerreronis Keifer. Este eriofideo foi introduzido recentemente no continente asiático, causando sérios prejuízos em diversos países, onde esta cultura constitui uma das bases da agricultura autosustentável. Atualmente, tenta-se descobrir o centro de origem desta espécie para buscar neste local informações a respeito de seus inimigos naturais, capazes de atenuar os efeitos causados por sua infestação.

\subsection{1 Ácaros no Brasil}

Os ácaros constituem um dos grupos de animais que mostram grande diversidade de formas, habitats e comportamento, sendo encontrados em quase todos os locais acessíveis à vida animal. Estima-se que existam pelo menos cerca de 500 mil espécies de ácaros no mundo. Contudo, apenas cerca de 30 mil espécies são atualmente conhecidas. Portanto, o conhecimento sobre a diversidade de espécies de ácaros é ainda bastante incipiente (Flechtmann, 1983). 
De maneira geral, pode-se dizer que a maioria dos grupos de ácaros da fauna nacional é pouco conhecida. Alguns grupos foram mais explorados, especialmente as famílias Rhinonyssidae e Laelapidae (Amaral, 1968; Castro, 1948); Uropodidae (Wisniewski, 1993), carrapatos (Aragão, 1936); oribatídeos (Perez-Inigo \& Bagio, 1994, 1996, 1997), ácaros fitófagos das famílias Tetranychidae, Tenuipalpidae, Tarsonemidae e superfamília Eriophyoidea (Flechtmann, 1983) e os predadores da família Phytoseiidae (Denmark \& Muma, 1973; El-Benhawy, 1978; Moraes \& McMurtry, 1983).

Além destes trabalhos, algumas publicações importantes tratam de certos grupos de ácaros em nível mundial, incluindo os ácaros encontrados no Brasil. Estas publicações são catálogos como aqueles das famílias Tetranychidae (Bolland et al., 1998), superfamília Eriophyoidea (Amrine \& Stasny, 1994) e família Phytoseiidae (Moraes et al., 1986).

\subsection{2 Ácaros em arecáceas no Brasil}

A composição de espécies de ácaros em plantas da família Arecaceae ainda é pouco conhecida no Brasil, à exceção de alguns trabalhos específicos da superfamília Eriophyoidea (Flechtmann, 1989, 1994, 1997a, 1998).

Apenas 7 espécies de eriofideos foram relatadas sobre estas plantas no Brasil, sendo elas: A. guerreronis em C. nucifera (Aquino \& Amuda, 1976) e Lytocaryum weddellianum (H. Wendl.) Tol. (Flechtmann, 1989), Amrineus cocofolius Flechtmann em C. nucifera (Flechtmann, 1994), Notostrix attenuata Keifer em C. nucifera (Flechtmann \& Santana, 1997), Notostrix exigua Flechtmann em E. edulis (Flechtmann, 1989); Notostrix jamaicae Keifer em C. nucifera (Santana \& Flechtmann, 1998), Rhynacus palmeus Flechtmann em Syagrus romanzoffiana (Cham.) Glassman (Flechtmann, 1998), e Retracrus johnstoni Keifer em C. nucifera e S. romanzoffiana (Santana et al., 1994).

Três espécies de ácaros fitófagos da familia Tetranychidae foram identificados no Brasil, Tetranychus mexicanus (McGregor) em C. nucifera, Tetranychus neocaledonicus André em B. gasipaes e Tetranychus nomurai Flechtmann em Attalea 
phalerata Mart. ex Spreng. Uma espécie não identificada de tetraniquídeo do gênero Oligonychus em Roystonea oleraceae (N.J. Jacquin) O.F. Cook e B. gasipaes (Flechtmann, 1967 e 1997b; Santana \& Flechtmann, 1998). A única outra espécie fitófaga registrada no Brasil foi o tenuipalpídeo Brevipalpus phoenicis (Geijskes) em Phoenicis canariensis Hort. ex Chaband., R. oleracea, E. guineensis e Syagrus sp. (Santana \& Flechtmann, 1988).

Quase todas as outras espécies registradas pertencem à família Phytoseiidae, constituída por ácaros predominantemente predadores. As espécies encontradas foram Paraseiulella eliptica (DeLeon) em C. nucifera (Flechtmann, 1967), Amblyseius chiapensis DeLeon em A. phalerata, Amblyseius herbicolus (Chant) em $S$. romanzoffiana, Euseius alatus DeLeon em C. nucifera e Euseius citrifolius Denmark \& Muma em R. oleracea (Santana \& Flechtmann, 1998).

Outras espécies encontradas foram os predadores Cheletogenes ornatus (Canestrini \& Fangozo) (Cheyletidae) e Zetzellia sp. (Stigmaeidae), assim como Tydeus sp. (Tydeidae), cujo hábito alimentar ainda não é devidamente conhecido (Santana \& Flechtmann, 1998).

\subsubsection{Eriophyoidea em Arecaceae}

A família Arecaceae é composta por aproximadamente 2700 espécies (Henderson et al., 1995), enquanto a superfamília Eriophyoidea é composta por aproximadamente 3100 espécies (Amrine \& Stasny, 1994). Contudo, a ocorrência de eriofídeos em arecáceas é conhecida em apenas 16 espécies de palmeiras, sendo elas: Aiphanes 'sp., Borassus flabellifer L., Calamus australis L., Chamaedorea sp., Chamaerops humilis L., C. nucifera, E. guineensis, E. edulis, L. weddellianum, $P$. canariensis, Phoenix dactilifera L., Phoenix reclinata N.J. Jacquin, Roystonea regia (H.B.K) O.F. Cook, Roystonea sp., S. romanzoffiana e Trachycarpos fortunei (W.J. Hooker) H. Wendl. (Amrine \& Stasny, 1994; Santana \& Flechtmann, 1998). Dentre estas, apenas $B$. flabellifer e $C$. australis não ocorrem neste país, e apenas 3 espécies são nativas do Brasil, sendo elas: E. edulis, $L$. weddellianum e $S$. romanzoffiana, as demais 
são introduzidas (Lorenzi, 1996).

Em arecáceas são conhecidas 35 espécies de eriofídeos reunidos em 23 gêneros. Estes gêneros apresentam uma variação, quanto a sua especificidade em relação as arecáceas. Alguns só ocorrem em palmeiras, enquanto outros ocorrem em palmeiras e outros grupos de plantas. Os gêneros Acathrix, Adenoptus, Amrineus, Dialox, Gilorovella, Mackiella, Nacerimina, Neocupacarus, Neodialox, Notostrix, Propilus, Retracrus, Rhynacus, Tumescoptes e Scolocenus são bastante específicos, ou seja todas as espécies constituintes destes gêneros só são encontrados até o momento em arecáceas. Enquanto os gêneros Acamina, Aceria, Acrinotus, Colocerus, Diptacus, Epitrimerus, Phyllocoptes e Tegonotus possuem espécies que ocorrem em arecáceas e outras espécies que ocorrem em plantas de famílias diferentes (Amrine \& Stasny, 1994; Flechtmann, 1998).

A especificidade dos eriofídeos é bastante conhecida e a maioria das espécies possui uma única planta hospedeira ou um grupo bastante reduzido, constituído por vegetais do mesmo gênero ou família (Oldfield, 1996). Isto pode ser facilmente demonstrado em arecáceas. O gênero Propilus é constituído por 2 espécies que só ocorrem em Aiphanes sp. que é um gênero endêmico da região Neotropical. $\mathrm{O}$ gênero Notostrix é composto por 4 espécies que ocorrem apenas em palmeiras nas regiões Neotropical e Oriental. O gênero Retracrus é composto por 2 espécies que ocorrem em várias espécies de palmeiras na região Neotropical (Amrine \& Stasny, 1994).

\subsubsection{Aspectos bioecológicos de Eriophyoidea}

Os eriofideos são ácaros vermiformes, medindo de 0,1 a $0,3 \mu \mathrm{m}$ de comprimento. Constituem um grupo que além do pequeno tamanho apresenta uma grande simplificação na estrutura geral do corpo, sendo todos fitófagos (Flechtmann, 1975).

A maior parte dos ácaros é ovípara, dando origem a larvas geralmente hexápodas, exceto na superfamilia Eriophyoidea, que apresenta apenas dois pares de pernas durante todos os estágios de desenvolvimento. As formas imaturas dos ácaros passam normalmente por três estágios ninfais até chegarem a fase adulta. Já os 
eriofideos passam por apenas 2 estágios imaturos (Flechtmann, 1983). Contudo, nem todos os eriofideos apresentam um desenvolvimento simples. Alguns mostram alternância de gerações e tais espécies são conhecidas de plantas de folhas decíduas da região temperada (Flechtmann, 1975).

Em seu processo reprodutivo, os ácaros apresentam, via de regra, a fertilização dos ovos, com a subsequente produção de uma descendência constituída por machos e fềmeas. Pode ocorrer a cópula, com a introdução do material seminal na fềmea, ou o macho pode deixar este material sobre o substrato, que é recolhido pela fềmea (Flechtmann, 1983). Em eriofídeos, a transferência direta de espermatozóides não ocorre. Os machos depositam os espermatozóides em espermatóforos, sobre o substrato. As fềmeas localizam este material e recolhem o esperma ou o endoespermatóforo contido nesta estrutura (Oldfield \& Michalska, 1996).

Os eriofídeos apresentam comportamento diferente em relação aos seus hospedeiros, alguns causando vários tipos de alterações nos tecidos das plantas e outros que não causam dano algum. Uma característica geral para a maioria das espécies é o pequeno número de plantas hospedeiras. Algumas espécies só ocorrem em uma espécie de vegetal, enquanto outras se restringem a plantas de um único gênero ou família (Flechtmann, 1975).

\subsubsection{Familia Phytoseiidae}

Os fitoseídeos constituem o principal grupo de ácaros predadores de ácaros fitófagos. A diversidade deste grupo era pouco conhecida até aproximadamente a metade deste século. A partir de então, desmatamentos, utilização de agrotóxicos e grandes alterações no ecossistema decorrentes das atividades agrícolas proporcionaram 0 surgimento cada vez mais crescente de surtos de ácaros fitófagos. Subsequentemente, o estudo da utilização dos fitoseídeos como inimigos naturais de ácaros fitófagos possibilitou o incremento da taxonomia deste grupo (Moraes, 1991).

De acordo com os padrões biológicos, espécies são grupos de populações naturais com capacidade de reprodução entre si e que são isolados reprodutivamente de 
outros grupos de populações (Mayr, 1977). Contudo, a identificação das espécies é normalmente feita baseando-se apenas em caracteres morfológicos. Esta prática tem causado equívocos ao longo dos anos, exigindo às vezes a necessidade de realização de outros testes para a correta identificação. $O$ estudo da identificação de espécies pode ainda ser feito por meios biológicos (testes de cruzamento e de comportamento), bioquímicos (eletroforese) e moleculares (Furtado, 1997).

Diversos são os casos na literatura que mostram diferentes populações de fitoseídeos identificadas morfologicamente como pertencentes a determinada espécie, mas que apresentam algum tipo de incompatibilidade reprodutiva. Em alguns casos, evidencia-se que estas populações pertencem a espécies próximas, mas diferentes (Braun et al., 1993; McMurtry, 1980). No caso específico de predadores desta família, uma identificação errônea pode causar grandes prejuízos, particularmente em programas de controle biológico, ao se identificar e utilizar uma espécie inadequada de predador.

A distinção entre espécies morfologicamente muito próximas pode ser frequentemente feita através de testes de cruzamento, onde se analisa a compatibilidade reprodutiva entre diferentes populações. A incompatibilidade reprodutiva pode estar ligada às características de cada população, ou a outros fatores, como pela presença de microorganismos simbiontes no aparelho reprodutivo dos ácaros (Werren, 1997). 


\section{3 ÁCAROS (ARTHROPODA, ACARI) ASSOCIADOS A PALMEIRAS (ARECACEAE) EM ÁREAs dos ESTAdos de São PaUlo E PERNAMBUCO}

\section{RESUMO}

Este trabalho relata a ocorrência de ácaros em 24 espécies de Arecaceae nativas e 13 espécies de Arecaceae exóticas em áreas dos Estados de São Paulo e Pernambuco. São relatados pela primeira vez no Brasil Propilus gentyi Keifer e Propilus spinosus Keifer (Prostigmata: Phytoptidae); Steneotarsonemus furcatus DeLeon (Prostigmata: Tarsonemidae); Tenuipalpus coyacus DeLeon (Prostigmata: Tenuipalpidae) e os gêneros Cyta (Prostigmata: Bdellidae); Neotarsonemoides e Xenotarsonemus (Prostigmata: Tarsonemidae); Apotriophtydeus, Metatriophtydeus, Neollorryia, Nudilorryia, Perafrotydeus e Quasitydeus (Prostigmata: Tydeidae). 


\section{MITES (ARTHROPODA, ACARI) ASSOCIATED WITH PALM THREES ARECACEAE IN AREAS OF SÃO PAULO AND PERNAMBUCO STATES}

\section{SUMMARY}

This work reports the occurrence of mites on 24 species of native and 13 species of exotic Arecaceae in areas of the States of São Paulo and Pernambuco. The following species are reported for the first time in Brazil: Propilus gentyi Keifer; Propilus spinosus Keifer (Prostigmata: Phytoptidae); Steneotarsonemus furcatus DeLeon (Prostigmata: Tarsonemidae); Tenuipalpus coyacus DeLeon (Prostigmata: Tenuipalpidae) and the genera Cyta (Prostigmata: Bdellidae); Neotarsonemoides and Xenotarsonemus (Prostigmata: Tarsonemidae); Apotriophtydeus, Metatriophtydeus, Neollorryia, Nudilorryia, Perafrotydeus and Quasitydeus (Prostigmata: Tydeidae). 


\subsection{INTRODUÇÃO}

Apesar da grande importância das palmeiras, pouco se conhece sobre a fauna de ácaros que ocorrem neste grupo de plantas no Brasil. São conhecidas até o momento 7 espécies de eriofídeos, 3 de tetraniquídeos, 1 de tenuipalpídeo, 5 de fitoseídeos, 1 de queiletídeo e espécies não identificadas dos gêneros Tydeus e Zetzellia (Flechtmann 1967, 1997a, 1997b, 1998; Santana \& Flechtmann, 1998). Dentre estas, Aceria guerreronis Keifer (Eriophyidae) é considerada uma praga de grande importância econômica, ocorrendo em Cocos nucifera L., em várias regiões das Américas e África (Moore \& Howard, 1996), tendo sido recentemente introduzida no Sudeste Asiático (G.J de Moraes, informação pessoal).

Tem havido recentemente um grande aumento da área plantada com culturas da família Arecaceae no Brasil, principalmente C. nucifera e Bactris gasipaes Kunth. (Ferreira, 1997; Tonet et al., 1999) e em menor escala, palmeiras do gênero Euterpe. O aumento da área plantada com estas culturas pode favorecer a ocorrência de altas populações de ácaros fitófagos, principalmente em locais onde o clima é bastante diferente do ambiente natural destas plantas. Recentemente, também tem sido verificadas altas infestações de Retracrus johnstoni Keifer (Phytoptidae) em plantios de $B$. gasipaes, atribuindo-se esta incidência ao uso de genótipos mais susceptíveis (Ferrreira, 1997).

Em virtude do pouco conhecimento atual sobre a composição faunística dos ácaros presentes em palmeiras no Brasil, foi realizado um levantamento de ácaros em plantas exóticas e nativas desta família, nos Estados de São Paulo e Pemambuco, para se conhecer melhor a fauna de ácaros fitófagos, assim como de seus inimigos naturais.

\subsection{MATERIAL E MÉTODOS}

No Estado de São Paulo, as avaliações foram realizadas em duas épocas diferentes, nos municípios de Piracicaba (21 espécies de palmeiras em III-98 e VIII-98), Pariquera-açu (12 espécies em IV-98 e X-98) e Cananéia (6 espécies em IV-98 e X-98). 
No Estado de Pernambuco, as avaliações foram feitas nos municípios de Goiana (4 espécies), Igarassu (5 espécies), Itamaracá (4 espécies), Itambé (4 espécies) e Recife (5 espécies), todas avaliações nos meses de VI-98 e I-99. As espécies escolhidas para a amostragem foram as mais comuns em cada local de coleta, estando algumas presentes em mais de um município.

As espécies nativas amostradas foram Acrocomia aculeata (Jacq.) Lodd. ex Mart., Acrocomia intumescens Drude, Aiphanes aculeata Willd., Astrocaryum aculeatissimum (Schott) Burret, Attalea dubia (Mart.) Burret, Attalea phalerata Mart. ex Spreng., Attalea oleifera Barb. Rodr., Attalea sp., Bactris ferruginea Burret., B. gasipaes, Bactris setosa Mart., Butia eriospatha (Mart.) Becc., C. nucifera, Euterpe edulis Mart., Euterpe sp., Geonoma elegans Mart., Geonoma gamiova Barb. Rodr., Geonoma pohliana Mart., Geonoma schottiana Mart., Lytocaryum weddellianum $(\mathrm{H}$. Wendl.), Polyandrococus caudescens (Mart.) Barb. Rodr., Syagrus romanzoffiana (Cham.), Syagrus schizopylla (Mart.) Glass. e Syagrus sp. As espécies exóticas amostradas foram Archontophoenix cunninghamii H. Wendl. \& Drude, Caryota mitis Lour., Caryota urens L., Chamaerops humilis L., Cryosophila nana (Kunth) Blume ex Salomon, Dypsis lutescens H. Wendl., Elaeis. guineensis N.J. Jacquin, Phoenix dactylifera L., Phoenix reclinata N.J. Jacquin, Phoenix roebelenii O'Brien, Pritchardia pacifica Seemann \& H. wendl., Ptychosperma macarthurii (H. Wendl.) Nicholson, Roystonea oleraceae (N.J. Jacquin).

Foram coletados folíolos de 3 estratos distintos da copa da planta (folíolos basais, medianos e apicais). Em cada local de coleta foram amostradas 3 plantas diferentes de uma mesma espécie botânica, coletando-se 10 folíolos de cada estrato por planta. Frutos do coqueiro foram coletados sempre que presentes e quando o porte da planta permitia a coleta. Todo o material coletado foi levado ao laboratório em caixas de isopor refrigeradas. No laboratório, os ácaros foram coletados manualmente, com auxílio de microscópio estereoscópico e pincel de cerdas finas, e montados em lâminas com meio de Hoyer, exceto os eriofideos, que foram montados com meio de Berlese modificado (Amrine \& Manson, 1996). As preparações foram estudadas em microscópio com contraste de fase. As identificações foram feitas com base principalmente nos 
trabalhos de André (1980), Amrine \& Stasny (1994); Bolland et al. (1998), Chant \& McMurtry (1994), Flechtmann (1994, 1997a, 1997b, 1998), Jeppson et al. (1975), Kazmierski (1996), Krantz (1970), Lofego (1998), Smiley (1992) e Summers \& Price (1970).

Todos os ácaros foram coletados por M.G.C. Gondim Jr., sendo os espécimes representativos depositados no setor de zoologia da Universidade de São Paulo - Escola Superior de Agricultura Luiz de Queiroz. As exsicatas das espécies botânicas foram depositadas no Museu de Botânica da ESALQ-USP, sob os números 49697 a 49734, sendo as espécies identificadas com base nos trabalhos de Rodrigues (1994), Henderson et al. (1995) e Lorenzi (1996).

\subsection{RESULTADOS E DISCUSSĀO}

As espécies de ácaros encontrados no presente trabalho, são abaixo relacionadas com seus respectivos hospedeiros, local e data de coleta, além de outras observações pertinentes.

\section{PROSTIGMATA \\ BDELLOIDEA \\ BDELLIDAE}

Bdella sp.

Material Examinado:

Pernambuco: Igarassu em Euterpe sp. (VI-98); Itambé em E. guineensis (VI-98 e I-99); Itamaracá em $R$. oleraceae (VI-98); Goiana em $A$. intumescens (I-99), A. oleifera (VI-99 e I-99) e C. nucifera (VI-98); Recife em C. mitis. (VI-99), D. lutescens (VI-98 e I-99) e Euterpe sp. (I-99).

São Paulo: Piracicaba em $B$. eriospatha (VIII-98), C. nana (III-98) e $P$. macarthurii (III-98). 
Cyta sp.

Material Examinado:

Pernambuco: Igarassu em Euterpe sp. (VI-98).

São Paulo: Cananéia em $A$. aculeatissimum (X-98), e G. schottiana (X-98); Pariquera-açu em $A$. aculeatissimum (X-98).

Observações:

Este é o primeiro relato deste gênero no Brasil.

Spinibdella sp.

Material Examinado:

São Paulo: Piracicaba em Acrocomia aculeata (III-98), Aiphanes aculeata (III98), A. phalerata (III-98), Attalea sp. (III-98), B. eriospatha (VIII-98), C. nana (III-98), $P$. reclinata (III-98), P. caudescens (III-98) e S. romanzoffiana (III-98 e VIII-98).

\section{CUNAXIDAE}

Cunaxa sp.

Material Examinado:

Pernambuco: Igarassu em E. guineensis (VI-98); Goiana em $A$. intumescens (VI98); Recife em Euterpe sp. (VI-98).

São Paulo: Cananéia em $A$. aculeatissimum (X-98) e $B$. setosa (X-98); Pariqueraaçu em $A$. aculeatissimum (IV-98), B. setosa (X-98), C. nucifera (IV-98), E. guineensis (X-98), G. elegans (IV-98 e X-98), G. gamiova (IV-98) e G. pohliana (X-98); Piracicaba em C. mitis (III-98).

Observações:

Dentre os cunaxídeos este foi o gênero mais frequentemente encontrados neste trabalho.

Dactyloscirus sp.

Material Examinado:

Pernambuco: Goiana em $A$. intumescens (VI-98) e E. guineensis (I-99). 
São Paulo: Pariquera-açu em C. nucifera (IV-98), E. guineensis (IV-98 e X-98) e E. edulis (IV-98 e X-98).

Neocunaxoides sp.

Material Examinado:

Pernambuco: Igarassu em E. guineensis (VI-98).

São Paulo: Cananéia em $A$. aculeatissimum (IV-98 e X-98) e B. setosa (X-98); Pariquera-açu em A. aculeatissimum (IV-98 e X-98), B. gasipaes (X-98), G. elegans (X98), G. gamiova (IV-98), G. pohliana (IV-98 e X-98) e Syagrus sp. (X-98).

Pulaeus sp.

Material Examinado:

São Paulo: Pariquera-açu em B. setosa (IV-98 e X-98), E. guineensis (IV-98 e X98) e E. edulis (X-98).

\section{CHEYLETOIDEA \\ CHEYLETIDAE}

Cheyletus ornatus (Canestrini \& Fanzago, 1876): 106.

Cheletogenes ornatus Baker, 1949: 305.

Material Examinado:

Pernambuco: Goiana em A. oleifera (VI-98); Recife em D. lutescens (VI-98).

Observações:

No Brasil, esta espécie foi encontrada primeira vez em folhas de $C$. nucifera em Fortaleza (Santana \& Flechtmann, 1988).

Cheletomimus sp.

Material Examinado:

Pernambuco: Itamaracá em $P$. pacifica (I-99). 
Hemicheyletia sp.

Material Examinado:

Pernambuco: Recife em C. nucifera (I-99), D. lutescens (I-99), E. guineensis (VI-98) e Euterpe sp. (I-99).

São Paulo: Piracicaba em Acrocomia aculeata (III-98 e VIII-98), Attalea sp. (III98), B. gasipaes (VII-98), C. urens (VIII-98), C. humilis (III-98), C. nana (III-98), L. weddellianum (III-98), P. dactylifera (III-98) e $P$. caudescens (III-98).

Observações:

Ácaros deste gênero foram coletados em folhas de C. nucifera na Bahia (Santana \& Flechtmann, 1998). Neste trabalho, Hemicheyletia foi o gênero de Cheyletidae mais frequentemente encontrado.

Mexecheles sp.

Material Examinado:

Pernambuco: Recife em E. guineensis (VI-98).

São Paulo: Pariquera-açu em E. guineensis (IV-98) e S. romanzoffiana (IV-98).

\section{ERIOPHYOIDEA}

\section{DIPTILOMIOPIDAE}

Rhynacus palmeus Flechtmann, 1998: 115.

Material Examinado:

São Paulo: Cananéia e Pariquera-açu em $E$. edulis (IV-98 e X-98) e $S$. romanzoffiana (IV-98 e X-98).

Observações:

Espécie descrita de folhas de $S$. romanzoffiana provenientes de Itatiaia, Estado do Rio de Janeiro (Flechtmann, 1998).

\section{ERIOPHYIDAE}

Aceria guerreronis Keifer, 1965a: 7.

Material Examinado: 
Pernambuco: Igarassu e Recife em C. nucifera (VI-98 e I-99).

Observações:

É considerada uma das pragas mais importantes do coqueiro, ocorrendo em diversas regiões das Américas e África, causando deformação, necrose e queda de frutos (Moore \& Howard, 1996). Sua ocorrência já foi constatada em praticamente todos os Estados do Nordeste e Sudeste (Santana \& Flechtmann, 1998). Além do coqueiro foi também constatada por Flechtmann (1989) em L. weddellianum, espécie nativa da Mata litorânea do Sudeste do Brasil (Flechtmann, 1989). Neste trabalho, A. guerreronis não foi encontrado em amostras de folhas de $L$. weddellianum coletadas em Piracicaba. Apesar de ser considerada uma séria praga do coqueiro, seus danos ainda são subestimados por produtores e pesquisadores, pelo fato de estarem normalmente associados a outras pragas do coqueiro.

Amrineus cocofolius Flechtmann, 1994: 57.

Material Examinado:

Pernambuco: Recife em C. nucifera (VI-98 e I-99).

São Paulo: Piracicaba em C. nucifera (III-98 e VIII-98).

Observações:

Esta espécie foi descrita de folhas de C. nucifera provenientes de Jales, Estado de São Paulo (Flechtmann, 1994). Foi constatada também em coqueiro na Bahia, Pernambuco e Sergipe (Santana \& Flechtmann, 1998). Neste trabalho, $A$. cocofolius foi encontrado na superficie abaxial das folhas de $C$. nucifera, sempre em baixas infestações, aparentemente sem causar danos à planta.

Notostrix attenuata Keifer, 1963: 7.

Material Examinado:

São Paulo: Piracicaba em Acrocomia aculeata (III-98 e VIII-98) e $S$. romanzoffiana (III-98 e VIII-98).

Observações:

Espécie descrita de folhas de C. nucifera provenientes das Filipinas (Keifer, 
1963). No Brasil foi relatada pela primeira vez em folhas desta mesma planta em Sergipe (Flechtmann \& Santana, 1997).

Notostrix exigua Flechtmann, 1998: 113.

Material Examinado:

Pernambuco: Igarassu em Euterpe sp. (VI-98 e I-99).

São Paulo: Cananéia e Pariquera-açu em E. edulis (IV-98 e X-98).

Observações:

Espécie descrita de folhas de E. edulis proveniente de Itatiaia, Estado do Rio de Janeiro (Flechtmann, 1998).

\section{PHYTOPTIDAE}

Propilus gentyi Keifer, 1975b: 21.

Material Examinado:

São Paulo: Cananéia em $A$. aculeatissimum (X-98); Pariquera-açu em $A$. aculeatissimum (IV-98 e X-98).

Observações:

P. gentyi foi descrito de folhas de Aiphanes sp., procedentes da Colômbia (Keifer, 1975b). Este é o primeiro relato da ocorrência desta espécie após sua descrição, tendo sido encontrado na superfície abaxial de folhas de $A$. aculeatissimum. P. genty $i$ é um ácaro achatado, sugerindo sua ocorrência mais provável em folhas glabras. Chamou a atenção o fato desta espécie ter sido encontrada em folhas desta palmeira por serem estas densamente recobertas por fina pilosidade. Aiphanes aculeata, é única espécie deste gênero encontrada no Brasil e foi examinada em Piracicaba, mas nenhum espécime de $P$. gentyi foi encontrado.

Propilus spinosus Keifer, 1975b: 23.

Material Examinado:

São Paulo: Pariquera-açu em B. setosa (IV-98 e X-98) e S. romanzoffiana (X98). 
Observações:

P. spinosus também foi descrito de folhas de Aiphanes sp. procedente da Colômbia (Keifer, 1975b). Este é o primeiro relato da ocorrência desta espécie após sua descrição original. Ao contrário da espécie anterior, esta foi encontrada em plantas de folhas glabras.

Retracrus johnstoni Keifer, 1965b: 8.

Material Examinado:

Pernambuco: Igarassu e Recife em E. guineensis (VI-98 e I-99) e Euterpe sp. (VI-98 e I-99).

São Paulo: Cananéia em B. setosa (X-98), C. nucifera (X-98), E. edulis (IV-98 e X-98) e G. schottiana (X-98); Pariquera-açu em A. aculeatissimum (IV-98), B. gasipaes (IV-98), B. setosa (IV-98), E. edulis (IV-98), G. gamiova (IV-98 e X-98), G. pohliana ((IV-98 e X-98) e S. romanzoffiana (IV-98 e X-98); Piracicaba em C. nucifera (IV-98 e X-98) e S. romanzoffiana (IV-98 e X-98).

Observações:

Esta espécie foi descrita de folhas de Chamaedorea sp. procedentes do México (Keifer, 1965b). Santana \& Flechtmann (1998) relataram esta espécie no Brasil em $C$. nucifera e $S$. romanzoffiana. Este ácaro foi o eriofideo que apresentou o maior número de plantas hospedeiras, totalizando 11 espécies. Altas populações de $R$. johnstoni foram encontradas em $S$. romanzoffiana em Piracicaba, causando manchas cloróticas que evoluíam para uma lesão amarelada nas folhas. Estas regiões apresentavam aspecto pulverulento a olho nu devido à grande quantidade de exúvias que se apresentam sempre cobertas por abundante quantidade de cera produzida por todos os estágios ativos do ácaro. Ferreira (1997) afirmou que este ácaro é a praga mais importante da pupunha ( $B$. gasipaes). Santana \& Flechtmann (1998) coletaram ácaros deste gênero em E. oleraceae e afirmaram que estes apresentavam alguns caracteres morfológicos com valores intermediários entre $R$. johnstoni e Retracrus elaeis Keifer, em relação ao comprimento de algumas setas, recomendando maiores estudos para esclarecimento do caso. Os espécimes coletados neste trabalho foram considerados como $R$. johnstoni, por 
apresentar o eixo central do empódio integro, o que o distingue de $R$. elaeis.

Algumas espécies novas de eriofídeos coletadas neste trabalho não são aqui citadas pelo fato de serem tratadas especificamente no Capítulo 4, onde são descritas.

\section{EUPODOIDEA}

\section{EUPODIDAE}

Eupodes sp.

Material Examinado:

Pernambuco: Igarassu em $A$. intumescens (VI-98 e I-99), E. guineensis (I-99) e Euterpe sp. (VI-98).

São Paulo: Cananéia em E. edulis (IV-98 e X-98); Pariquera-açu em A. dubia (IV-98), C. nucifera (X-98), E. guineensis (IV-98), E. edulis (IV-98 e X-98), G. gamiova (X-98) e S. romanzoffiana (IV-98 e X-98).

\section{RAPHIGNATHOIDEA \\ NEOPHYLLOBIIDAE}

Neophyllobius sp.

Material Examinado:

Pernambuco: Itamaracá em C. nucifera (VI-98).

\section{RAPHIGNATHIDAE}

Raphignathus sp.

Material Examinado:

São Paulo: Piracicaba em $A$. phalerata (III-98) e B. eriospatha (III-98); Pariquera-açu em $A$. aculeatissimum (IV-98) e $C$. nucifera (IV-98).

\section{STIGMAEIDAE}

Agistemus spp.

Material Examinado:

Pernambuco: Igarassu em $A$. intumescens (VI-98 e I-99), B. ferruginea (VI-98) e 
E. guineensis (VI-98); Recife em E. guineensis (VI-98).

São Paulo: Cananéia em C. nucifera (X-98) e E. edulis (IV-98 e X-98); Pariquera-açu em A. aculeatissimum (X-98), B. gasipaes (IV-98), B. setosa (X-98), C. nucifera (IV-98), E. guineensis (X-98), E. edulis (IV-98 e X-98), G. elegans (IV-98), G. gamiova (IV-98) e S. romanzoffiana (IV-98); Piracicaba em Acrocomia aculeata (III-98 e VIII-98), Aiphanes aculeata (III-98), A. phalerata (III-98), Attalea sp. (III-98), B. gasipaes (III-98), C. mitis (III-98 e VIII-98), C. urens (III-98 e VIII-98), C. humilis (VIII-98), C. nana (VIII-98), L. chinensis (VIII-98), P. dactylifera (III-98 e VIII-98), $P$. reclinata (III-98), P. roebelenii (III-98), P. caudescens (III-98 e VIII-98), P. macarthurii (III-98) e R. oleraceae (III-98 e VIII-98).

Observações:

Este foi o gênero de Stigmaeidae mais frequentemente encontrado neste levantamento. Aparentemente, mais de uma espécie foi coletada neste trabalho.

\section{Ledermulleria sp.}

Material Examinado:

São Paulo: Cananéia em G. schottiana (IV-98); Pariquera-açu em $A$. aculeatissimum (X-98).

\section{Zetzellia sp.}

Material Examinado:

São Paulo: Cananéia em E. edulis (IV-98); Pariquera-açu em E. guineensis (IV98); Piracicaba em C. mitis (III-98) e L. chinensis (III-98).

Observações:

Indivíduos deste gênero haviam sido encontrados em folhas de $E$. edulis em Viçosa, Estado de Minas Gerais (Santana \& Flechtmann, 1998). 


\section{TARSONEMOIDEA}

\section{TARSONEMIDAE}

Daidalotarsonemus sp.

Material Examinado:

Pernambuco: Igarassu e Itambé em C. nucifera (I-99).

Fungitarsonemus sp.

Material Examinado:

Pernambuco: Recife em C. mitis (VI-98), E. guineensis (VI-98 e I-99) e Euterpe sp. (I-99).

São Paulo: Cananéia em E. edulis (X-99); Pariquera-açu em E. guineensis (X-99) e Piracicaba em C. mitis (III-98).

Neotarsonemoides sp.

Material Examinado:

São Paulo: Cananéia em S. romanzoffiana (X-98); Pariquera-açu em B. gasipaes (X-98).

Observações:

Este é o primeiro relato deste gênero no Brasil.

Rhynchotarsonemus sp.

Material Examinado:

Pernambuco: Goiana em A. oleifera (VI-98).

Steneotarsonemus furcatus DeLeon, 1956: 105.

Material Examinado:

Pernambuco: Igarassu em C. nucifera (VI-98).

Observações:

Este é o primeiro relato desta espécie no Brasil. Os ácaros foram encontrados sob as brácteas dos frutos, isoladamente ou associados a $A$. guerreronis. Estes frutos 
apresentavam necrose externa da epiderme, sintomas comuns nos frutos infestados por A. guerreronis. É possivel que estes sintomas sejam causados também por $S$. furcatus. Este ácaro foi encontrado em frutos de $C$. nucifera em El Salvador, causando lesões necróticas na epiderme dos frutos (Ochoa et al., 1991) e na Malasia (Sathiamma, 1995).

Tarsonemus (Tarsonemus) spp.

Material Examinado:

Pernambuco: Igarassu em C. nucifera (VI-98), E. guineensis (VI-98) e Euterpe sp. (VI-98); Recife em C. mitis (VI-98), C. nucifera (VI-98) e Euterpe sp. (VI-98).

São Paulo: Cananéia em S. romanzoffiana (IV-98 e X-98); Piracicaba em Acrocomia aculeata (III-98), Attalea sp. (III-98), C. mitis (III-98), C. nucifera (III-98), P. reclinata (III-98), P. caudescens (III-98), P. macarthurii (III-98) e S. romanzoffiana (III-98).

Observações:

Dentre todos os tarsonemídeos coletados, este foi o gênero mais frequentemente encontrado neste trabalho. Foram coletadas várias espécies deste gênero.

Xenotarsonemus sp.

Material Examinado:

Pernambuco: Igarassu em $A$. intumescens (I-99).

São Paulo: Pariquera-açu em A. aculeatissimum (IV-98) e B. setosa (IV-98). Observações:

Este é o primeiro relato deste gênero no Brasil.

\section{TETRANYCHOIDEA \\ TENUIPALPIDAE}

Brevipalpus phoenicis Geijskes, 1939: 230.

Brevipalpus phoenicis, Baker, 1949: 36; Gonzales, 1975: 82.

Material Examinado:

Pernambuco: Igarassu em B. fermuginea (VI-98) e E. guineensis (I-99); 
Itamaracá em C. nucifera (VI-98 e I-99), P. pacifica (VI-98), D. lutescens (I-99) e $R$.

oleraceae (I-99); Goiana em C. nucifera (VI-98 e I-99); Recife em C. mitis (VI-98), C. nucifera (VI-98 e I-99), D. lutescens (VI-98 e I-99), Euterpe sp. (VI-98) e E. guineensis (VI-98).

São Paulo: Cananéia em E. edulis (IV-98 e X-98); Pariquera-açu em C. nucifera (IV-98); Piracicaba em B. gasipaes (III-98), C. mitis (III-98), C. humilis (III-98), C. nucifera (III-98 e VIII-98), C. nana (III-98) e R. oleraceae (III-98 e VIII-98).

Observações:

No Brasil, B. phoenicis foi relatado pela primeira vez em arecáceas sobre $E$. edulis (Itatiaia - Rio de Janeiro), E. guineensis e E. oleraceae, P. canariensis (Brasília Distrito Federal), $R$. oleraceae (Sete Lagoas - Minas Gerais) e em Syagrus sp. (Santa Luzia - Sergipe) (Santana \& Flechtmann, 1998). Este ácaro foi encontrado sempre em baixas infestações, sem causar danos aparentes.

Tenuipalpus coyacus DeLeon, 1957: 83.

Material Examinado:

São Paulo: Cananéia em E. edulis (IV-98) e S. romanzoffiana (IV-98 e X-98); Pariquera-açu em A. dubia (IV-98), C. nucifera (IV-98 e X-98), E. edulis (IV-98), S. romanzoffiana (IV-98) e Syagrus sp. (IV-98).

Observações:

Descrito de folhas de C. nucifera provenientes do México (Baker \& Tuttle, 1987). Este é o primeiro relato desta espécie no Brasil.

\section{TETRANYCHIDAE}

Eutetranychus nomurai Flechtmann, 1997a: 269.

Material Examinado:

São Paulo: Pariquera-açu em E. edulis (X-98) e S. romanzoffiana (X-98); Piracicaba em $A$. phalerata (III-98 e VIII-98).

Observações:

Esta espécie foi descrita de folhas de $A$. phalerata procedentes de Piracicaba - 
São Paulo (Flechtmann, 1997a).

Monoceronychus sp.

Material Examinado:

Pernambuco: Itambé em E. guineensis (I-99)

São Paulo: Cananéia em E. edulis (IV-99).

Observações:

Provavelmente, trata-se de uma nova espécie, mas o número reduzido de fềmeas coletadas e a ausência de machos impediu uma identificação específica.

Oligonychus yothersi McGregor, 1914

Oligonychus yothersi Pritchard \& Baker, 1955: 330.

Material Examinado:

São Paulo: Cananéia em E. edulis (IV-98).

Observações:

Esta espécie tem sido relatada em diversos hospedeiros e está amplamente distribuída no continente americano (Bolland et al., 1998). Este é o primeiro relato desta espécie em Arecaceae.

Oligonychus sp.

Material Examinado:

Pernambuco: Igarassu em E. guineensis (VI-98 e I-99); Recife em C. nucifera (VI-98 e I-99).

São Paulo: Piracicaba em C. nucifera (III-98 e VIII-98) e P. reclinata (III-98 e VIII-98).

Observações:

Fêmeas do gênero Oligonychus sp. foram relatadas em $R$. oleraceae no Estado de Minas Gerais e em B. gasipaes em Piracicaba - São Paulo (Santana \& Flechtmann, 1998). As amostras de Oligonychus sp. coletadas neste trabalho não foram identificadas ao nível de espécie pela ausência de machos. 
Schizotetranychus sp.

Material Examinado:

São Paulo: Cananéia em E. edulis (IV-98).

Observações:

Uma única fềmea deste gênero foi coletada não sendo possível a identificação da espécie.

Tetranychus mexicanus (McGregor, 1950): 323.

Material Examinado:

Pernambuco: Igarassu em $A$. intumescens (VI-98); Goiana em C. nucifera (VI98) e $A$. oleifera (VI-98).

São Paulo: Pariquera-açu em E. guineensis (IV-98) e C. nucifera (IV-98). Observações:

T. mexicanus é uma espécie polífaga e amplamente distribuída por todo continente americano (Bolland et al., 1998). Em Arecaceae, foi constatada pela primeira vez em folhas de $C$. nucifera em Piracicaba (Flechtmann, 1967). Recentemente, foi encontrado por Santana \& Flechtmann (1998) em Livistona sp. (Paraíba), B. gasipaes (Pernambuco), A. speciosa (Maranhão) e E. guineensis (Pará).

Tetranychus sp.

Material Examinado:

São Paulo: Cananéia em E. edulis (IV-98 e X-98) e G. schottiana (IV-98); Pariquera-açu em $B$. gasipaes (IV-98 e X-98), E. edulis (IV-98) e S. romanzoffiana (IV98 e X-98); Piracicaba em Aiphanes aculeata (III-98), Acrocomia aculeata (III-98 e VIII-98), B. gasipaes (III-98 e VIII-98), C. mitis (III-98), E. edulis (VIII-98), $P$. reclinata (III-98 e VIII-98), R. oleraceae (III-98 e VIII-98) e S. romanzoffiana (III-98 e VIII-98).

Observações:

Não foi possível a identificação da espécie devido a ausência de machos. 


\section{TYDEOIDEA}

\section{TYDEIDAE}

Afrotydeus sp.

Material Examinado:

Pernambuco: Igarassu em A. intumescens (I-99); Recife em E. guineensis (VI98).

São Paulo: Pariquera-açu em B. setosa (IV-98).

Apotriophtydeus sp.

Material Examinado:

São Paulo: Cananéia em A. aculeatissimum (X-98), C. nucifera (X-98) e $S$. romanzoffiana (X-98); Pariquera-açu em C. nucifera (X-98) e S. romanzoffiana (X-98). Observações:

Este é o primeiro relato deste gênero no Brasil.

Lorryia spp.

Material Examinado:

Pernambuco: Igarassu em $A$. intumescens (VI-98 e I-99) e C. nucifera (VI-98); Goiana em $A$. intumescens (VI-98) e E. guineensis (VI-98); Recife em D. lutescens (VI98), E. guineensis (VI-98 e I-99) e Euterpe sp. (I-99)

São Paulo: Cananéia em C. nucifera (IV-98) e E. edulis (X-98); Pariquera-açu em A. aculeatissimum (IV-98), B. setosa (X-98), C. nucifera (X-98), E. edulis (IV-98), G. elegans (IV-98), G. gamiova (IV-98) e G. pohliana (IV-98); Piracicaba em Acrocomia aculeata (III-98 e VIII-98), Aiphanes aculeata (III-98 e VIII-98), A. cunninghamii (III-98 e VIII-98), A. phalerata (III-98 e VIII-98), Attalea sp. (III-98 e VIII-98), B. gasipaes (III-98 e VIII-98), B. eriospatha (III-98 e VIII-98), C. mitis (III-98 e VIII-98), C. urens (III-98 e VIII-98), C. humilis (III-98 e VIII-98), C. nucifera (III-98 e VIII-98), C. nana (III-98), L. chinensis (III-98 e VIII-98), L. weddellianum (III-98), $P$. dactylifera (VIII-98), $P$. reclinata (III-98 e VIII-98), $P$. roboelenii (III-98), $P$. 
caudescens (III-98 e VIII-98), P. macarthurii (III-98 e VIII-98), R. oleraceae (III-98 e VIII-98) e S. romanzoffiana (III-98 e VIII-98).

Observações:

Este foi o gênero de Tydeidae mais frequentemente verificado neste trabalho, tendo sido representado por várias espécies.

Metatriophtydeus sp.

Material Examinado:

Pernambuco: Goiana em $A$. oleifera (VI-98 e I-99); Itambé em S. schizopylla (I99); Recife em C. nucifera (VI-98).

São Paulo: Cananéia em B. setosa (IV-98), G. schottiana (IV-98) e $S$. romanzoffiana (IV-98); Pariquera-açu em A. dubia (X-98) e G. pohliana (X-98); Piracicaba em $A$. phalerata (III-98), B. eriospatha (III-98), C. nucifera (III-98) e $L$. weddellianum (III-98).

Observações:

Este é o primeiro relato deste gênero no Brasil.

Neolorryia sp.

Material Examinado:

Pernambuco: Igarassu em E. guineensis (VI-98 e I-99); Itamaracá em C. nucifera (VI-98).

São Paulo: Pariquera-açu em B. setosa (IV-98) e E. guineensis (IV-98 e X-98); Piracicaba em A. phalerata (III-98), Attalea sp. (III-98), L. chinensis (III-98), L. weddellianum (III-98), P. macarthurii (III-98), P. reclinata (III-98), P. caudescens (III98) e $S$. romanzoffiana (III-98).

Observações:

Este é o primeiro relato deste gênero no Brasil.

Nudilorryia sp.

Material Examinado: 
São Paulo: Cananéia em E. edulis (IV-98); Piracicaba em $P$. reclinata (IV-98) e S. romanzoffiana (IV-98 e X-98).

Observações:

Este é o primeiro relato deste gênero no Brasil.

Parapronematus aff. acaciae Baker, 1965: 115.

Material Examinado:

Pernambuco: Goiana em $A$. intumescens (VI-98 e I-99), C. nucifera (VI-98) e $E$. guineensis (VI-98); Igarassu em $A$. intumescens (VI-98); Itambé em $A$. intumescens (VI98 e I-99) e E. guineensis (VI-98 e I-99); Recife em C. mitis (VI-98), C. nucifera (VI98), D. lutescens (VI-98), E. guineensis (I-99) e Euterpe sp. (VI-98).

São Paulo: Cananéia em $A$. aculeatissimum (X-98) e $B$. setosa (IV-98); Piracicaba em A. cunninghamii (III-98 e VIII-98), C. urens (III-98), C. nucifera (III-98 e VIII-98), S. romanzoffiana (III-98) e R. oleraceae (III-98).

Pronematus sp.

Material Examinado:

Pernambuco: Igarassu em $A$. intumescens (VI-98); Itambé em $A$. intumescens (VI-98).

São Paulo: Piracicaba em Acrocomia aculeata (III-98), A phalerata (III-98), $B$. gasipaes (III-98), C. nucifera (III-98), P. dactylifera (III-98) e S. romanzoffiana (III-98).

Perafrotydeus sp.

Material Examinado:

São Paulo: Piracicaba em Aiphanes aculeata (III-98), C. mitis (III-98), C. nana (III-98) e P. macarthurii (III-98).

Observações:

Este é o primeiro relato deste gênero no Brasil. 
Pretydeus aff. henriandrei Kazmierski, 1996: 173.

Material Examinado:

Pernambuco: Igarassu em E. guineensis (VI-98).

São Paulo: Cananéia em A. aculeatissimum (X-98) e C. nucifera (X-98).

Quasitydeus sp.

Material Examinado:

São Paulo: Piracicaba em Attalea sp. (III-98).

Observações:

Este é o primeiro relato deste gênero no Brasil.

Tydeus sp.

Material Examinado:

Pernambuco: Goiana em $A$. intumescens (I-99); Igarassu em E. guineensis (I-99); Itambé em $A$. intumescens (VI-98); Recife em $D$. lutescens (VI-98).

São Paulo: Cananéia em C. nucifera (IV-98).

\section{MESOSTIGMATA \\ PARASITOIDEA \\ ASCIDAE}

Asca sp.

Material Examinado:

Pernambuco: Igarassu em Euterpe sp. (VI-98).

São Paulo: Cananéia em A. aculeatissimum (X-98) e G. schottiana (X-98); Pariquera-açu em A. aculeatissimum (IV-98 e X-98), B: gasipaes (IV-98), C. nucifera (IV-98), E. edulis (X-98) e G. elegans (X-98) ; Piracicaba em P. roebelenii (III-98).

Lasioseius sp.

Material Examinado:

Pernambuco: Igarassu em A. intumescens (VI-98). 


\section{PHYTOSEIIDAE}

Dentre todos os grupos de ácaros predadores observados neste trabalho, os fitoseídeos foram os mais frequentemente encontrados em todas as plantas amostradas e em todos os locais de coleta. Foram identificadas 44 espécies de fitoseídeos neste trabalho. Este grupo de ácaros é tratado de maneira específica nos capítulos 5, 6 e 8 .

\subsection{CONCLUSÕES}

1) Eriophyoidea é o grupo de ácaros fitófagos mais diverso em Arecaceae nas regiões estudadas.

2) R. johnstoni é o eriofídeo mais frequente em arecáceas nas regiões estudadas.

3) Phytoseiidae é o grupo de ácaros predadores mais diverso em Arecaceae nas regiões estudadas. 


\section{QUATRO NOVAS ESPÉCIES DE ERIOPHYOIDEA (ARTHROPODA: ACARI) ASSOCIADOS A PALMEIRAS (ARECACEAE) EM ÁREAS DOS ESTADOS de SÃo PAUlo E PERNAMBUCO}

\section{RESUMO}

Quatro espécies novas de eriofiídeos coletados em Arecaceae são descritos neste rabalho. Notostrix butiae Gondim Jr., Flechtmann \& Moraes sp. n., de Butia eriospatha (Mart.) Becc.; Notostrix nasutiformes Gondim Jr., Flechtmann \& Moraes sp. n., de Cocos nucifera L.; Knorella geonomae Gondim Jr., Flechtmann \& Moraes sp. n., de Geonoma schottiana Mart. e Propilus syagris Gondim Jr., Flechtmann \& Moraes sp. n., de Syagrus romanzoffiana (Cham.) Glassman. 
FOUR NEW SPECIES OF ERIOPHYOIDEA (ARTHROPODA: ACARI) ASSOCIATES WITH PALM TRHEES (ARECACEAE) IN EM AREAS OF SĀO PAULO AND PERNAMBUCO STATES

\section{SUMMARY}

Four new species of eriophyids collected from Arecaceae are described: Notostrix butiae Gondim Jr., Flechtmann \& Moraes sp. n., from Butia eriospatha (Mart.) Becc; Notostrix nasutiformes Gondim Jr., Flechtmann \& Moraes sp. n., from Cocos nucifera L.; Knorella geonomae Gondim Jr., Flechtmann \& Moraes sp. n., from Geonoma schottiana Mart. and Propilus syagris Gondim Jr., Flechtmann \& Moraes sp. $\mathrm{n}$., from Syagrus romanzoffiana (Cham.) Glassman. 


\subsection{INTRODUÇÃO}

O primeiro eriofídeo relatado em palmeiras no Brasil foi Aceria guerreronis Keifer, causando necrose e queda de frutos em coqueiro (Cocos nucifera L.), no Estado do Rio de Janeiro (Robbs \& Peracchi, 1965). Este ácaro havia sido descrito, neste mesmo ano, de frutos de C. nucifera provenientes do México (Keifer, 1965a). Logo em seguida foi relatado também no Estado de Pemambuco, causando necrose no "olho do coqueiro" (Aquino \& Arruda, 1967). Atualmente, encontra-se disseminado em todas as regiões tropicais do mundo, sendo uma das pragas mais importantes do coqueiro (Moore \& Howard, 1996).

O segundo eriofídeo relatado no Brasil foi Amrineus cocofolius Flechtmann, descrito de folhas de C. nucifera do Estado de São Paulo (Flechtmann, 1994). Posteriormente, foi também encontrado em Sergipe, Bahia e Pernambuco (Santana \& Flechtmann, 1998). Se passaram quase 20 anos para que uma segunda espécie de eriofideo fosse relatado em palmeiras no Brasil. Certamente, não pela baixa diversidade destes ácaros em arecáceas, mas principalmente pela ausência de trabalhos explorativos da fauna de ácaros neste grupo de plantas. Entretanto, a partir da descrição de $A$. cocofolius, vários outros trabalhos foram publicados, relatando a superfamilia Eriophyoidea em palmeiras no Brasil (Flechtmann, 1994; 1998; Flechtmann \& Santana, 1997; Santana \& Flechtmann, 1994; 1998).

Em seguida, Retracrus johnstoni Keifer foi coletado em C. nucifera em Sergipe (Santana et al., 1994), sendo posteriormente estendida sua distribuição para vários estados do Brasil, além de ser constatado também em Syagrus romanzoffiana (Cham.) Glassman, no Paraná e em Euterpe oleracea Mart., no Pará (Santana \& Flechtmann, 1998).

Flechtmann \& Santana (1997) relataram pela primeira vez no Brasil uma espécie, pertencente ao gênero Notostrix, já conhecida de Arecaceae. Esta espécie foi Notostrix attenuata Keifer, encontrada em C. nucifera no Estado de Sergipe. Posteriormente, outra espécie deste gênero, Notostrix jamaicae Keifer, foi encontrada em S. romanzoffiana, no Distrito Federal e Rio de Janeiro e em Attalea sp. no Distrito Federal (Santana \& 
Flechtmann, 1998).

Finalmente, Flechtmann (1998) descreveu duas novas espécies de eriofídeos de palmeiras no Brasil. Uma foi Notostrix exigua Flechtmann, descrita de folhas de Euterpe edulis Mart. provenientes do Rio de Janeiro e a outra foi Rhynacus palmeus Flechtmann, descrita de folhas $S$. romanzoffiana provenientes do mesmo estado.

Um considerável aumento da área plantada com culturas da família Arecaceae, tem ocorrido no centro sul do Brasil, principalmente coqueiro (C. nucifera), palmito doce (E. edulis) e pupunha (Bactris gasipaes Kunth). Este fato tem despertado interesse em se conhecer melhor a fauna acarológica dessas plantas, para oferecer subsídios ao reconhecimento desses ácaros em cultivos comerciais, e desta forma entender possíveis alterações futuras da importância destes artrópodos sobre essas plantas. Este trabalho dá continuidade ao levantamento de espécies de eriofídeos em palmeiras (Arecaceae) no Brasil, que até o momento registrou 7 espécies (Santana \& Flechtmann, 1998).

\subsection{MATERIAL E MÉTODOS}

Foi realizado um levantamento de ácaros da superfamília Eriophyoidea em arecáceas no Estado de São Paulo, nos municípios de Piracicaba (21 espécies de arecáceas em III-98 e VIII-98), Pariquera-açu (12 espécies em IV-98 e X-98) e Cananéia (6 espécies em IV-98 e X-98). No Estado de Pernambuco, foram amostradas arecáceas nos municípios de Goiana (4 espécies), Igarassu (5 espécies), Itamaracá (4 espécies), Itambé (4 espécies) e Recife ( 5 espécies), todas coletas em VI-98 e I-99. As espécies escolhidas para a amostragem foram as mais comuns em cada local de coleta, estando algumas presentes em mais de um município.

As espécies nativas amostradas foram Acrocomia aculeata (Jacq.) Lodd. ex Mart., Acrocomia intumescens Drude, Aiphanes aculeata Willd., Astrocaryum aculeatissimum (Schott) Burret, Attalea dubia (Mart.) Burret, Attalea phalerata Mart. ex Spreng., Attalea oleifera Barb. Rodr., Attalea sp., Bactris ferruginea Burret., B. gasipaes, Bactris setosa Mart., Butia eriospatha (Mart.) Becc., C. nucifera, E. edulis,

Euterpe sp., Geonoma elegans Mart., Geonoma gamiova Barb. Rodr., Geonoma 
pohliana Mart., Geonoma schottiana Mart., Lytocaryum weddellianum (H. Wendl.), Polyandrococus caudescens (Mart.) Barb. Rodr., S. romanzoffiana, Syagrus schizopylla (Mart.) Glass. e Syagrus sp. As espécies exóticas amostradas foram Archontophoenix cunninghamii H. Wendl. \& Drude, Caryota mitis Lour., Caryota urens L., Chamaerops humilis L., Cryosophila nana (Kunth) Blume ex Salomon, Dypsis lutescens H. Wendl., Elaeis. guineensis N.J. Jacquin, Phoenix dactylifera L., Phoenix reclinata N.J. Jacquin, Phoenix roebelenii O'Brien, Pritchardia pacifica Seemann \& H. wendl., Ptychosperma macarthurii (H. Wendl.) Nicholson, Roystonea oleraceae (N.J. Jacquin).

Foram coletados folíolos de 3 estratos distintos da copa da planta (folíolos basais, medianos e apicais). Em cada local de coleta foram amostradas 3 plantas diferentes de uma mesma espécie botânica, coletando-se 10 folíolos de cada estrato por planta. Frutos do coqueiro foram coletados sempre que presentes e quando o porte da planta permitia a coleta. Todo o material obtido foi levado ao laboratório em caixas de isopor refrigeradas. No laboratório, os eriofídeos foram coletados com auxilio de pincel de cerdas finas sob microscópio estereoscópio, sendo posteriormente montados em lâminas para microscopia com meio modificado de Berlese (Amrine \& Manson, 1996). As espécies novas foram desenhadas e medidas com auxílio de microscópio óptico. Adicionalmente, foram feitas imagens de microscopia eletrônica para o melhor entendimento da morfologia das espécies.

Para as observações em microscópio eletrônico (Zeiss DSM 940 A), parte dos ácaros foi separada e fixada por uma semana no fixador Kamovsky modificado (Glutaraldeido 2,5\%, formaldeido 2,5\% em tampão cacodilato de sódio 0,05 M, Ph 7,2). Em seguida foi feita a pós-fixação em tetróxido de ósmio (1\% em tampão cacodilato de sódio $0,05 \mathrm{M}, \mathrm{Ph} 7,2)$ por 2 horas e feita a secagem ao ponto crítico para posterior metalização com ouro (210 segundos).

Todos os ácaros foram coletados por M.G.C. Gondim Jr., sendo os holótipos e parte dos parátipos depositados no setor de zoologia da Universidade de São Paulo Escola Superior de Agricultura Luiz de Queiroz. Alguns parátipos foram depositados no United States National Museum of Washington (E.U.A.). As exsicatas das espécies botânicas foram depositadas no Museu de Botânica da ESALQ-USP, sob os números 
49697 a 49734, sendo as espécies identificadas com base nos trabalhos de Rodrigues (1994), Henderson et al. (1995) e Lorenzi (1996).

As medições são dadas em micrômetros $(\mu \mathrm{m})$, sendo as medições fora de parênteses correspondentes às medições do holótipo e as medições entre parênteses, correspondentes aos valores extremos observados nos parátipos.

\subsection{RESULTADOS E DISCUSSÃo}

No levantamento realizado foram identificadas 4 espécies novas de eriofideos, sendo 2 espécies do gênero Notostrix, 1 espécie do gênero Knorella e 1 espécie do gênero Propilus.

Notostrix butiae Gondim Jr., Flechtmann \& Moraes sp. n.

(Figura 1-2)

Diagnose: Notostrix jamaicae Keifer (1970) e Notostrix exigua Flechtmann (1998) diferem desta nova espécie por apresentarem o eixo central do empódio simples, terminando esta estrutura com a extremidade bifurcada para primeira espécie e dividido em 3 ramos para a segunda. Além disso, $N$. jamaicae e $N$. exigua têm 2 séries de estrias longitudinais, separadas por uma área relativamente larga de cutícula lisa no epigínio, enquanto esta nova espécie tem apenas uma série de estrias longitudinais, fragmentadas anteriormente, ocupando todo o epigínio. Notostrix flabellifera Mohanasundaram (1982) tem uma única série distal de estrias longitudinais no epigínio, enquanto $N$. attenuata Keifer (1963) apresenta um padrão simétrico composto por diversas linhas curvas convergentes no centro desta estrutura. Estas duas últimas espécies diferem de $N$. butiae por apresentarem a seta escapular $s c$ longa (8 e 21, respectivamente); $N$. flabellifera difere desta nova espécie por apresentar a seta escapular sc inserida próxima da margem posterior do escudo prodorsal.

Fêmea ( $\mathrm{n}=10)$ : Idiossoma: delgado, alongado, 256 (194-256) de comprimento, 56 (47-57) de largura, de coloração verde clara quando vivo e com excreções laterais de 


\section{$50 \mu \mathrm{m}$}
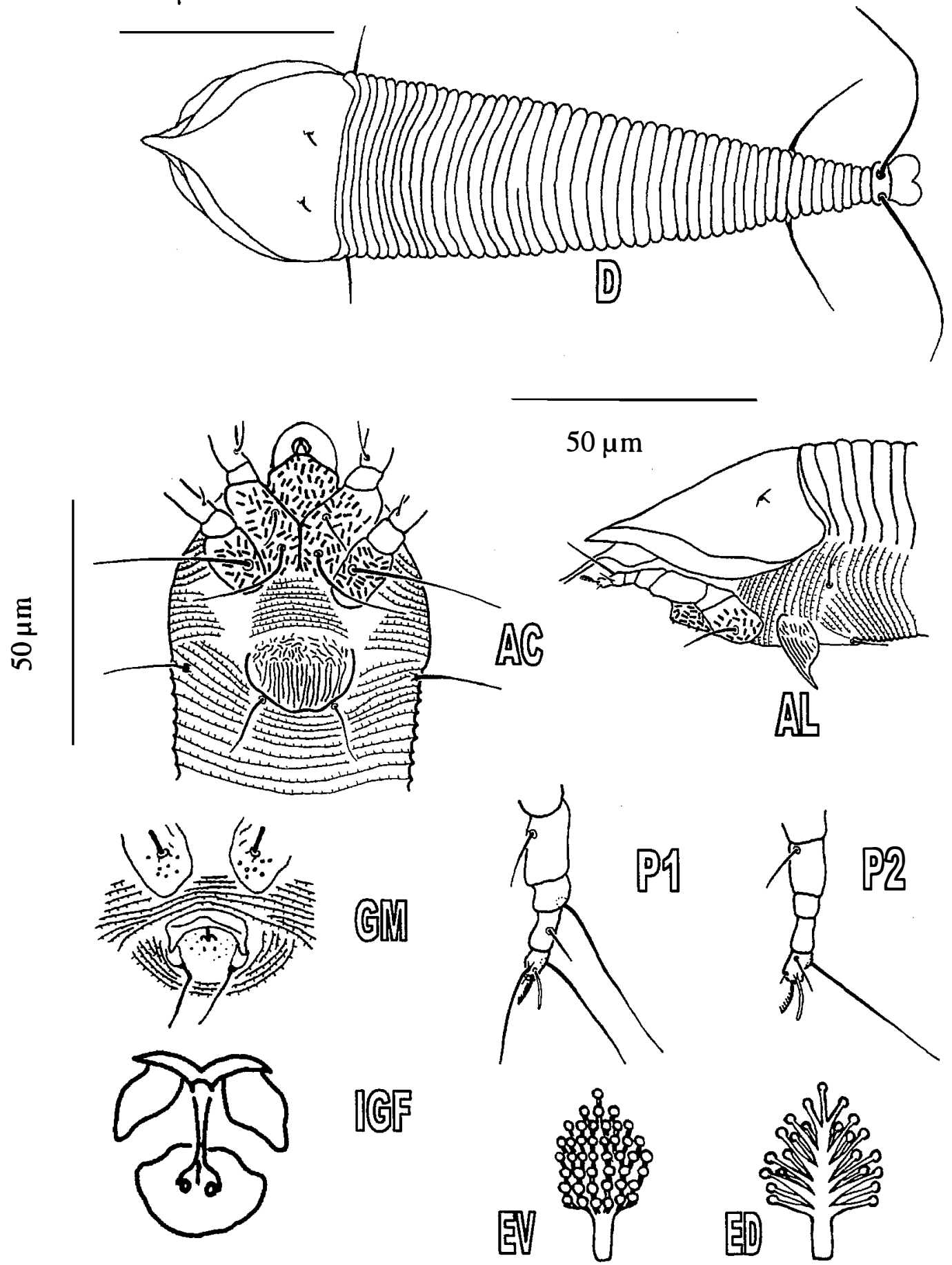

Figura 1. Notostrix butiae sp. n. D - Dorso; AC -Área coxigenital; AL - Vista anteriorlateral; P1 - Perna I; P2 - Perna II; GM - Área Genital do macho; IGF Estruturas genitais internas da fêmea; ED - Empódio da perna I (vista dorsal); EV - Empódio da perna I (vista ventral). 


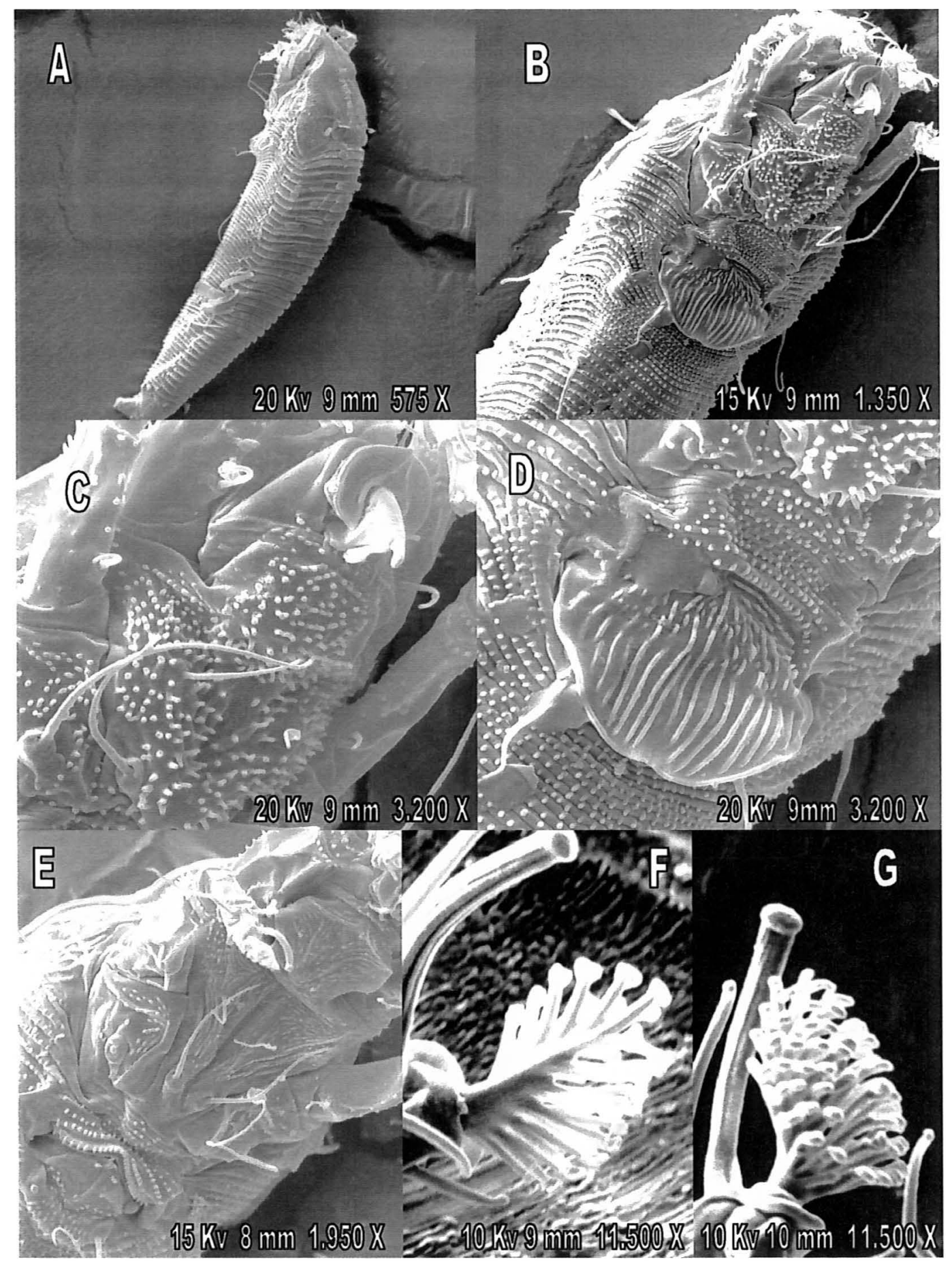

Figura 2. Notostrix buticie sp. n. A - Vista lateral; B - Área coxigenital da fêmea; C - Área intercoxal da fêmea; D - Epigínio; E - Área coxigenital do macho; F - Empódio da perna I (vista dorsal); G. Empódio da perna I (vista ventral). 
cera. Gnatossoma: 28 (23-28) de comprimento; seta da coxa do pedipalpo ep com 3 (34) de comprimento, inseridas em tubérculos; seta dorsal do genu do pedipalpo $d$ com 4 (4) de comprimento; estiletes quelicerais com 20 (18-20) de comprimento. Escudo prodorsal: 54 (48-54) de comprimento; 56 (47-57) de largura, liso, triangular, com o angulo anterior alongado e projetando-se sobre o gnatossoma; emarginado lateralmente. Seta escapular sc inserida em tubérculos, 10 (9-11) anterior à margem posterior do escudo prodorsal, convergentes e dirigidas para trás, com 5 (5) de comprimento, distância entre elas 17 (17-19). Perna: Sem seta no genu II. Perna I: 31 (29-31) de comprimento; trocânter 3 (3-4); fêmur 12 (11-12), seta basiventral do fêmur $b v 9$ (8-9); genu 5 (4-5), seta anteaxial do genu l' 25 (24-27); tíbia 6 (6), seta paraxial da tibia l' 5 (5); tarso 5 (5-6), seta fastigial paraxial do tarso $f t$ ' 15 (14-15), seta fastigial anteaxial do tarso ft' 18 (18-19), seta unguinal paraxial do tarso $u$ ' 2 (2), solenídio do tarso $\omega 6$ (6), empódio simples, com eixo central íntegro, com 5 (5) de comprimento e 7 pares de raias. Perna II: 29 (28-29) de comprimento; trocânter 5 (4-5); fêmur 13 (12-13), seta basiventral do fêmur $b v 7$ (6-7); genu 4 (3-4); tíbia 5 (5); tarso 5 (5), seta fastigial paraxial do tarso $f t$ ' 4 (4-5), seta fastigial anteaxial do tarso $f t$ "' 21 (21-22), seta unguinal paraxial do tarso $u^{\prime} 2$ (2-3), solenídio do tarso $\omega 6$ (6), empódio simples, com eixo central íntegro, com 5 (5) de comprimento e 7 pares de raias. Região coxiesternal: Setas proximais do coxisterno I $1 a$ inseridas em tubérculos, com 15 (15-17) de comprimento, afastadas entre si de 7 (7); setas anterolaterais do coxisterno I $1 b$ inseridas em tubérculos, com 8 (7-8) de comprimento, afastadas entre si de 11 (10-11). Setas proximais do coxisterno II $2 a$ sobre tubérculos, com 35 (32-37) de comprimento, afastadas entre si de 22 (20-22). Linha esternal com 14 (12-14) de comprimento; área entre o coxisterno II e o epigínio com 9 (9-11) anéis, com microtubérculos acuminados. Região coxisternal e área ventral anterior com microtubérculos mamilares. Epigínio: 23 (22-23) de comprimento, 16 (16-17) de largura, com uma única série de 17 (15-19) estrias longitudinais, fragmentadas anteriormente e ocupando todo epigínio. Apódema genital anterior conectado com um par de estruturas laterais largas; apódema genital posterior largo até o mesmo nível da espermateca; duto da espermateca curto. Seta proximal do coxisterno II $3 a$ com 13 (12-13) de comprimento. Opistossoma: Tanossoma 
com 39 (38-39) anéis dorsais, lisos; com uma depressão central que se esvanece posteriormente. Apresenta 68 (59-68) anéis ventrais, providos de microturbéculos acuminados. Telossoma apresenta 7 (7-8) anéis dorsais, lisos; 8 (8-9) anéis ventrais providos de microtubérculos acuminados. Seta $c 2$ sobre tubérculos, com 19 (18-19) de comprimento, no anel ventral 5 (4-5). Seta $d$ com 57 (53-58) de comprimento, afastadas entre si de 26 (25-28), no anel ventral 20 (18-20). Seta $e$ com 50 (47-53) de comprimento, afastadas entre si de 15 (15-16), no anel ventral 39 (34-39). Seta $f$ com 24 (23-25) de comprimento, afastadas entre si de 23 (20-23), no anel ventral 68 (59-68). Seta $h l$ ausente. Seta $h 2$ com 70 (67-76) de comprimento.

Macho ( $\mathrm{n}=5)$ : Idiossoma: delgado, alongado, menor que a fêmea, com (161-221) de comprimento; (42-49) de largura, coloração verde clara quando vivo e com excreções laterais de cera. Gnatossoma: Seta da coxa do pedipalpo ep sobre tubérculos, com (4-5) de comprimento; seta dorsal do genu do pedipalpo $d$ com (11) de comprimento; estiletes quelícerais com (16-18) de comprimento. Escudo prodorsal: (46-50) de comprimento; (42-49) de largura, liso, triangular, com o ângulo anterior alongado e projetando-se sobre o gnatossoma; emerginado lateralmente. Seta escapular sc inserida em tubérculos, (9-11) anterior à margem posterior do escudo prodorsal, convergentes e dirigidas para trás, com (4) de comprimento, distantes entre si de (14-15). Perna: Sem seta no genu II. Perna I: (30-32) de comprimento; trocânter (3-4); fêmur (12), seta basiventral do fềmur bv (911); genu (4-5), seta anteaxial do genu l' '(22-23); tíbia (6), seta paraxial da tíbia l' (5); tarso (5), seta fastigial paraxial do tarso $f t$ ' (13), seta fastigial antaxial do tarso $f t^{\prime \prime}$ ' (1618), seta unguinal paraxial do tarso $u$ ' (2), solenídio do tarso $\omega$ (6-7), empódio como na fềmea, com (5-6) de comprimento. Perna II: (28-30) de comprimento; trocânter (4-5); fêmur (12-13), seta basiventral do fêmur $b v$ (7); genu (3-4); tíbia (4-5); tarso (5), seta fastigial paraxial do tarso $f t^{\prime}(3-4)$, seta fastigial antaxial do tarso $f t^{\prime \prime}$ (18-19), seta unguinal paraxial do tarso $u^{\prime}$ (2), solenídio do tarso $\omega(6-7)$, empódio como na fêmea, com (6) de comprimento. Região coxiesternal: Setas proximais do coxisterno I $1 a$ inseridas em tubérculos, com (19-21) de comprimento, afastadas entre si de (4-5); setas anterolaterais do coxisterno I $l b$ inseridas em tubérculos, com (6-7) de comprimento, afastadas entre si de (8-11). Setas proximais do coxisterno II $2 a$ inseridas em tubérculos, 
com (36-38) de comprimento, afastadas entre si de (18-19). Linha esternal com (19) de comprimento; área entre coxisterno II e o epigínio com (9-10) anéis providos de microtubérculos acuminados. Região coxisternal e área ventral anterior estriada, sem microtubérculos. Epigínio (14-15) de largura; cutícula da fossa genital granulada. Seta proximal do coxisterno III $3 a$ com (17-20) de comprimento. Opistossoma: Tanossoma com (37-41) anéis dorsais, lisos, com uma depressão central que se esvanece posteriormente. Apresenta (65-67) anéis ventrais providos de microtubérculos acuminados. Telossoma com (8-9) anéis dorsais, lisos; (8-9) anéis ventrais providos de microtubérculos acuminados. Setas $c 2$ inseridas em tubérculos, com (19-21) de comprimento, no anel ventral (5-6). Setas $d$ com (59-67) de comprimento, afastadas entre si de (21-23), no anel ventral (17-18). Setas $e$ com (45-50) de comprimento, afastadas entre si de (11-12), no anel ventral (36-37). Setas $f$ com (22-28) de comprimento, afastadas entre si de (19-21), no anel ventral (56-67). Seta $h 1$ ausente. Seta $h 2$ com (67-77) de comprimento.

Material Tipo: Holótipo fềmea, 31 fềmeas e 9 machos parátipos, em 10 preparações microscópicas, depositadas na coleção do setor de Zoologia do Departamento de Entomologia, Fitopatologia e Zoologia Agrícola da Universidade de São Paulo- ESALQ, Piracicaba, São Paulo. Sete fềmeas e 1 macho parátipos em 2 preparações microscópicas depositadas, no USNM, Washington, D.C., E.U.A.

Localidade Tipo: Campus da Escola Superior de Agricultura "Luiz de Queiroz", Piracicaba, São Paulo, Brasil. Coletado por M.G.C. Gondim Jr. em V-1999 nas coordenadas: $22^{\circ} 42^{\prime} 30^{\prime \prime}$ de latitude sul e $47^{\circ} 37^{\prime} 54^{\prime \prime}$ de longitude oeste.

Plantas Hospedeiras: Coletado na superficie abaxial de folhas de $B$. eriospatha (Arecaceae).

Etimologia: butiae, refere-se ao gênero da planta sobre a qual a espécie foi encontrada. 
Notostrix nasutiformes Gondim Jr., Flechtmann \& Moraes sp. n.

(Figura 3-4)

Diagnose: Notostrix jamaicae Keifer (1970) e Notostrix exigua Flechtmann (1998) diferem desta nova espécie por apresentarem o eixo central do empódio simples, terminando esta estrutura com a extremidade bifurcada para primeira espécie e dividido em 3 ramos para a segunda. Além disto, $N$. jamaicae e $N$. exigua apresentam duas séries de estrias longitudinais no epigínio separadas por uma área relativamente larga e lisa de cutícula. Notostrix butiae difere desta nova espécie por possuir apenas uma série longitudinal de estrias, que são fragmentadas anteriormente. Notostrix flabellifera Mohanasundaram (1982) apresenta uma série distal de estrias longitudinais no epigínio, enquanto $N$. attenuata apresenta um formato simétrico composto por diversas linhas, curvas que se convergem no centro desta estrutura. Estas duas últimas espécies diferem ainda de Notostrix nasutiformes $\mathrm{n}$. sp. por apresentarem a seta sc longa (8 e 21, respectivamente). Além disso, $N$. flabellifera apresenta os tubérculos onde se inserem as setas sc localizados próximo à margem posterior do escudo prodorsal.

Fêmea ( $\mathrm{n}=10)$ : Idiossoma: delgado e alongado; 213 (186-231) de comprimento; 50 (50-53) de largura, coloração verde clara quando vivo, e com excreções laterais de cera no idiossoma e prodorso. Gnatossoma: 30 (30) de comprimento; setas ep inseridas em tubérculos, com 4 (4-5) de comprimento; setas $d$ com 4 (4-5) de comprimento; estiletes quelícerais com 19 (18-19) de comprimento. Escudo prodorsal: 50 (48-51) de comprimento; 50 (50-53) de largura; liso, triangular, com ângulo anterior alongado e projetando-se sobre o gnatossoma; emarginado lateralmente e com um lóbulo mediano na linha submarginal. Setas $s c$ inseridas em tubérculos, 11 (9-11) anteriores à margem posterior do escudo prodorsal, afastadas entre si de 18 (18-19), convergentes e dirigidas posteriormente, com 4 (4) de comprimento. Perna: Sem setas no genu II. Perna I: 28 (2728) de comprimento; trocânter 3 (3-4); fêmur 10 (10-11), seta bv 8 (8-9); genu 4 (4), seta l' 23 (23-24); tíbia 5 (5), seta l' 14 (13-15); tarso 5 (5-6), seta $f t$ ' 12 (11-12), seta $f t$ '' 16 (16), seta $u^{\prime} 3$ (2-3), solenídio $\omega 5$ (5), empódio simples, com eixo central íntegro, com 5 (4-5) de comprimento e 7 pares de raias. Perna II: 27 (26-28) de comprimento; trocânter 

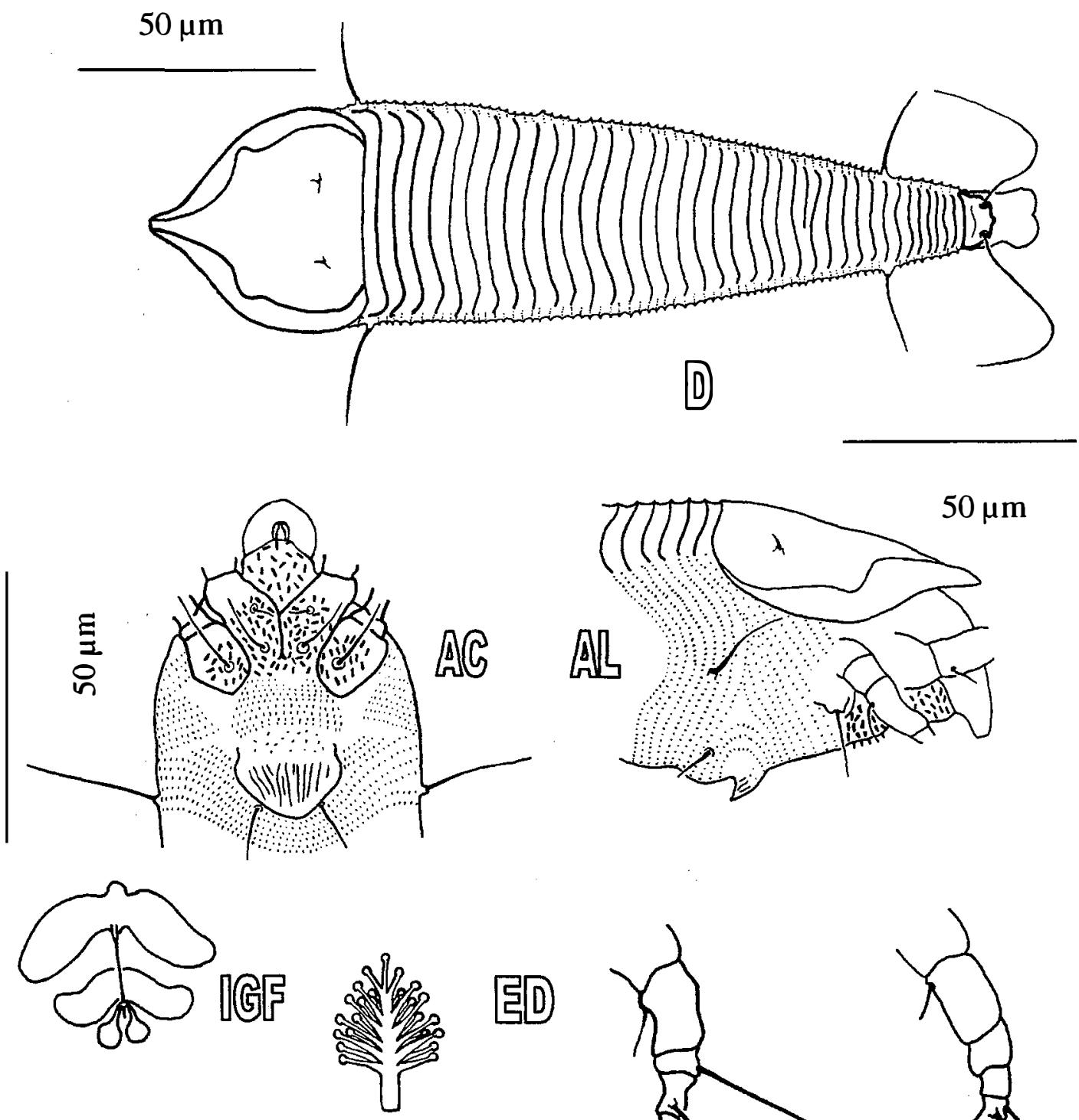

臨
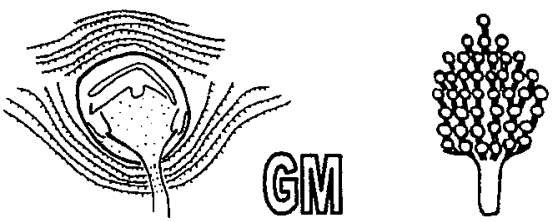

區
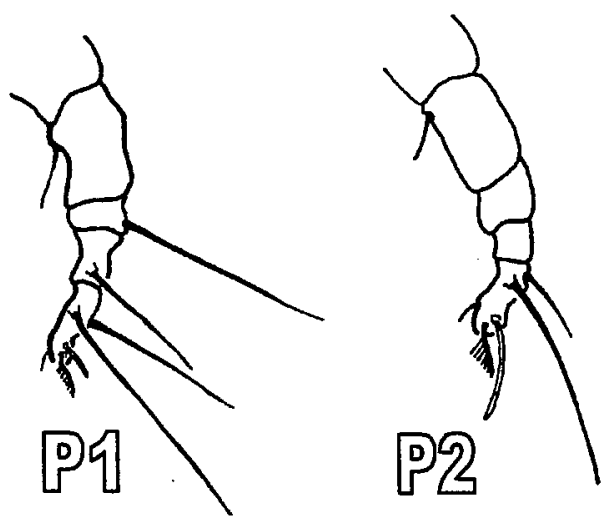

Figura 3. Notostrix nasutiformes sp. n. D - Dorso; AC - Área Coxigenital; AL - Vista Anteriorlateral; P1 - Perna I; P2 - Perna II; IGF - Estruturas internas da fêmea; GM - Área genital do macho; ED - Empódio (vista dorsal); EV - Empódio (vista ventral). 


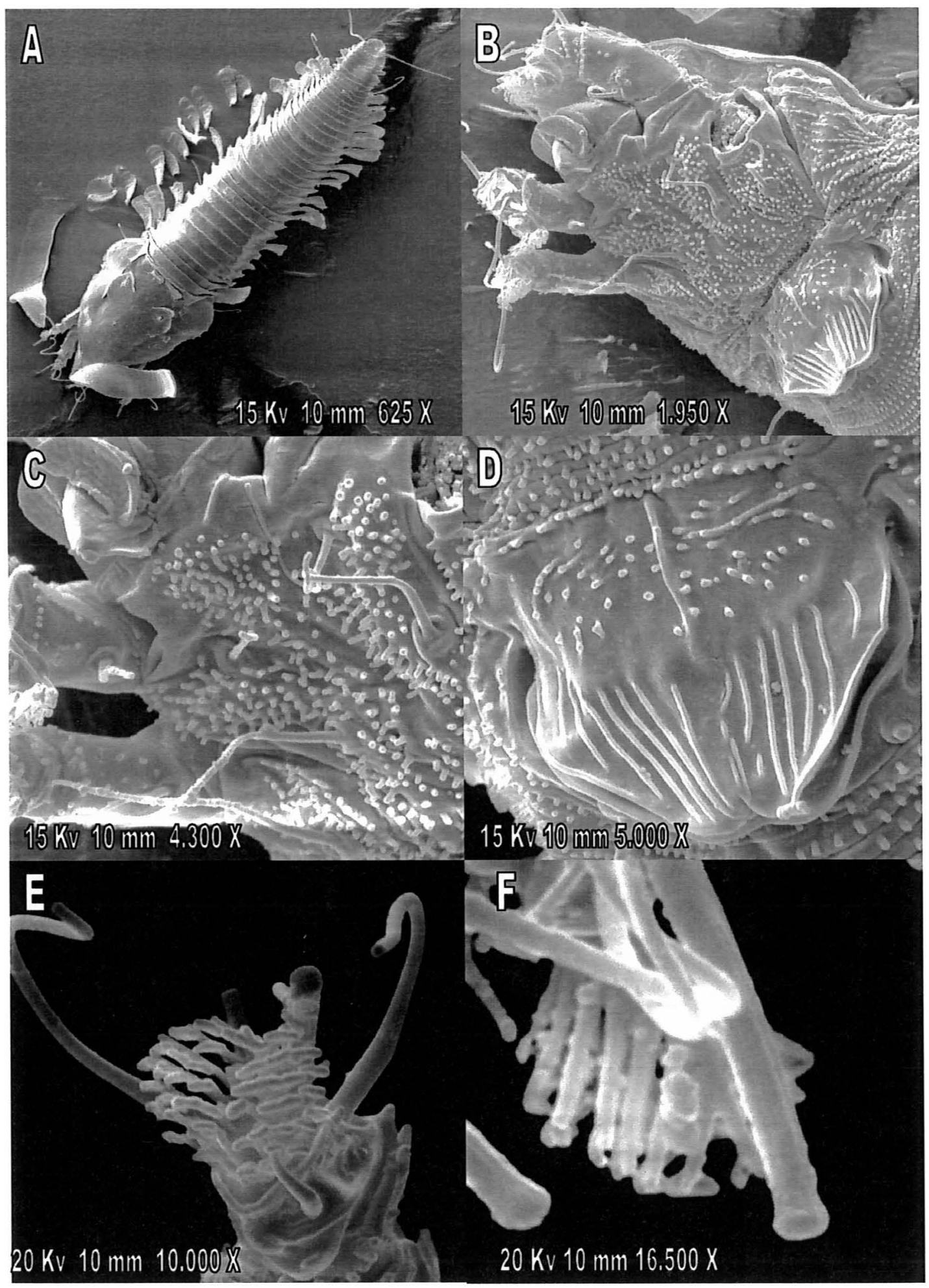

Figura 4. Notostrix nasutiformes sp. n. A - Dorso; B - Área coxigenital; C - Área intercoxal; D - Epigínio; E - Empódio da perna I (Vista ventral), F Empódio da perna I (Vista dorsal). 
3 (3-4); fềmur 11 (11), seta bv 7 (7-8); genu 4 (3-4); tíbia 4 (4); tarso 6 (6), seta ft' 6 (57), seta ft' 21 (20-21), seta u' 2 (2-3), solenídio $\omega 9$ (9), empódio tarsal como na pema I, com 5 (5) de comprimento. Região coxisternal: Setas $1 a$ inseridas em tubérculos, com 15 (15-17) de comprimento, afastadas entre si de 7 (7-8); setas $1 b$ inseridas em tubérculos, com 6 (6-7) de comprimento, afastadas entre si de 9 (9). Setas $2 a$ inseridas em tubérculos, com 34 (32-37) de comprimento, afastadas entre si de 21 (20-22). Linha esternal com 11 (11-12) de comprimento; área entre o coxiesterno II o epigínio com 11 (9-11) anéis providos de microtubérculos acuminados. Região coxisternal e área ventral anterior a ele com microtubérculos mamilares. Epigínio com 17 (15-17) de comprimento, 21 (20-21) de largura, com uma única série de estrias longitudinais em número de (12-14), em sua metade distal e um padrão granulado na metade anterior. Apódemas genitais anterior e posterior curvado distalmente para trás; duto da espermateca curto. Setas $3 a$ com 15 (14-15) de comprimento. Opistossoma: Tanossoma com 30 (28-31) anéis dorsais, lisos, com uma depressão central que se esvanece posteriormente. Apresenta 71 (67-73) anéis ventrais providos de microtubérculos acuminados. Telossoma com 9 (8-9) anéis dorsais, lisos, com 9 (8-9) anéis ventrais providos de microtubérculos acuminados. Setas $c 2$ inseridas em tubérculos, com 30 (2832) de comprimento, localizada no anel ventral 5 (5-6). Setas $d$ com 66 (63-70) de comprimento, afastadas entre si de 29 (27-29), no anel ventral 22 (20-22). Setas $e$ com 57 (53-61) de comprimento, afastadas entre si de 16 (15-17), no anel ventral 42 (38-42). Setas $f$ com 25 (24-26) de comprimento, afastadas entre si de 25 (24-26), no anel ventral 71 (67-73). Seta $h 1$ ausente. Seta $h 2$ com 68 (64-74) de comprimento.

Macho ( $\mathrm{n}=4)$ : Idiossoma: delgado, alongado, com (186-192) de comprimento; (45-49) de largura, coloração verde clara quando vivo, com excreções laterais de cera. Gnatossoma: (21-23) de comprimento, seta ep inseridas em tubérculos, com (4-5) de comprimento; seta $d$ com (4-5) de comprimento; estiletes quelicerais com (15-18) de comprimento. Escudo prodorsal: (42-45) de comprimento; (45-49) de largura, liso, triangular, com ângulo anterior alongado e projetando-se sobre o gnatossoma; emarginado lateralmente e com um lóbulo mediano na linha submarginal. Setas $s c$ inseridas em tubérculos, (8) anteriores à margem posterior do escudo, afastadas entre si 
de (15-17), convergentes e dirigidas posteriormente, com (4) de comprimento. Perna: Sem setas no genu II. Perna I: (28-39) de comprimento; trocânter (3); fêmur (9), seta $b v$ (8-9); genu (3-4), seta l' (22-24); tíbia (5-6), seta l' (11-13); tarso (5-6), seta ft' (11-12), seta ft" (14-16), seta $u$ ' (3), solenídio $\omega$ (6-7), empódio como na fềmea. Perna II: (2728) de comprimento; trocânter (3-4); fềmur (9-11), seta $b v$ (7-8); genu (3-4); tíbia (4); tarso (5-6), seta $f t^{\prime}$ (5-6), seta $f t^{\prime \prime}$ (19-21), seta $u^{\prime}$ (2-3), solenídio $\omega(8-9)$, eixo central do empódio como na fêmea. Região coxisternal: Setas $1 a$ inseridas em tubérculos, com (2021) de comprimento, afastadas entre si de (7-8); setas $I b$ inseridas em tubérculos, com (5-6) de comprimento, afastadas de (9). Setas $2 a$ inseridas em tubérculos, com (32-35) de comprimento, afastadas entre si de (21). Linha esternal com (8-9) de comprimento; área entre coxisterno II e epigínio com (8-9) anéis providos de microtubérculos acuminados. Região coxisternal e área ventral anterior a este estriada, sem microtubérculos. Epigínio com (11-12) de largura, cutícula da fossa genital granulada. Setas $3 a$ (18-20) de comprimento. Opistossoma: Tanossoma com (30) anéis dorsais, lisos; com uma depressão central que esvanece posteriormente. Apresenta ventralmente (62-67) anéis providos de microtubérculos acuminados. Telossoma com (9-11) anéis dorsais, lisos; (10-11) anéis ventrais providos de microtubérculos acuminados. Setas $c 2$ inseridas em tubérculos, com (26-28) de comprimento, no anel ventral (8-9). Setas $d$ com (61-63) de comprimento, afastadas entre si de (20-21), no anel ventral (15-18). Setas $e$ com (50-53) de comprimento, afastadas entre si de (11-12), no anel ventral (3537). Setas $f$ com (27-29) de comprimento, afastadas entre si de (22-23), no anel ventral (62-67). Seta $h 1$ ausente. Seta $h 2$ com (62-63) de comprimento.

Material Tipo: Holótipo fềmea, 53 fềmeas e 4 machos parátipos, em 12 preparações microscópicas, na coleção do setor de Zoologia do Departamento de Entomologia, Fitopatologia e Zoologia Agrícola da Universidade de São Paulo ESALQ, Piracicaba, São Paulo, Brasil. Cinco fềmeas e 1 macho parátipos em 1 preparação microscópica depositada no USNM, Washington, D.C., E.U.A.

Localidade Tipo: Igarassu, Pernambuco, Brasil. Coletado por M.G.C. Gondim Jr. em VI-1998 sobre C. nucifera nas coordenadas $7^{\circ} 53^{\prime} 28^{\prime}$ 'de latitude sul e $34^{\circ} 58^{\prime} 35^{\prime \prime}$ ' de longitude oeste. 
Plantas Hospedeiras: Coletado na superfície abaxial de $A$. dubia (Pariquera-açu - São Paulo), A. phalerata (Piracicaba - São Paulo), B. gasipaes (Pariquera-açu - São Paulo), B. ferruginea (Igarassu - Pernambuco), B. setosa (Pariquera-açu - São Paulo), C. nucifera (Igarassu - Pernambuco) (Arecaceae).

Etimologia: nasutiformes, refere-se ao formato de nariz da porção anterior do escudo prodorsal.

Knorella geonomae Gondim Jr., Flechtmann \& Moraes sp. n.

(Figura 5-6)

Diagnose: Knorella gigantochloae Keifer (1975a) e Knorella fuzhoui Amrine \& Stasny (1994) diferem desta nova espécie por apresentarem projeções nos anéis $(1,3,6$, 9, 12 e 15) do tanossoma, enquanto Knorella thailandica Hong (1996) difere por apresentar o epigínio totalmente estriado. Esta nova espécie difere de todas as outras espécies, incluindo Knorella bambusae Kuang \& Feng (1989) por apresentar uma área triangular lateralmente ao coxisterno II com ornamentação tubercular.

Fêmea ( $\mathrm{n}=7)$ : Idiossoma: curto, fusiforme; 138 (137-150) de comprimento; 61 (56-62) de largura, coloração amarela clara quando vivo. Gnatossoma: 20 (20-21) de comprimento; seta ep 2 (2-3); seta $d 2$ (2); estiletes quelicerais 12 (11-13). Escudo prodorsal: 44 (44-49) de comprimento; 59 (56-62) de largura; sem setas, liso, com um curto lóbulo anterior projetando-se sobre o gnatossoma. Perna: Sem setas no fềmur I e II e no genu II. Perna I: 22 (20-23) de comprimento; trocânter 3 (2-3); fêmur 10 (9-10); genu 2 (2-3), seta l' 15 (15-16); tíbia 3 (3), seta l' 14 (13-14); tarso 5 (5), seta $f t^{\prime} 11$ (1112), seta $f t$ "' 16 (14-16), seta $u$ ' 2 (2-3), solenídio $\omega 5$ (5), empódio com 5 (4-5) de comprimento, eixo central bifurcado na base, tendo cada ramo 6 fileiras de 3 raias. Perna II: 19 (18-20) de comprimento; trocânter 3 (2-3); fêmur 8 (7-8); genu 2 (2); tíbia 2 (2); tarso 5 (4-5), seta $f t$ ' 5 (4-5), seta $f t^{\prime \prime} 13$ (13-15), seta $u^{\prime} 2$ (2-3), solenídio $\omega 5$ (5), empódio semelhante a perna I, com 4 (4-5) de comprimento. Região coxisternal: Setas 

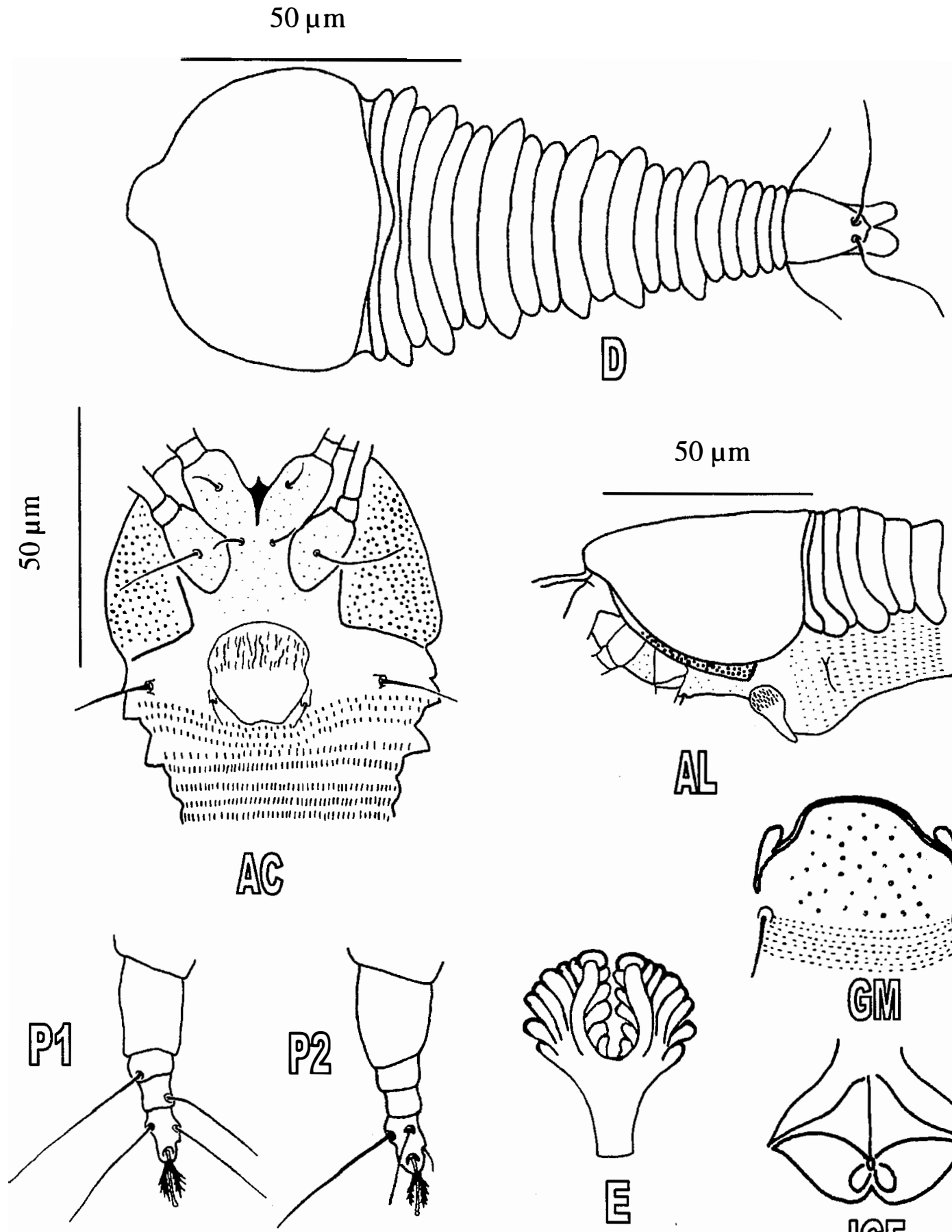

$0 \mu \mathrm{m}$

S
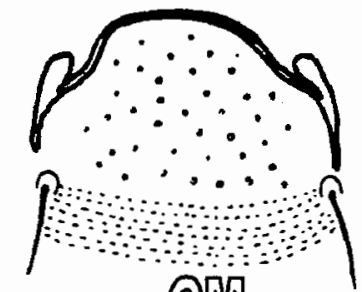

G以ג

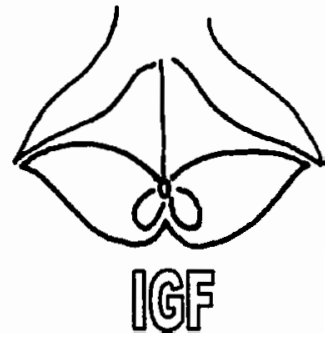

Figura 5. Knorella geonomae sp. n. D - Dorso; AC - Área Coxigenital; AC - Vista anteriorlateral; P1 - Perna I; P2 - Perna II; E - Empódio; GM - Área genital do macho: IGF - Estruturas Internas da genitália feminina. 


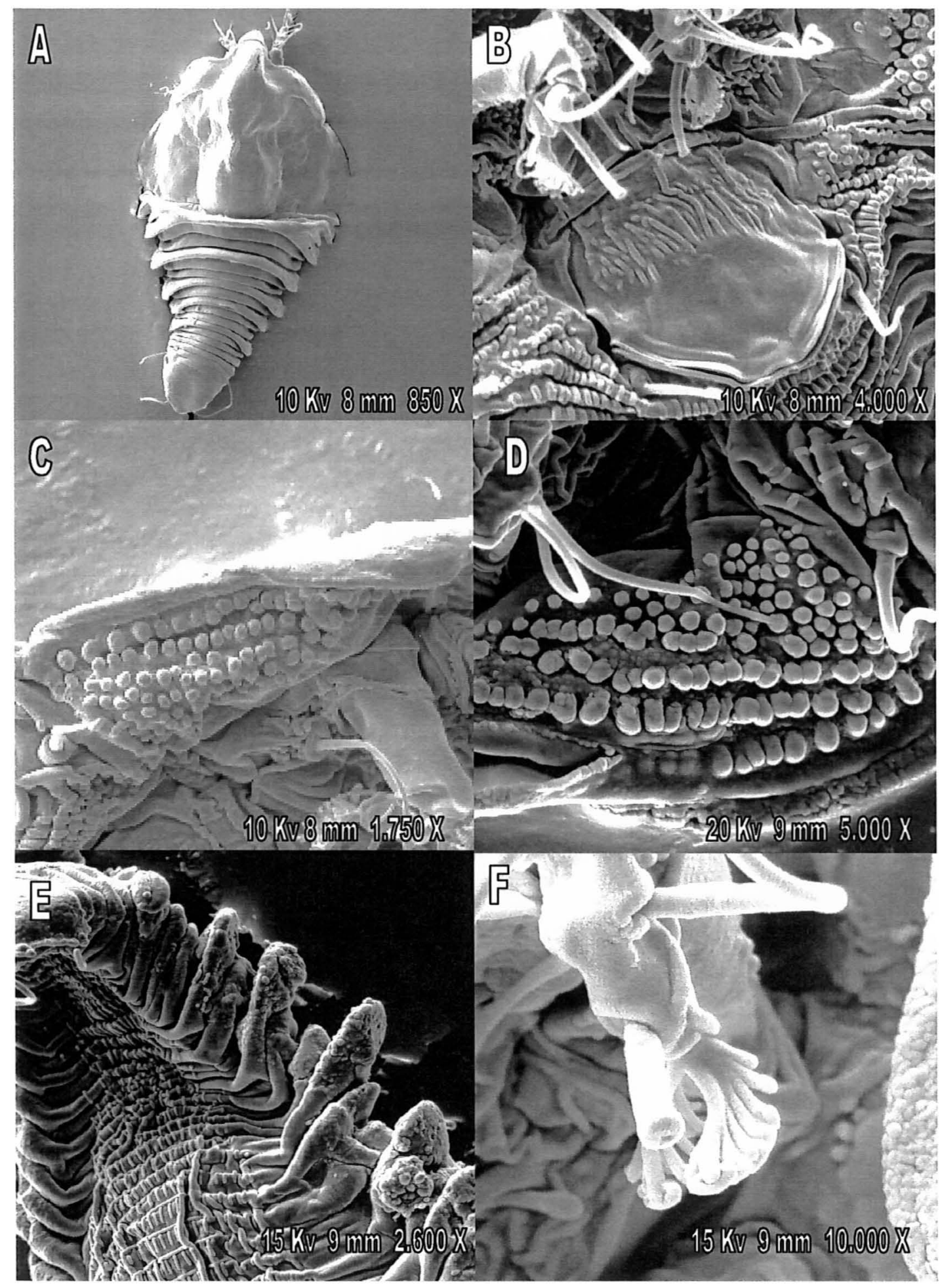

Figura 6. Knorella geonomae sp. n. A - Dorso; B - Epigínio; C - Área lateral do coxisterno II; D - Ornamentação da área lateral do coxisterno II; E - Vista ventral do opistosoma; F - Empódio da Perna I. 
$1 a$ inseridas em tubérculos, com 9 (9-10) de comprimento, afastadas entre si de 6 (6-7); setas $1 b$ inseridas em tubérculos, com 8 (8-9) de comprimento, afastadas entre si de 14(13-14). Setas $2 a$ inseridas em tubérculos, com 15 (14-16) de comprimento, afastadas entre si de 22 (21-22). Linha esternal com 11 (9-11) de comprimento; área entre o coxisterno II e o epigínio, assim como o coxisterno I e II com ornamentação granular. Área triangular lateral ao coxisterno II com ornamentações em forma de tubérculo. Epigínio 17 (17-19) de comprimento, 19 (19-20) de largura, com várias estrias longitudinais interrompidas, na metade proximal do epigínio. Apódema genital anterior distalmente curvado para trás; apódema genital posterior distalmente curvado para frente; duto da espermateca curto. Setas $3 a$ com 8 (7-8) de comprimento. Opistossoma: Tanossoma com 20 (20) anéis dorsais, lisos, com expansões laterais nos anéis (2, 4, 7, 10, 12 e 15) e com expansões laterais pequenas nos demais; com 34 (33-35) anéis ventrais providos de microtubérculos alongados e acuminados. Telossoma com anéis dorsais fundidos, lisos; com 5 (5) anéis ventrais providos de microtubérculos alongados e acuminados. Setas $d$ e $e$ ausentes. Setas $c 2$ com 14 (13-15) de comprimento, no anel ventral 2 (2-3). Setas $f$ com 14 (13-15) de comprimento, afastadas entre si de 17 (1517), no anel ventral 34 (33-35). Seta $h 1$ ausente. Seta $h 2$ com 26 (25-27) de comprimento.

Macho (n=2): Idiossoma: curto, fusiforme; (137-138) de comprimento; (56-58) de largura, coloração amarela clara quando vivo. Gnatossoma: seta $d$ não visualizada; seta ep com (2-3) de comprimento. Escudo prodorsal: (43) de comprimento; (56-58) de largura, sem setas, liso, com um curto lóbulo anterior projetando-se sobre o gnatossoma. Perna: Sem setas no fềmur I e II e genu II. Perna I: (22-23) de comprimento; trocânter (2-3); fêmur (9-10); genu (2), seta l' (15); tíbia (3), seta l' (11); tarso (5), seta ft' (1011), seta $f t$ ' (13-14), seta $u^{\prime}$ (3), solenídio $\omega(5-6)$, empódio semelhante ao da fềmea, com (4) de comprimento. Perna II: (18) de comprimento; trocânter (3); fềmur (6-7); genu (2); tíbia (2); tarso (4), seta ft' (4-5), seta $f t$ ' (14-15), seta $u$ ' (3), solenídio $\omega(5-6)$, empódio semelhante ao da fềmea, com (4-5) de comprimento. Região coxisternal: Setas $1 a$ inseridas em tubérculos, com (9) de comprimento, afastadas entre si de (6); setas $1 b$ inseridas em tubérculos, com (7-8) de comprimento, afastadas entre si de (12-13). Setas 
$2 a$ inseridas em tubérculos, com (15-16) de comprimento, afastadas de (22). Linha esternal com (10) de comprimento; área entre o coxistemo II e epigínio e o coxisterno I e II com ornamentações granulosas. Área triangular lateralmente ao coxisterno II com ornamentações em forma de tubérculo. Epigínio indistinto; abertura genital com (17-21) de largura, com a cutícula da fossa genital granulada. Setas $3 a$ com (7-8) de comprimento. Opistossoma: Tanossoma com (20) anéis dorsais, lisos, com expansões laterais maiores nos anéis $(2,4,7,10,12$ e 15) e menores nos demais; com (34-36) anéis ventrais, providos de microtubérculos alongados e acuminados. Telosssoma com anéis dorsais fundidos, lisos; (5) anéis ventrais providos de microtubérculos alongados e acuminados. Setas $d$ e $e$ ausentes. Seta $c 2$ com (12) de comprimento, no anel ventral (23). Setas $f$ com (13) de comprimento, afastadas entre si de (16), no anel ventral (34-36). Seta $h 1$ ausente. Seta $h 2$ com (25) de comprimento.

Material Tipo: Holótipo fềmea, 25 fềmeas e 7 machos parátipos, em 12 preparações microscópicas depositadas na coleção do setor de Zoologia do Departamento de Entomologia, Fitopatologia e Zoologia Agrícola da Universidade de São Paulo - ESALQ, Piracicaba, São Paulo. Cinco fềmeas e 2 machos parátipos em 2 preparações microscópicas depositadas no USNM, Washington, D.C., E.U.A.

Localidade Tipo: Cananéia, São Paulo, Brasil. Coletado por M.G.C. Gondim Jr. em 21-IV-1998, 13-X-1998 e 21-VII-1999, nas coordenadas $24^{\circ} 54^{\prime} 45^{\prime \prime}$ de latitude sul e $47^{\circ} 51^{\prime} 51$ ''de longitude oeste.

Plantas Hospedeiras: Coletado na superfície abaxial de folhas de G. schottiana (Arecaceae).

Etimologia: geonomae, referente ao gênero da única espécie de planta hospedeira conhecida deste ácaro.

Propilus syagris Gondim Jr., Flechtmann \& Moraes sp. n.

(Figura 7-8)

Diagnose: Propilus spinosus Keifer e Propilus gentyi Keifer (Keifer, 1975b) diferem desta nova espécie por apresentarem as setas ve visíveis em vista dorsal, na 
margem anterior do escudo prodorsal. $P$. spinosus também difere por apresentar um lóbulo anterior no escudo prodorsal, com padrão estriado longitudinalmente, além de possuir estrias longitudinais no epigínio. $O$ tanossoma de $P$. gentyi não apresenta lateralmente projeções espiniformes, como ocorre na espécie nova.

Fêmea: São dadas as medidas do holótipo e entre parenteses a variação de 8 parátipos. Idiossoma: curto e fusiforme, 175 (162-175) de comprimento, 74 (69-79) de largura, coloração amarela clara quando vivo. Gnatossoma: 22 (21-23) de comprimento; seta $d$ com 11 (9-11) de comprimento, estiletes quelicerais com 16 (14-17) de comprimento. Escudo prodorsal: Com uma região central elevada e rugosa, e liso lateralmente; com um bordo anterior estreito, levemente mais elevado e arqueado para baixo anteriormente; com 2 projeções laterais espiniformes posteriormente; 54 (51-56) de comprimento; 74 (69-79) de largura; seta escapular sc ausente, seta vertical ve inserida em tubérculos, com 4 (4-5) de comprimento, localizados ventralmente na parte anterior do escudo, afastadas entre si de 18 (16-19). Perna: Sem setas na tíbia I. Perna I: 33 (32-33) de comprimento; trocânter 4 (4-5); fềmur 14 (12-14), seta $b v 8$ (7-8); genu 4 (3-4), seta l' 21 (21-23); tíbia 3 (3); tarso 8 (7-8), seta $f t$ ' 11 (11-12), seta ft" 15 (1315), seta $u^{\prime} 2$ (2-3), solenídio $\omega 4$ (3-4), empódio com eixo central íntegro, com 3 (2-3) de comprimento e 5 (4-5) pares de raias. Perna II: 30 (28-30) de comprimento; trocânter 4 (3-4); fêmur 12 (11-12), seta bv 7 (6-7); genu 3 (3-4), seta l" 15 (13-15); tíbia 3 (3); tarso 7 (7-8), seta $f t^{\prime} 5$ (4-5), seta $f t^{\prime \prime} 13$ (13-14), seta $u^{\prime} 2$ (2-3), solenídio $\omega 3$ (3-4), empódio com eixo central íntegro, com 2 (2-3) de comprimento e 5 (4-5) pares de raias. Perna I e II com ornamentações granulosas observadas apenas ao microscópio eletrônico. Região coxisternal: Setas $1 a 12$ (11-13) de comprimento, afastadas entre si de 14 (13-14); setas $1 b 7$ (6-7) de comprimento, afastadas entre si de 18 (17-19). Setas $2 a 25$ (24-26) de comprimento, afastadas entre si de 32 (30-33). Linha esternal ausente; apresenta uma linha curva divergindo anterolateralmente entre as bases das setas $1 a \mathrm{e}$ $1 b$; área entre o coxisterno II e o epigínio com 3 (3-4) anéis desprovidos de microtubérculos. Coxistemo I e II lisos. Epigínio bem delimitado, com 20 (18-20) de comprimento, 23 (21-23) de largura, predominantemente liso, mas com uma faixa 

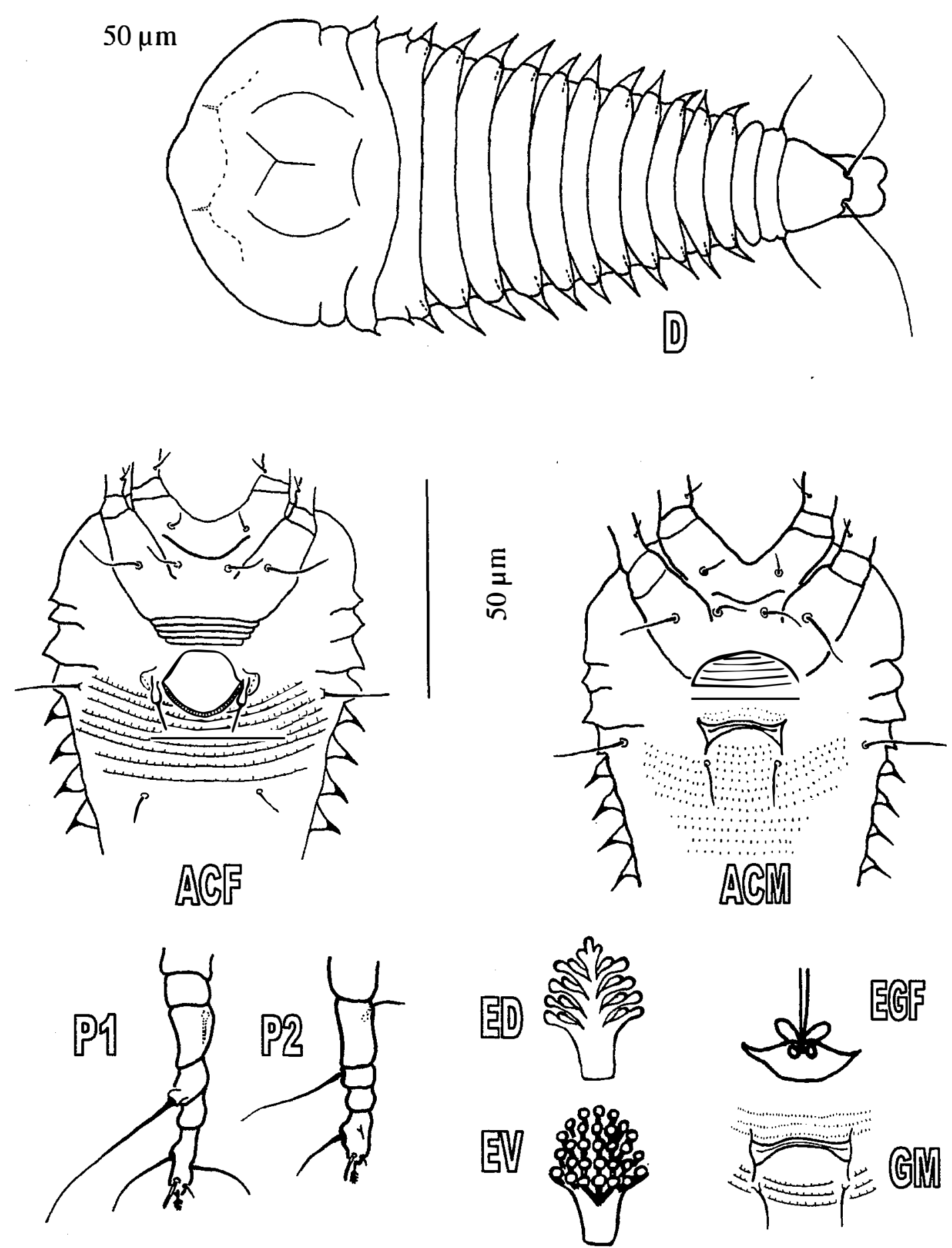

Figura 7. Propilus syagris sp. n. D - Dorso; ACF - Área coxigenital da fêmea; ACM - Área coxigenital do macho; P1 - Perna I; P2 - Perna II; ED - Empódio (vista dorsal); EV - Empódio (vista ventral); EGF - Estruturas genitais internas da fêmea; GM - Área genital do macho. 


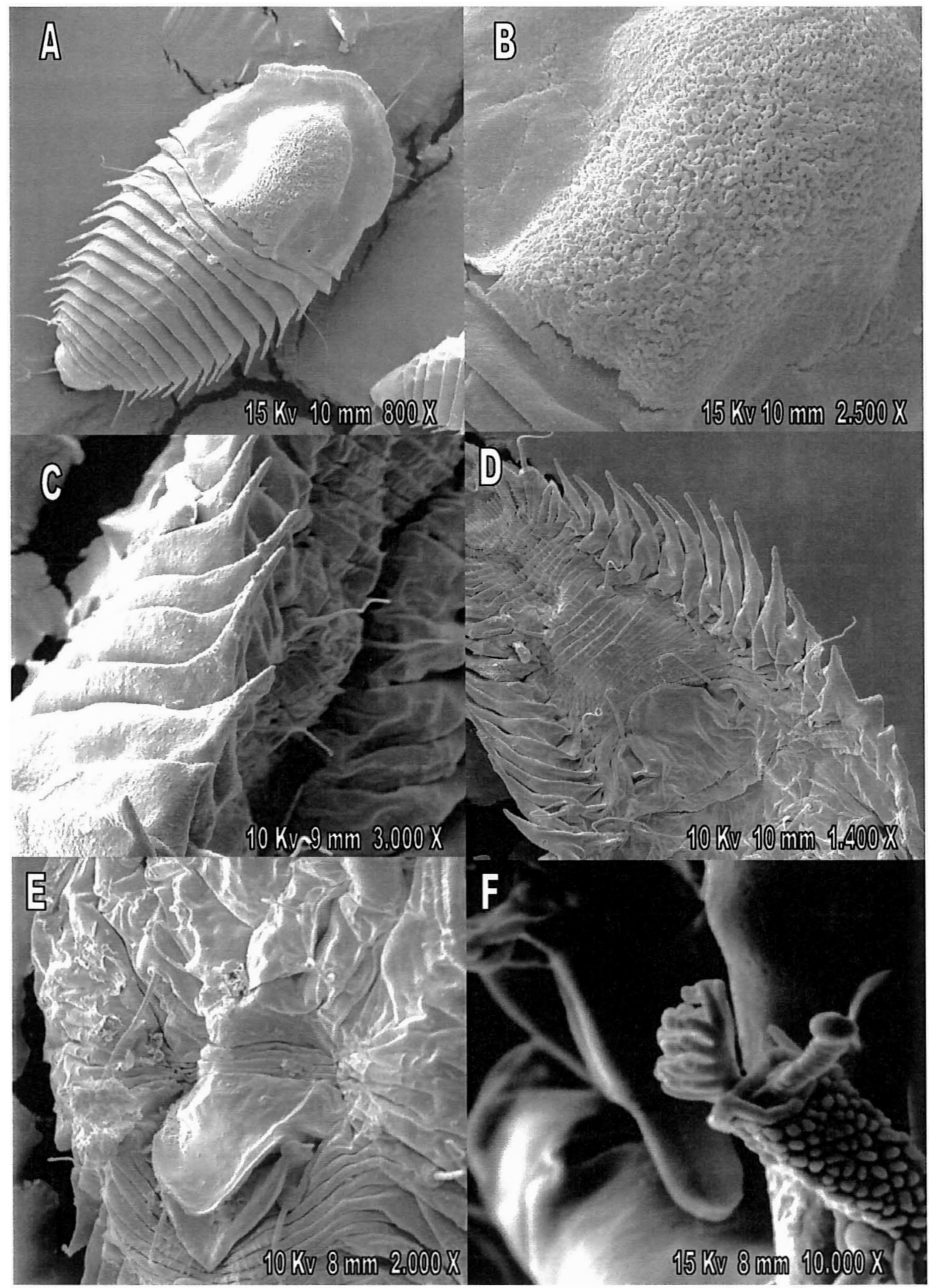

Figura 8. Propilus syagris sp. n. A - Dorso; B - Área porosa do escudo prodorsal; C Projeções espiniforme dos anéis; D - Vista ventral da fêmea; E - Área coxigenital da fêmea; F - Tarso da perna I. 
lateral diferenciada. Duto da espermateca curto. Setas $3 a$ com 11 (11-12) de comprimento. Opistossoma: Tanossoma com 13 (13-14) anéis dorsais, lisos, apresentando lateralmente expansões espiniformes, exceto nos dois últimos anéis; com 37 (36-38) anéis ventrais providos de microtubérculos alongados e acuminados. Telossoma: apresenta os anéis dorsalmente fundidos, lisos; ventralmente apresenta 4 (4) anéis providos de microtubérculos alongados e acuminados. Setas $c 2$ com 23 (21-23) de comprimento, no anel ventral 3 (2-3). Setas $d$ com 9 (9-11) de comprimento, afastadas entre si de 25 (25-27), no anel ventral 8 (8-9). Setas $e$ com 8 (7-8) de comprimento, afastadas entre si de 14 (13-14), no anel ventral 22 (21-22). Setas $f$ com 19 (15-19) de comprimento, afastadas entre si de 27 (26-27), no anel ventral 37 (36-38). Seta $h 1$ ausente. Seta $h 226$ (24-27) de comprimento.

Macho (n=5): Idiossoma: curto, fusiforme, (143-160) de comprimento; (61-65) de largura, de coloração amarelo clara quando vivo. Gnatossoma: Com (16) de comprimento; seta $d$ (9-11); estiletes quelicerais (14-15). Escudo prodorsal: Com uma região central elevada e rugosa, e liso lateralmente; com um bordo anterior estreito, levemente mais elevado e arqueado para baixo anteriormente; com 2 projeções laterais espiniformes posteriormente; (46-53) de comprimento; (61-65) de largura; seta $s c$ ausente, seta ve inserida em tubérculos, com (4) de comprimento, localizados ventralmente na parte anterior do escudo, afastadas de (16-17). Perna: Sem seta na tibia I. Perna I: (32-33) de comprimento; trocânter (3); fêmur (13-14), seta bv (6-7); genu (4), seta l"' (22-24); tíbia (3-4); tarso (9), seta $f t$ ' (11-12), seta $f t$ '" (13-15), seta $u$ ' (2-3), solenídio $\omega$ (3-4), empódio como na fêmea. Perna II: (29-31) de comprimento; trocânter (3); fêmur (12), seta $b v$ (5-6); genu (3-4), seta l' (14-15); tíbia (3); tarso (8-9), seta $f t$ ' (4), seta ft' '(13-14), seta u' (2), solenídio $\omega(3-4)$, empódio como na fềmea, com (3) de comprimento. Pema I e II com ornamentações granulosas observadas apenas ao nível do microscópio eletrônico. Região coxisternal: Setas $1 a$ com (15-16) de comprimento, afastadas entre si de (9-11); setas $1 b$ com (6-7) de comprimento, afastadas entre si de (15-16). Setas $2 a$ com (24-27) de comprimento, afastadas entre si de (27-28). Linha esternal ausente, mas com uma linha curva divergindo anterolateralmente entre as bases das setas $l a$ e $l b$, voltando um pouco para trás na extremidade; área entre o coxisterno II 
e o epigínio com (7-9) anéis, sem microtubérculos. Coxisterno I e II lisos. Epigínio com (16-17) de largura, cutícula da fossa genital lisa; seta $3 a$ com (16-17) de comprimento. Opistossoma: Tanossoma com 13 anéis dorsais, lisos, apresentando expansões laterais espiniformes, exceto os dois últimos anéis; apresenta (36-37) anéis ventrais providos de microtubérculos alongados e acuminados. Telosssoma apresenta os anéis fundidos dorsalmente, lisos; apresenta (4) anéis ventrais providos de microtubérculos alongados e acuminados. Setas $c 2$ com (23-26) de comprimento, no anel ventral (2). Setas $d$ com (11-13) de comprimento, afastadas entre si de (21-22), no anel ventral (9-10). Setas $e$ com (11-12) de comprimento, afastadas entre si de (13-14), no anel ventral (22). Setas $f$ com (21) de comprimento, afastadas de (22-24), no anel ventral (36-37). Seta $h 1$ ausente. Seta $h 2$ (44-46) de comprimento.

Material Tipo: Holótipo fềmea, 28 fêmeas e 16 machos parátipos, em 14 preparações microscópicas na coleção do setor de Zoologia do Departamento de Entomologia, Fitopatologia e Zoologia Agrícola da Universidade de São Paulo-ESALQ, Piracicaba, São Paulo. Cinco fêmeas e quatro machos parátipos em 2 preparações microscópicas depositadas no USNM, Washington, D.C., E.U.A.

Localidade Tipo: Pariquera-açu, São Paulo, Brasil. Coletado por M.G.C. Gondim Jr., em 21-IV-1998 e 20-VII-1999, nas coordenadas 24³6’39' de latitude sul e $47^{\circ} 53^{\prime} 00^{\prime}$ 'de longitude oeste.

Plantas Hospedeiras: Coletado na superfice abaxial de folhas de $S$. romanzoffiana (Arecaceae).

Etimologia: syagris, referente ao gênero da única espécie de planta hospedeira conhecida deste ácaro. 


\section{FITOSEÍdeOS (ACARI : PHYTOSEIIDAE) ASSOCIADOS A PALMEIRAS (ARECACEAE) EM ÁREAs dOS ESTAdos DE SÃo PAULO E PERNAMBUCO}

\section{RESUMO}

Este trabalho relata 43 espécies de fitoseídeos encontrados em plantas nativas e exóticas da família Arecaceae, em áreas dos Estados de São Paulo e Pernambuco. As coletas foram feitas em 24 espécies nativas e 14 espécies exóticas de palmeiras. Dez espécies novas de fitoseídeos são descritas: Amblyseius euterpes sp. n., Amblyseius geonomae sp. n., Amblyseius igarassuensis sp. n., Iphiseiodes setillus sp. n., Neoseiulus recifensis sp. n., Neoseiulus veigai sp. n., Paraamblyseius multicircularis sp. n., Typhlodromips ariri sp. n., Typhlodromips cananeiensis sp. n. e Typhlodromips jucara sp. n. As espécies mais frequentes em áreas de matas pertencem aos gêneros Amblyseius e Typhlodromips, enquanto que as mais frequentes em áreas alteradas pertencem aos gêneros Amblyseius, Euseius e Iphiseiodes. 


\section{PHYTOSEIID MITES (ACARI: PHYTOSEIIDAE) ASSOCIATED WITH PALM TREES (ARECACEAE) IN AREAS OF SÃo PAULO AND PERNAMbUCO STATES}

SUMMARY

This work reports 43 species of phytoseids on native and exotic plants of the family Arecaceae, in the areas of the States of São Paulo and Pernambuco. The survey was done on 24 native and 14 exotic species of palm trees. Ten new species of phytoseiid mites are described: Amblyseius euterpes n.sp., Amblyseius geonomae n.sp., Amblyseius igarassuensis n.sp., Iphiseiodes setillus n.sp., Neoseiulus recifensis n.sp., Neoseiulus veigai $\mathrm{n} . \mathrm{sp} .$, Paraamblyseius multicircularis n.sp., Typhlodromips ariri n.sp., Typhlodromips Cananeiensis n.sp. and Typhlodromips jucara n.sp. The most frequent species in the wild belong to Amblyseius and Typhlodromips, while those most frequent in altered areas belong to the genera Amblyseius, Euseius and Iphiseiodes. 


\subsection{INTRODUÇÃO}

Recentemente tem havido um grande aumento da área plantada com espécies da

família Arecaceae no sudeste do Brasil, principalmente coqueiro (Cocos nucifera L.) e os palmitos juçara (Euterpe edulis Mart.) e pupunha (Bactris gasipaes Kunth.). A origem de $C$. nucifera ainda é discutível, embora se acredite que seja originário da Ásia, E. edulis é uma planta nativa do litoral sul do Brasil, enquanto $B$. gasipaes é natural da região amazônica. $\mathrm{O}$ aumento da área plantada, pode favorecer a ocorrência de altas populações de ácaros fitófagos, principalmente em locais onde o clima é bastante diferente do ambiente natural destas plantas. Pouco se conhece sobre as espécies de ácaros que ocorrem nas palmeiras do Brasil. Flechtmann (1967, 1997a, 1997b, 1998) e Santana \& Flechtmann (1998) relataram 7 espécies de eriofideos, 3 de tetraniquídeos, 1 de tenuipalpídeo e 5 de fitoseídeos em palmeiras no Brasil. A fauna de Phytoseiidae, principal grupo de ácaros predadores de ácaros fitófagos, é portanto muito pouco conhecida no país. Este trabalho reporta espécies de fitoseídeos coletados no presente trabalho em arecáceas nativas e exóticas no Brasil, além de descrever 10 espécies novas para a ciência.

\subsection{MATERIAL E MÉTODOS}

No Estado de São Paulo, o levantamento foi realizado nos municípios de Piracicaba em III-98 e VIII-98 (21 espécies de palmeiras), Pariquera-açu em IV-98 e X98 (12 espécies) e Cananéia em IV-98 e X-98 (6 espécies). No Estado de Pernambuco, o levantamento foi realizado nos municípios de Goiana (4 espécies), Igarassu (5 espécies), Itamaracá (4 espécies), Itambé (4 espécies) e Recife (5 espécies), todos nos meses de VI98 e I-99. Algumas das espécies examinadas estavam presentes em mais de um município. As espécies escolhidas para a amostragem foram as mais comuns em cada local de coleta, estando algumas presentes em mais de um [x1]município.

As espécies nativas amostradas foram Acrocomia aculeata (Jacq.) Lodd. ex Mart., Acrocomia intumescens Drude, Aiphanes aculeata Willd., Astrocaryum 
aculeatissimum (Schott) Burret, Attalea dubia (Mart.) Burret, Attalea phalerata Mart. ex Spreng., Attalea oleifera Barb. Rodr., Attalea sp., Bactris ferruginea Burret., B. gasipaes, Bactris setosa Mart., Butia eriospatha (Mart.) Becc., C. nucifera, E. edulis, Euterpe sp., Geonoma elegans Mart., Geonoma gamiova Barb. Rodr., Geonoma pohliana Mart., Geonoma schottiana Mart., Lytocaryum weddellianum (H. Wendl.), Polyandrococus caudescens (Mart.) Barb. Rodr., Syagrus romanzoffiana (Cham.) Glassman, Syagrus schizopylla (Mart.) Glass. e Syagrus sp. As espécies exóticas amostradas foram Archontophoenix cunninghamii H. Wendl. \& Drude, Caryota mitis Lour., Caryota urens L., Chamaerops humilis L., Cryosophila nana (Kunth) Blume ex Salomon, Dypsis lutescens H. Wendl., Elaeis. guineensis N.J. Jacquin, Phoenix dactylifera L., Phoenix reclinata N.J. Jacquin, Phoenix roebelenii O'Brien, Pritchardia pacifica Seemann \& H. wendl., Ptychosperma macarthurii (H. Wendl.) Nicholson, Roystonea oleraceae (N.J. Jacquin).

Foram coletados folíolos de 3 estratos distintos da copa da planta (folíolos basais, medianos e apicais). Em cada local de coleta foram amostradas 3 plantas diferentes de uma mesma espécie botânica, coletando-se 10 folíolos de cada estrato por planta. Frutos do coqueiro foram coletados sempre que presentes e quando o porte da planta permitia a coleta. Todo o material coletado foi levado ao laboratório em caixas de isopor refrigeradas. No laboratório, os ácaros foram coletados manualmente, com auxílio de microscópio estereoscópico e pincel de cerdas finas, e montados em lâminas com meio de Hoyer.

A nomenclatura das setas utilizada neste trabalho é aquela proposta por Rowell et al. (1978) para a superficie dorsal e Chant \& Yoshida-Shaul (1991) para a superfície ventral do idiossoma. A citação da distribuição geográfica das espécies é baseada em Moraes et al. (1986); informações adicionais são indicadas no texto acompanhadas das respectivas referências. Apresentam-se medições para as espécies novas, para as espécies relatadas pela primeira vez no Brasil e para as que apresentaram certas diferenças morfológicas em relação ao verificado na literatura. As medições são sempre apresentadas em micrômetros.

Todos os espécimes analisados foram coletados por M.G.C. Gondim Jr., sendo os 
espécimes representativos e os tipos depositados no setor de zoologia da Escola Superior de Agricultura "Luiz de Queiroz" da Universidade de São Paulo (Piracicaba - São Paulo - Brasil). Parátipos também foram depositados no Florida State Collection of Arthropods (FSCA)/United States National Museum of Natural History (USNMNH). As coordenadas de latitude e longitude dos pontos de coleta das espécies novas são citados no texto e as exsicatas das espécies botânicas, sobre as quais os fitoseídeos foram coletados, estão depositados no Museu de Botânica da ESALQ-USP, sob os números de 49697 a 49734.

\subsection{RESULTADOS E DISCUSSÃO}

Amblyseius aerialis (Muma)

Amblyseiopsis aerialis Muma 1955: 264; Garman, 1958:75.

Typhlodromus (Amblyseius) aerialis, Chant, 1959: 88; Muma, 1961: 287.

Amblyseius aerialis, DeLeon, 1966: 91; Moraes \& Mesa, 1988: 71; Denmark \& Muma, 1989: 15; Kreiter \& Moraes, 1997: 377; Feres \& Moraes, 1998: 126.

DISTRIBUIÇÃO: Argélia, Bermudas, Brasil, Cuba, EUA, Galápagos, Guiana, Honduras, Índia, Jamaica e México; Colômbia (Moraes \& Mesa, 1988); Guadalupe e Martinica (Kreiter \& Moraes, 1997).

ESPÉCIMES EXAMINADOS: Pernambuco: Goiana, $A$. oleifera (VI-98); Igarassu, $A$. intumescens (VI-98) e C. nucifera (VI-98, I-99); Itambé, A. intumescens e Syagrus sp. (I-99); Recife, D. lutescens (I-99), E. guineensis (I-99), Euterpe sp. (I-99) e C. nucifera (VI-98).

OBSERVAÇÕES: A medição de 4 fêmeas indicaram que jl (37) é maior que os valores observados por Moraes \& Mesa (1988) para espécimes coletados na Colômbia (24-31), e por Kreiter \& Moraes (1997) para espécimes coletados em Guadalupe e Martinica (2429). SgeIV (128) é maior que os valores observados por Moraes \& Mesa (1988) (91112). StiIII (41) é aproximadamente 2 vezes mais longo que dos espécimes estudados por Moraes \& Mesa (1988). O comprimento do cérvix da espermateca (16-17) é maior 
que o observado por Denmark \& Muma (1989) (11-12).

\section{Amblyseius chiapensis DeLeon}

Amblyseius chiapensis DeLeon, 1961: 85; 1962: 175; McMurtry, 1983: 250; Moraes \& Mesa, 1988: 72; Denmark \& Muma, 1989: 94; McMurtry \& Moraes, 1989: 185. Amblyseius triplaris DeLeon, 1967: 25 (sinonímia de acordo com Denmark \& Muma, 1989: 94).

DISTRIBUIÇÃO: Brasil, Colômbia, El-Salvador, Guatemala, México e Porto Rico; Peru (McMurtry \& Moraes, 1989); Honduras (Denmark et al., 1999).

ESPÉCIMES EXAMINADOS: São Paulo: Piracicaba, $A$. phalerata (III-98) e $C$. nucifera (III-98 e IX-98).

OBSERVAÇÕES: A medição de 4 fềmeas indicaram que z2 (9-11) é pouco menor que os valores observados por DeLeon (1961) (13-19) para espécimes do México. A seta Z5 (185-198) também foi menor que o observado pelo mesmo autor (1961) (214-235) e Denmark \& Muma (1989) (219-251). A macroseta StilV (52) é menor que os valores observados por Denmark \& Muma (1989) (59-63) e McMurtry \& Moraes (1989) (6570).

Amblyseius compositus Denmark \& Muma

Amblyseius compositus Denmark \& Muma , 1973: 240; 1989: 95, Moraes \& McMurtry, 1983: 134.

DISTRIBUIÇÃO: Brasil.

ESPÉCIMES EXAMINADOS: São Paulo: Piracicaba, $A$. aculeata (IX-98), $A$. cunninghamii (IX-98), A. phalerata (III-98, IX-98), Attalea sp. (IX-98), B. gasipaes (IX98), C. mitis (III-98, IX-98), L. chinensis (IX-98), L. weddellianum (IX-98), P. dactylifera (III-98), P. caudescens (IX-98) e $R$. oleracea (IX-98).

MEDIÇÕES (4 fêmeas): comprimento da placa dorsal 334 (328-347), largura 221 (213226), j1 28 (27-32), j3 49 (48-50), j4 8 (7-8), j5 4 (3-4), j6 6 (5-7), J2 6 (5-6), J5 7 (7-8), 
z2 12 (11-13), z4 12 (11-13), z5 5 (4-5), Z1 7 (6-7), Z4 88 (85-89), Z5 144 (138-150), s4 78 (75-79), S2 9, S4 8 (8-9), S5 9 (8-9), r3 19 (18-20), R1 12 (11-12), ST1-ST3 60 (5961), ST2-ST2 75 (72-76), ST5-ST5 69 (65-74), comprimento da placa ventrianal 118 (113-124), largura ao nível de ZV2 76 (75-77) e ao nível do ânus 76 (74-79), comprimento do cérvix da espermateca 5 (5-6), dígito fixo da quelícera com 32 (30-35) de comprimento e 10 dentes, dígito móvel com 37 (35-38) de comprimento e 3-4 dentes, SgeI 34 (33-35), SgeII 35 (33-36), SgeIII 34 (32-35), StiIII 26 (25-27), SgeIV 64 (6267), StiIV 40 (38-44), StIV 61 (56-67).

OBSERVAÇÕES: Os comprimentos de j3 e Z5 são 40\% maiores que aqueles observados na descrição original (35 e 104, respectivamente), enquanto que 0 comprimento de StiIV é 30\% menor que aquele da descrição original (55).

Amblyseius euterpes Gondim Jr. \& Moraes, sp. $\mathrm{n}$.

(Figs. 9-12)

DIAGNOSE - Esta espécie difere de Amblyseius chilcoti Chant \& Hansell, 1971 por apresentar Z5 e o cérvix da espermateca maiores e StiIV e StIV menores; de Amblyseius guianensis DeLeon, 1966 por apresentar as setas j3, Z5 e o cérvix da espermateca maiores; de Amblyseius modestus Chant \& Baker, 1965 por apresentar as setas $\mathrm{j} 3, \mathrm{Z4}, \mathrm{Z5}$, s4 e o cérvix da espermateca maiores.

FÊMEA ( $n=6)$

Dorso: Placa dorsal lisa, com 305 (299-320) de comprimento, 228 (218-239) de largura, j1 26 (21-30), j3 41 (38-43), j4 6 (4-7), j5 5 (4-6), j6 6 (6-7), J2 8 (7-8), J5 8 (78), z2 10 (8-11), z4 8 (7-8), z5 5 (5-7), Z1 9 (8-11), Z4 108 (100-113), Z5 263 (256269), s4 81 (75-86), S2 12 (11-12), S4 11 (11-12), S5 11 (11-12), r3 13 (12-13), R1 9 (89). Todas as setas são lisas. O padrão dorsal de setas desta espécie é 10A:9B.

Peritrema: Estendendo-se até o nível de j1.

Ventre: Placa esternal com margens bem delimitadas, sem estriações, com 3 pares de setas e 2 pares de poros. Distância entre as setas ST1-ST3 60 (59-62), ST2-ST2 67 (65-70) e ST5-ST5 69 (65-74). Placa ventrianal pentagonal, lisa, com 3 pares de 


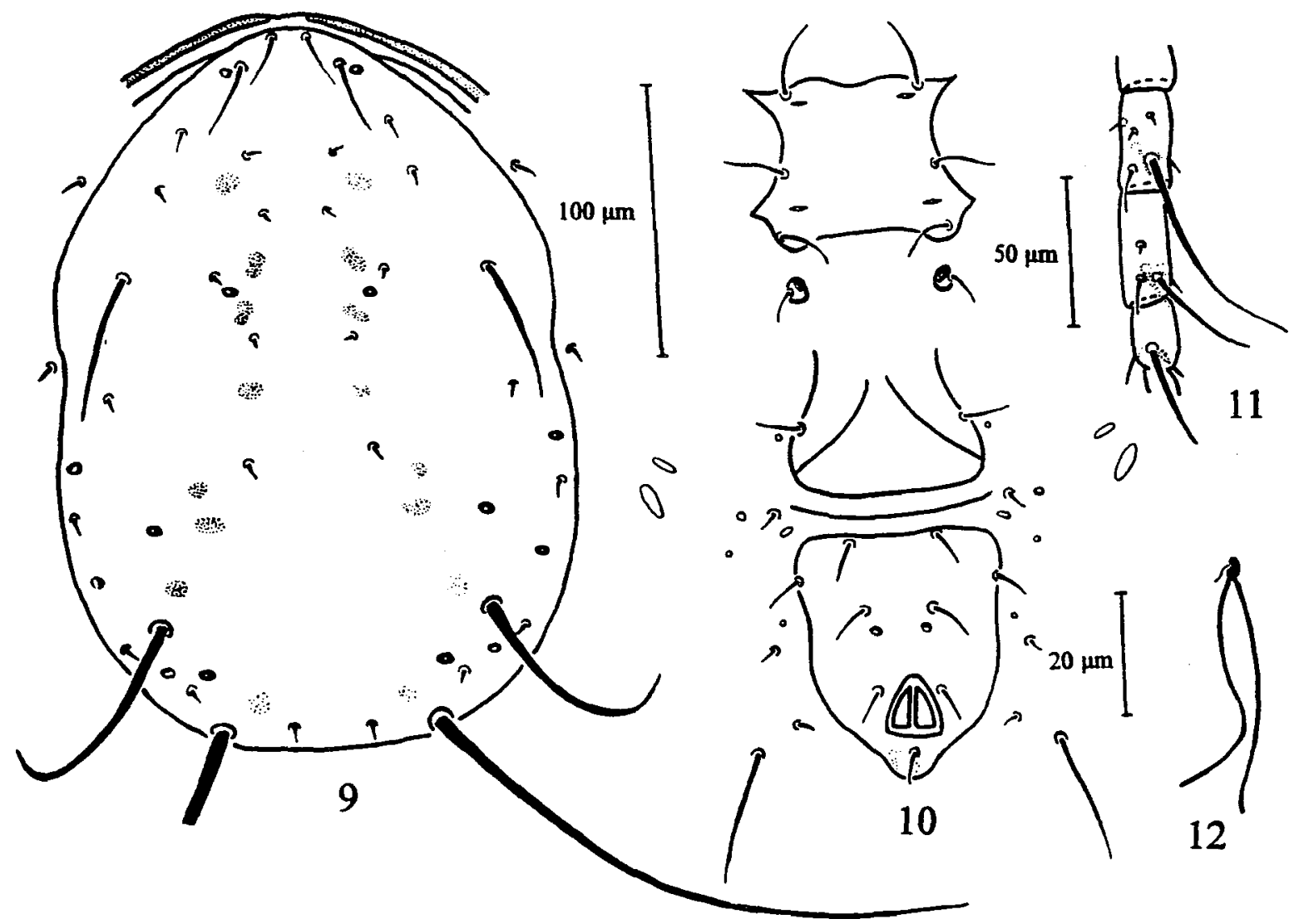

Figuras 9-12. Amblyseius euterpes $\mathrm{sp}$. n. 9, placa dorsal; 10, placas ventrais; 11, genu, tíbia e pré-tarso da perna IV; 12 , cérvix da espermateca. 
setas pré-anais e um par de poros, com 98 (89-105) de comprimento, 89 (86-91) de largura ao nível de ZV2 e 57 (53-61) ao nível do ânus. Com 2 pares de placas metapodais.

Espermateca: Cérvix alongado, constricto na região mediana, com 39 (35-42) de comprimento. Átrio relativamente pequeno.

Pernas: Macrosetas com extremidades afiladas: SgeI 35 (32-35), SgeII 34 (3235), SgeIII 43 (40-45), StiIII 30 (28-30), SgeIV 95 (89-102), StiIV 53 (51-54) e StIV 45 (32-49). Seta ereta dorso-proximal presente no tarso I. Quetotaxia do genu II 2;2/0;2/0;1/genu III $1 ; 2 / 1 ; 2 / 0 ; 1$.

MACHO: Desconhecido.

LOCALIDADE E MATERIAL TIPO: Holótipo fêmea e 5 parátipos fềmeas de Euterpe sp. ( $7^{\circ} 53^{\prime} 27^{\prime \prime}$ de latitude sul e $34^{\circ} 58^{\prime} 36^{\prime \prime}$ de longitude oeste). Todos os espécimes coletados em Igarassu (Pernambuco) em VI-98.

ETIMOLOGIA: euterpes, referente ao gênero da planta sobre na qual o ácaro foi encontrado.

Amblyseius geonomae Gondim Jr. \& Moraes, sp. n.

(Figs. 13-17)

DIAGNOSE: Esta espécie difere de Amblyseius kalandadzei Gomelauri, 1968 por apresentar s4, Z4 e Z5 maiores e StiIV menor; de Amblyseius mazatlanus Denmark \& Muma, 1989 por apresentar j1, j3, s4 menores e Z5 maior; de Amblyseius duncansoni Specht \& Rasmy, 1970 por apresentar j3, s4, Z4, SgeIV, StiIV e StIV menores; de Amblyseius januarius Wainstein \& Vartapetov, 1973 por apresentar j1 e o cérvix da espermateca maior e StiIV menor; de Amblyseius cessator DeLeon, 1962 por apresentar j3, s4, Z4, SgeIV, StiIV e StIV e o cérvix da espermateca menores.

FÊMEA $(n=8)$

Dorso: Placa dorsal lisa, 301 (289-328) de comprimento, 230 (210-245) de largura, j1 26 (24-28), j3 40 (37-42), j4 5 (5-6), j5 5 (5-6), j6 7 (6-7), J2 8 (6-9), J5 9 (89), z2 10 (9-12), z4 8 (7-9), z5 5 (5-6), Zl 9 (8-9), Z4 107 (102-113), Z5 258 (237-264), 


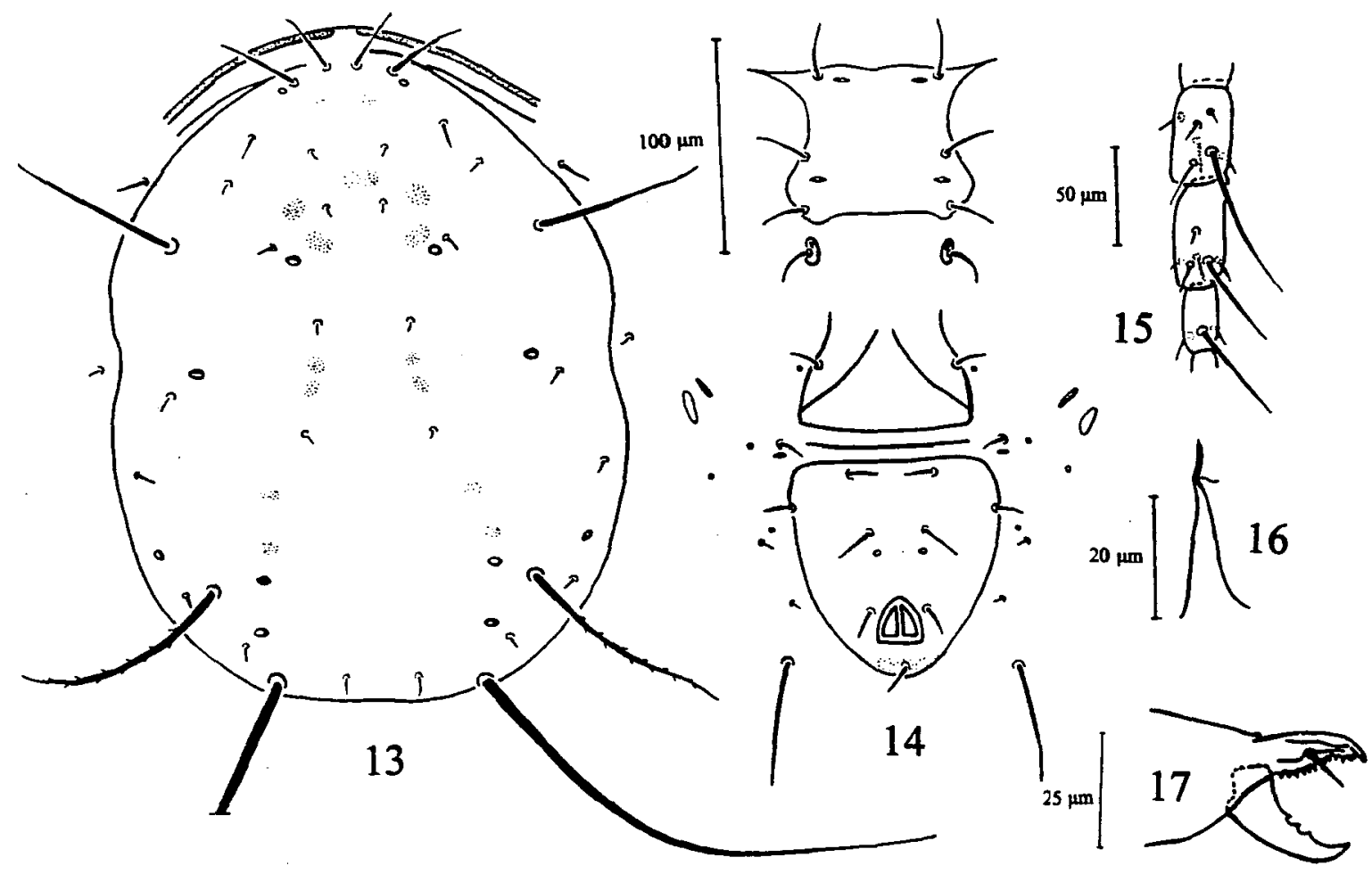

Figuras 13-17. Amblyseius geonomae sp. n 13, placa dorsal; 14, placas ventrais; 15, genu, tíbia e pré-tarso de perna IV; 16 , cérvix da espermateca; 17 , quelícera. 
s4 78 (73-83), S2 10 (9-11), S4 10 (9-11), S5 10 (9-11), r3 14 (12-15), R1 9 (7-13). Todas as setas são lisas, exceto $\mathrm{Z} 4$ que é serreada. O padrão da quetotaxia dorsal é 10A:9B.

Peritrema: Estendendo-se até o nível de j1.

Ventre: Placa esternal com margens bem delimitadas, sem estriações, 3 pares de setas, 2 pares de poros. Distância entre ST1-ST3 61 (58-64), ST2-ST2 68 (63-70), ST5ST5 68 (65-71). Placa ventrianal em forma de escudo, lisa, com 3 pares de setas préanais e 1 par de poros, com 100 (90-105) de comprimento, 100 (93-105) de largura ao nível de ZV2 e 80 (73-83) ao nível do ânus. Com 2 pares de placas metapodais.

Espermateca: Cérvix em forma de trombeta, com 21 (20-22) de comprimento e átrio quase imperceptível.

Quelícera: Dígito fixo com 27 (26-28) de comprimento e 12-13 dentes; dígito móvel com 29 (28-30) de comprimento e 3 dentes.

Pernas: Macrosetas com extremidades afiladas: SgeI 38 (36-39), Sgell 34 (3336), SgeIII 42 (40-43), StiII 29 (26-32), SgeIV 90 (86-99), StiIV 49 (47-51), StIV 51 (48-56). Seta ereta dorso-proximal presente no tarso I. Quetotaxia do genu II 2;2/0;2/0; $1 /$ genu III $1 ; 2 / 1 ; 2 / 0 ; 1$.

MACHO: Desconhecido.

LOCALIDADE E MATERIAL TIPO: Holótipo fêmea e 5 parátipos fêmeas de G. gamiova ( $24^{\circ} 36^{\prime} 38^{\prime \prime}$ ' de latitude sul e $47^{\circ} 52^{\prime} 55^{\prime \prime}$ de longitude oeste) em IV-98; 1 parátipo fềmea, de G. elegans ( $24^{\circ} 36^{\prime} 43^{\prime \prime}$ de latitude sul e $47^{\circ} 53^{\prime} 11^{\prime \prime}$ de longitude oeste) em X-98; 6 parátipos fêmeas, de G. pohliana $\left(24^{\circ} 36^{\prime} 51^{\prime \prime}\right.$ de latitude sul e 47 52 '58' de longitude oeste) em IV-98. Todos os espécimes coletados em Pariqueraaçu (São Paulo).

ETIMOLOGIA: geonomae, referente ao gênero da planta sobre a qual o ácaro foi encontrado.

\section{Amblyseius herbicolus (Chant)}

Typhlodromus (Amblyseius) herbicolus Chant, 1959: 84. 
Amblyseius herbicolus, Daneshvar \& Denmark, 1982: 5; McMurtry \& Moraes, 1984: 34; Denmark \& Muma, 1989: 59.

Amblyseius deleoni Muma \& Denmark, 1970: 68 (sinonimia, de acordo com Daneshvar \& Denmark, 1982: 5).

Amblyseius impactus Chaudhri, 1968: 553 (sinonímia, de acordo com Daneshvar \& Denmark, 1982: 5).

DISTRIBUIÇÃO: África do Sul, Angola, Austrália, Brasil, China, Colômbia, EUA, Guatemala, Índia, Indonésia, Iran, Japão, Madagascar, Nova Caledônia, Papua Nova Guine, Porto Rico, Tailândia e Taiwan; Costa Rica, Honduras, El Salvador (Denmark et al., 1999).

ESPÉCIMES EXAMINADOS: São Paulo: Piracicaba, Aiphanes aculeata Willd. (III-98, IX-98), A. cunninghamii (III-98, IX-98), A. phalerata (III-98, IX-98), Attalea sp. (II-98), C. mitis (IX-98), C. urens (III-98, IX-98), L. chinensis (IX-98), L. weddellianum (III-98, IX-98), P. reclinata (III-98, IX-98), P. roebelenii (III-98, IX-98), P. caudescens (III-98), P. macarthurii (III-98, IX-98), R. oleraceae (IX-98).

OBSERVAÇÕES: A medição de 4 fềmeas indicaram que o cérvix da espermateca (24) é $30 \%$ maior que o observado por Denmark \& Muma (1989).

Amblyseius igarassuensis Gondim Jr. \& Moraes, sp. n.

(Figs. 18-22)

DIAGNOSE: Esta espécie difere de Amblyseius compositus Denmark \& Muma, 1973 por apresentar as setas s4 e Z4 menores e o cérvix da espermateca maior; de Amblyseius operculatus DeLeon, 1967 por apresentar as setas j1, j3, s4, Z4 e Z5 menores.

FÊMEA (n=8)

Dorso: Placa dorsal lisa, com 298 (293-304) de comprimento, 194 (188-199) de largura, j1 23 (22-24), j3 33 (30-36), j4 6 (5-7), j5 6 (5-6), j6 9 (8-11), J2 9 (8-11), J5 8 (7-9), z2 8 (7-9), z4 8 (8-9), z5 5 (5-6), Z1 10 (9-11), Z4 59 (54-65), Z5 109 (91-118), s4 59 (56-65), S2 10 (9-12), S4 9 (8-11), S5 9(8-9), r3 13 (11-14), R1 8 (7-9). Todas as 


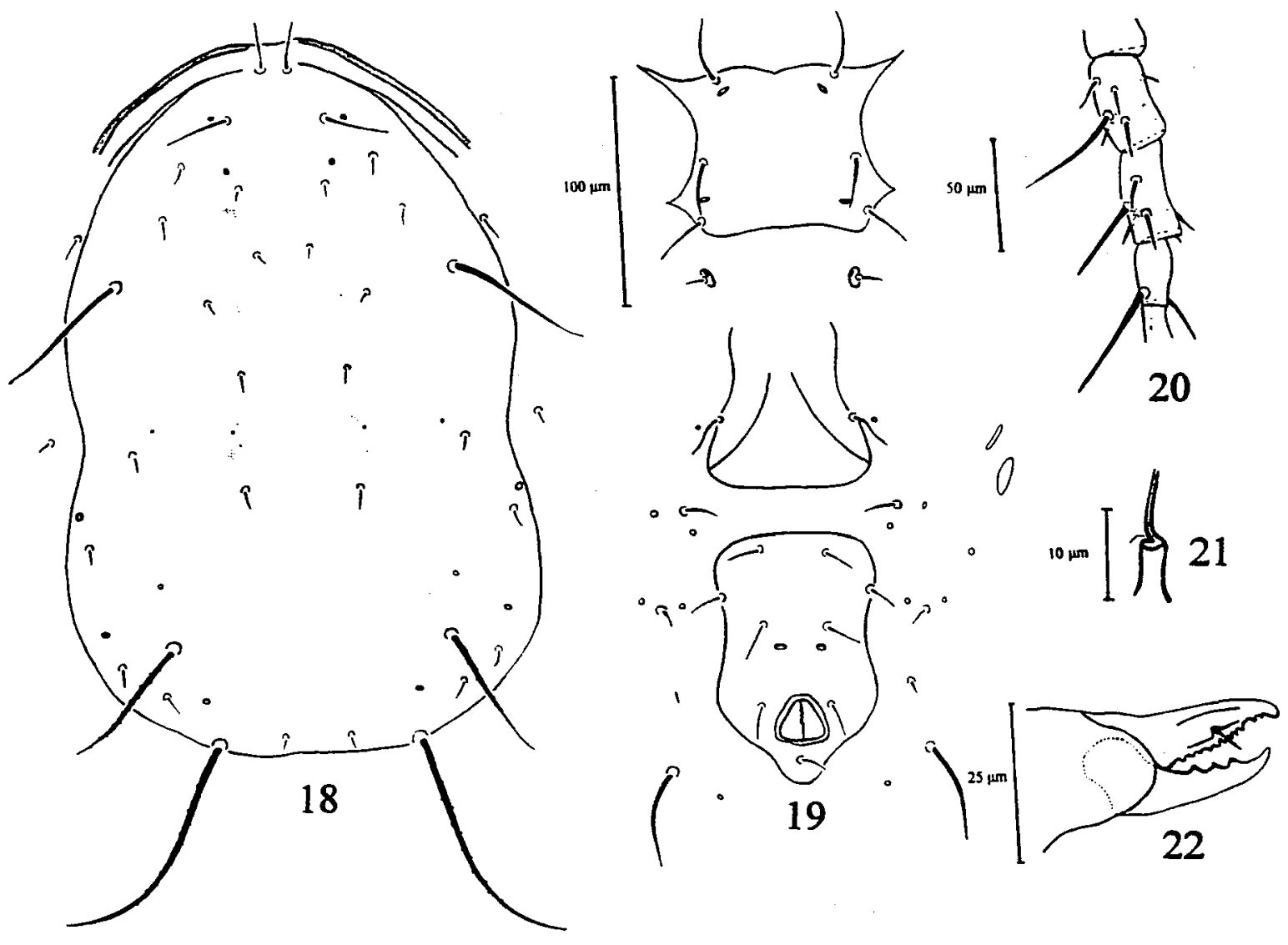

Figuras 18-22. Amblyseius igarassuensis sp. n. 18, placa dorsal; 19, placas ventrais; 20, genu, tíbia e pré-tarso da perna IV; 21 , cérvix da espermateca; 22, quelícera. 
setas são lisas, exceto Z4 e Z5 que são serreadas. O padrão de setas dorsal desta espécie é 10A:9B.

Peritrema: Estendendo-se até o nível de $\mathrm{j} 1$.

Ventre: Placa esternal com margens bem delimitadas, sem estriações, com 3 pares de setas e 2 pares de poros. Distância entre as setas ST1-ST3 58 (56-61), ST2-ST2 63 (59-65) e ST5-ST5 58 (56-61). Placa ventrianal constrita na região dos poros préanais, lisa, com 3 pares de setas pré-anais e um par de poros, com 100 (94-102) de comprimento, 67 (62-70) de largura ao nível de ZV2 e 67 (64-71) ao nível do ânus. Com 2 pares de placas metapodais.

Espermateca: Cérvix tubular, com 11 (9-11) de comprimento e átrio indistinto.

Quelíceras: Dígito fixo com 26 (25-27) de comprimento e 11-12 dentes; dígito móvel com 31 (30-32) de comprimento e 3 dentes.

Pernas: Macrosetas com extremidades afiladas: SgeI 34 (32-37), SgeII 31 (3032), SgeIII 29 (27-30), StiIII 24 (22-26), SgeIV 53 (48-56), StiIV 41 (38-42), StIV 53 (50-56). Seta ereta dorso-proximal presente no tarso I. Quetotaxia do genu II 2;2/0;2/0;1/genu III 1;2/1;2/0;1.

MACHO: Desconhecido.

LOCALIDADE E MATERIAL TIPO: Holótipo fêmea, de Euterpe sp. (7 $7^{\circ} 3^{\prime} 27^{\prime \prime}$ de latitude sul e 34 $58^{\prime} 36^{\prime \prime}$ de longitude oeste) em I-99; 3 parátipos fềmeas, em VI-98; 11 parátipos fềmeas em I-99. Todos os exemplares coletados em Igarassu (Pernambuco).

ETIMOLOGIA: igarassuensis, referente à localidade onde o ácaro foi encontrado.

\section{Amblyseius impressus Denmark \& Muma}

Amblyseius impressus Denmark \& Muma, 1973: 241; 1989: 39.

DISTRIBUIÇÃO: Brasil.

ESPÉCIMES EXAMINADOS: São Paulo: Piracicaba, C. urens (III-98). 
Amblyseius largoensis (Muma)

Amblyseiopsis largoensis Muma, 1955: 266; Garman, 1958: 76.

Amblyseius largoensis, Ehara, 1959: 293; Muma \& Denmark, 1970: 69; Denmark \& Muma, 1973: 238; 1989: 55; McMurtry \& Moraes, 1984: 29.

Typhlodromus (Amblyseius) largoensis, Chant, 1959: 238.

DISTRIBUIÇÃO: Cosmopolita.

ESPÉCIMES EXAMINADOS: Pernambuco: Goiana, $A$. intumescens (VI-98, I-99), $A$. oleifera (VI-98, I-99), C. nucifera (VI-98, I-99) e E. guineensis (VI-98, I-99); Itambé, $A$. intumescens (VI-98), C. nucifera (VI-98, I-99), E. guineensis (VI-98, I-99) e Syagrus sp. (VI-98); Recife, D. lutescens (VI-98), C. nucifera (VI-98, I-99), E. guineensis (I-99) e Euterpe sp. (VI-98).

OBSERVAÇÕES: A medição de 4 fềmeas indicou que o comprimento do cérvix da espermateca (24) é 30\% maior que o verificado por Denmark \& Muma (1989). Chamou atenção o fato desta espécie cosmopolita não ter sido encontrada em arecáceas em São Paulo, já que tem sido registrado em outras plantas no sudeste do país e foi verificada em grande quantidade em Arecaceae em Pernambuco.

\section{Amblyseius operculatus DeLeon}

Amblyseius operculatus DeLeon, 1967:26; Denmark \& Muma, 1989: 47.

DISTRIBUIÇÃO: Brasil e Trinidad-Tobago.

ESPÉCIMES EXAMINADOS: Pernambuco: Igarassu, $A$. intumescens (I-99), $C$. nucifera (I-99) e E. guineensis (VI-98, I-99); Itambé, $A$. intumescens (I-99). São Paulo: Cananéia, A aculeatissimum (X-98), B. setosa (X-98), C. nucifera (X-98), E. edulis (IV98, X-98) e G. schottiana (X-98).

MEDIÇÕES (4 fêmeas de Pemambuco e 4 de São Paulo): comprimento da placa dorsal 365 (358-373), largura 275 (268-282), j1 38 (35-42), j3 51 (46-55), j4 5 (5-7), j5 6 (5-7), j6 7 (5-9), J2 7 (6-9), J5 8 (7-9), z2 11 (11-15), z4 11 (8-13), z5 6 (5-7), Z1 9 (7-11), Z4 137 (121-151), Z5 292 (274-309), s4 112 (102-121), S2 13 (12-16), S4 13 (12-14), S5 
13 (11-14), r3 15 (14-18), R1 12 (11-13), ST1-ST3 72 (67-74), ST2-ST2 78 (75-81), ST5-ST5 74 (70-75), comprimento da placa ventrianal 134 (129-135), largura ao nível de ZV2 78 (75-82) e ao nível do ânus 83 (75-91), comprimento do cérvix da espermateca 11 (8-12), dígito fixo da quelícera com 38 (37-38) de comprimento e 16 dentes, dígito móvel com 45 (44-46) de comprimento e 4-5 dentes, SgeI 48 (40-53), SgeII 45 (43-48), SgeII 55 (51-62), StiIII 39 (35-44), SgeIV 119 (105-129), StiIV 83 (81-89), StIV 80 (75-86).

OBSERVAÇÕES: As dimensões dos ácaros deste trabalho são semelhantes às citadas por DeLeon (1967) e Denmark \& Muma (1989).

\section{Amblyseius perditus (Chant \& Baker)}

Iphiseius perditus Chant \& Baker, 1965: 16.

Amblyseius perditus, Denmark \& Muma, 1989: 105.

DISTRIBUIÇÃO: Honduras; Costa Rica (Denmark et al., 1999).

ESPÉCIMES EXAMINADOS: Pernambuco: Igarassu, $A$. intumescens (I-99), $C$. nucifera (I-99) e Euterpe sp. (I-99).

MEDIÇÕES (4 fêmeas): comprimento da placa dorsal 319 (304-339), largura 213 (204218), j1 31 (29-33), j3 38 (37-39), j4 6 (5-6), j5 4, j6 8 (7-8), J2 8, J5 7 (6-7), z2 6 (6-7), z4 7 (6-8), z5 5 (4-6), Z1 8 (8-9), Z4 60 (57-62), Z5 167 (161-172), s4 58 (56-60), S2 9 (8-9), S4 8 (7-9), S5 7, r3 16 (14-16), R1 11 (9-11), ST1-ST3 60 (58-60), ST2-ST2 69 (68-70), ST5-ST5 67 (65-69), largura da placa ventrianal ao nível de ZV2 67 (61-74), ao nível do ânus 67 (66-69), comprimento do cérvix da espermateca 21 (20-24), dígito fixo com 27 (26-28) de comprimento e 10 dentes e dígito móvel com 31 (30-32) de comprimento e 3 dentes, SgeI 42 (41-42), SgeII 40 (39-41), SgeIII 43 (41-44), StiIII 34 (32-36), SgeIV 72 (68-74), StirV 53 (51-54), StIV 65 (63-65).

OBSERVAÇÕES: As medições estão de acordo com os valores observados por Denmark \& Muma (1989). 
Amblyseius saopaulus Denmark \& Muma

Amblyseius saopaulus Denmark \& Muma, 1973: 243; 1989: 32.

DISTRIBUIÇÃO: Brasil.

ESPÉCIMES EXAMINADOS: São Paulo: Pariquera-açu, $A$. aculeatissimum (IV-98), $A$. dubia (IV-98, X-98), B. gasipaes (IV-98, X-98), C. nucifera (X-98) e E. guineensis (X98).

Amblyseius tamatavensis Blommers

Amblyseius tamatavensis Blommers, 1974: 144; Denmark \& Muma, 1989: 13; Moraes et al., 1991: 119.

Amblyseius maai Tseng, 1976: 123 (sinonímia, de acordo com Denmark \& Muma, 1989).

Amblyseius aegyptiacus Matthysse \& Denmark, 1981: 343 (sinonímia, de acordo com Denmark \& Muma, 1989).

DISTRIBUIÇÃO: África do Sul, Austrália, Indonésia, Madagascar, Nirgéria, New Hebrides, Papua Nova Guiné e Taiwan; Brasil (A.C. Lofego, informação pessoal); Cuba (Moraes et al., 1991).

ESPÉCIMES EXAMINADOS: Pernambuco: Goiana, C. nucifera (VI-98); Itambé, $A$. intumescens (IV-98).

Euseius alatus DeLeon

Euseius alatus DeLeon, 1966: 87; Denmark \& Muma, 1973: 262; Moraes \& McMurtry, 1983: 137; Feres \& Moraes, 1998: 127.

Euseius paraguayensis Denmark \& Muma, 1970: 224 (sinonímia, de acordo com Moraes \& McMurtry, 1983:137).

DISTRIBUIÇÃO: Brasil, Colômbia, Guiana e Paraguai; Peru (McMurtry \& Moraes, 
1989).

ESPÉCIMES EXAMINADOS: Pernambuco: Goiana, A. intumescens (VI-98) e $E$. guineensis (VI-98, I-99); Itamaracá, D. lutescens (VI-98, I-99), C. nucifera (VI-98, I99), P. pacifica (VI-98, I-99) e R. oleracea (VI-98, I-99); Recife, D. lutescens (I-99), E. guineensis (VI-98, I-99), Euterpe sp. (I-99), C. mitis (VI-98, I-99) e C. nucifera (VI-98, I-99). São Paulo: Piracicaba, Aiphanes aculeata (III-98, IX-98), A. cunninghamii (IX98), C. mitis (III-98, IX-98), C. urens (IX-98), C. humilis L. (IX-98), L. chinensis (IX98), P. reclinata (III-98), P.macarthurii (III-98, IX-98) e S. romanzoffiana (IX-98).

OBSERVAÇÕES: As medições de 4 fềmeas de Pernambuco e 4 de São Paulo indicaram que o cérvix da espermateca dos exemplares coletados (16) é $35 \%$ menor que o verificado no material tipo.

Euseius citrifolius Denmark \& Muma

Euseius citrifolius Denmark \& Muma, 1970: 222; Moraes \& McMurtry, 1983: 138; Moraes et al., 1991: 131; Feres \& Moraes, 1998: 127.

DISTRIBUIÇÃO: Brasil e Paraguai; Peru (McMurtry \& Moraes, 1989); Colômbia e Nicaragua (Moraes et al., 1991).

ESPÉCIMES EXAMINADOS: São Paulo: Piracicaba, Acrocomia aculeata (III-98, IX98), Aiphanes aculeata (IX-98), A. cunninghamii (IX-98), B. gasipaes (III-98, IX-98), C. mitis (III-98, IX-98), P. dactilifera (III-98), $R$. oleracea (III-98, IX-98) e $S$. romanzoffiana (IX-98).

MEDIÇÕES (4 fềmeas de São Paulo): comprimento da placa dorsal 324 (315-331), largura 234 (229-237), j1 28 (26-32), j3 26 (24-29), j4 13 (12-14), j5 14 (13-15), j6 15 (14-16), J2 16 (15-16), J5 7 (6-7), z2 21 (20-22), z4 22 (20-23), z5 14 (13-15), Zl 15 (14-15), Z4 18 (18-19), Z5 67 (65-70), s4 35 (33-38), S2 19 (18-20), S4 21 (19-22), S5 29 (27-32), r3 20 (20-21), R1 15 (14-15), ST1-ST3 57 (56-57), ST2-ST2 69 (69-70), ST5-ST5 76 (74-78), comprimento da placa ventrianal 106 (102-110), largura ao nível de ZV2 51 (49-54), ao nível do ânus 75 (73-78), comprimento do cérvix da espermateca 18 (16-20), dígito fixo com 24 de comprimento e 5 dentes, dígito móvel com 24 de 
comprimento e 1 dente, SgeI 19, SgeII 24 (23-24), SgeIII 30 (29-31), StiIII 24 (23-25), SgeIV 45 (43-48), StiIV 37 (35-38), StIV 63 (60-65).

OBSERVAÇÕES: As medições verificadas neste trabalho concordam com os dados apresentados por Feres \& Moraes (1998). As setas j4, j5, j6, J2, r3 e R1 são maiores que o material tipo (Denmark \& Muma, 1970), tendo este fato sido observado também por Feres \& Moraes (1998). As setas j3, z2, z4, Z5, s4 e S5 são maiores que os valores observados por Moraes et al. (1991). A.C. Lofego (informação pessoal) notou uma considerável variação no comprimento destas setas em espécimes coletados no Brasil.

\section{Euseius concordis (Chant)}

Typhlodromus (Amblyseius) concordis Chant, 1959: 69.

Amblyseius concordis, Chant \& Baker, 1965: 22.

Euseius flechtmanni Denmark \& Muma, 1970: 223; 1973: 261 (sinonímia, de acordo com Moraes et al., 1982: 18).

Euseius concordis, Denmark \& Muma, 1973: 264; Moraes \& Oliveira, 1982: 317;

Moraes \& McMurtry, 1983: 138; Feres \& Moraes, 1998: 127.

DISTRIBUIÇÃO: Argentina, Brasil, Colombia, Costa Rica, El Salvador, Guatemala, Nicaragua, Paraguai, Portugal, Trinidad-Tobago e Iugoslavia; Honduras (Denmark et al., 1999).

ESPÉCIMES EXAMINADOS: São Paulo: Piracicaba, C. nucifera (III-98).

OBSERVAÇÕES: Moraes et al. (1986) questionaram a ocorrência desta espécie na Iugoslávia, mencionada por Mijuskovic \& Tomasevic (1975).

\section{Euseius ho (DeLeon)}

Amblyseius (Euseius) ho DeLeon, 1965a: 125.

Euseius ho, Denmark \& Muma, 1973: 262; Moraes \& McMurtry, 1983: 139; Moraes et al., 1991: 132.

DISTRIBUIÇÃO: Brasil, Jamaica e Porto Rico; Colômbia, Equador, Mexico e Peru 
(Moraes et al., 1991).

ESPÉCIMES EXAMINADOS: São Paulo: Cananéia, E. edulis (IV, 98, X-98); Pariquera-açu, E. edulis (IV-98, X-98), G. gamiova (IV-98, X-98) e B. setosa (X-98).

OBSERVAÇÕES: A medição de 4 fêmeas de São Paulo indicam que os valores obtidos concordam com aqueles de Deleon (1965a) e Moraes \& McMurtry (1983).

Iphiseiodes setillus Gondim Jr. \& Moraes, sp. n.

(Figs. 23-27)

DIAGNOSE: Esta espécie difere de Iphiseiodes nobilis Chant \& Baker, 1965 e Iphiseiodes neonobilis Denmark \& Muma, 1978 por apresentar o escudo dorsal liso, as setas j4, j5, j6, J2, J5, z2, z4, Z1, Z4, Z5, S2, S4, S5, r3 e R1 maiores e as setas j1 e s4 menores. Difere também por apresentar os escudos genital e ventrianal lisos, além do cérvix da espermateca maior.

FÊMEA ( $n=3)$

Dorso: Placa dorsal lisa, bem esclerotizada e escurecida, com 266 de comprimento e 226 de largura, j1 7 (7-8), j3 15 (14-16), j4 16 (15-17), j5 17 (17-18), j6 18 (16-19), J2 18 (18-19), J5 8 (7-9), z2 13 (12-14), z4 18 (17-18), z5 16 (15-16), Z1 19 (18-19), Z4 20 (19-21), Z5 23 (21-24), s4 15 (14-15), S2 18 (17-20), S4 17 (16-19), S5 18 (16-18), r3 10 (9-11), R1 12. Todas as setas são lisas, exceto Z5 que é serreada. $O$ padrão dorsal das setas é 10A:9B.

Peritrema: estendendo-se até o nível de j1.

Ventre: Placa esternal com poucas estriações laterais, 3 pares de setas e dois pares

de poros, sendo uma vez e meia mais largo que longo. Distância entre ST1-ST3 39 (3740), ST2-ST2 58 (56-60) e ST5-ST5 77 (75-78). Placa ventrianal em forma de escudo, lisa, 3 pares de setas pré-anais e um par de poros, com 78 (74-82) de comprimento e 91 (89-92) de largura ao nível de ZV2. Todas as placas ventrais são bem esclerotizadas e escurecidas. Com 2 pares de placas metapodais.

Espemateca: Cérvix em forma de trombeta, com 11 (9-12) de comprimento. 

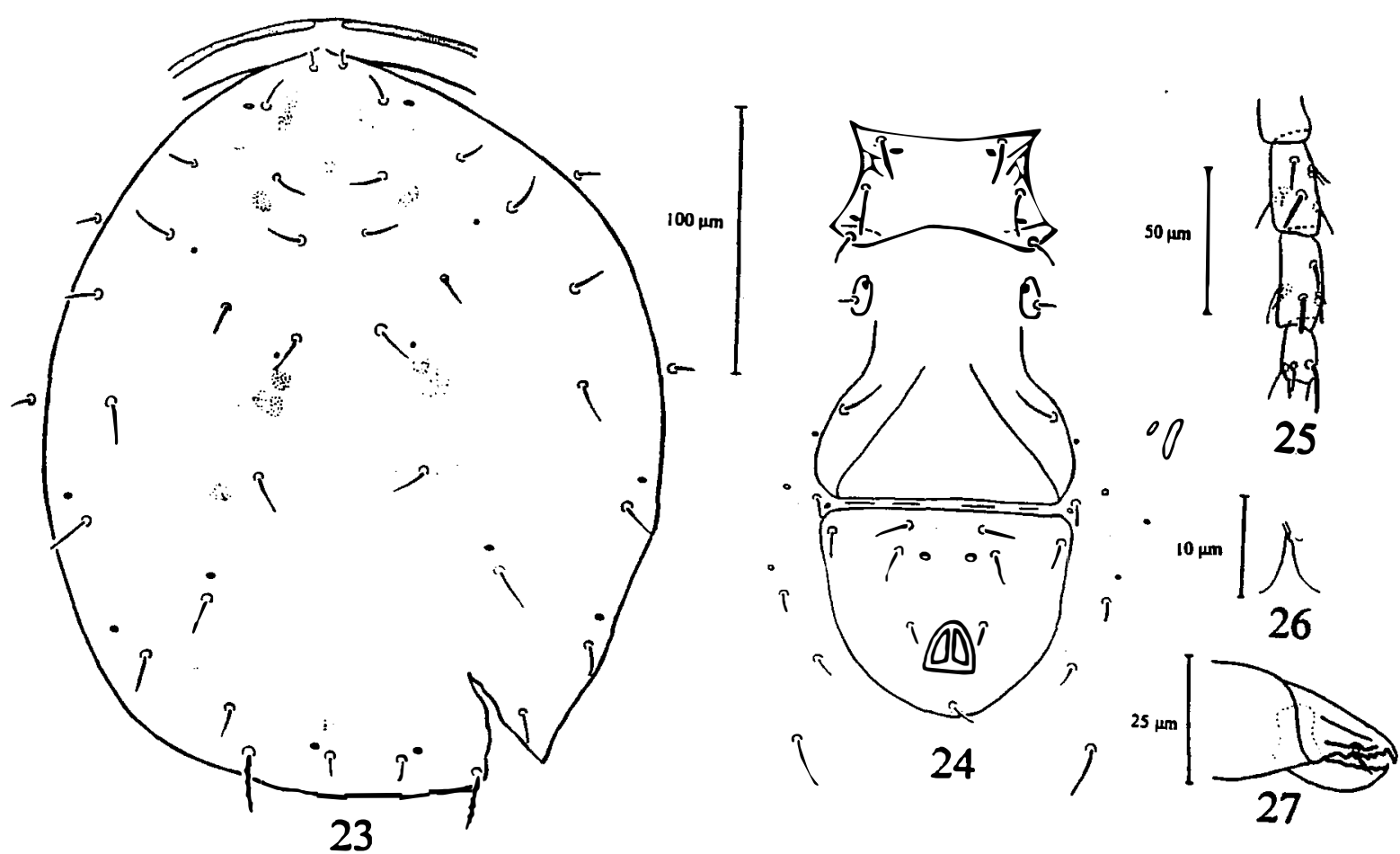

Figuras 23-27. Iphiseiodes setillus sp. n. 23, placa dorsal; 24, placas ventrais; 25, genu, tíbia e pré-tarso da perna IV; 26 , cérvix da espermateca; 27 , quelícera. 
Átrio quase indistinto.

Quelíceras: Dígito fixo com 19 (18-20) de comprimento e 5-6 dentes; dígito móvel com 22 (21-23) de comprimento e 2 dentes.

Pernas: Macrosetas com extremidades afiladas: SgeI 7, SgeII 9, SgeIII 13 (1213), StiIII 13 (12-13), SgeIV 12 (11-12), StiIV 15 (14-15), StIV 19 (18-19). Quetotaxia do genu II $2 ; 2 / 0 ; 2 / 0 ; 1 /$ genu III $1 ; 2 / 1 ; 2 / 0 ; 1$.

MACHO: Desconhecido.

LOCALIDADE E MATERIAL TIPO: Holótipo fêmea, de Euterpe sp. (7 $53^{\prime 2} 27^{\prime \prime}$ de latitude sul e $34^{\circ} 58^{\prime} 36^{\prime \prime}$ de longitude oeste) em VI-98; 1 parátipo em I-99; 1 parátipo em V-99. Todos espécimes coletados em Igarassu (Pernambuco).

ETIMOLOGIA: setillus, refere-se ao curto comprimento da seta s4.

\section{Iphiseiodes zuluagai Denmark \& Muma}

Iphiseiodes zuluagai Denmark \& Muma, 1972: 23; Aponte \& McMurtry, 1995: 165;

Kreiter \& Moraes, 1997: 377; Feres \& Moraes, 1998: 127.

Amblyseius zuluagai, Moraes \& Mesa, 1988: 79; Moraes et al., 1991: 125.

DISTRIBUIÇÃO: Brasil, Colômbia e Porto Rico; Cuba e Panamá (Moraes et al., 1991); Guadalupe (Kreiter \& Moraes, 1997).

ESPÉCIMES EXAMINADOS: Pernambuco: Goiana, $A$. intumescens (VI-98), $C$. nucifera (VI-98) e E. guineensis (VI-98); Igarassu, C. nucifera (VI-98, I-99) e $E$. guineensis (I-99); Itambé, C. nucifera (VI-98), E. guineensis (VI-98) e Syagrus sp. (VI98); Recife, C. mitis (VI-98), C. nucifera (VI-98), E. guineensis (I-99) e Euterpe sp. (VI98, I-99). São Paulo: Cananéia, C. nucifera (IV-98, X-98); Pariquera-açu, B. gasipaes (IV-98), C. nucifera (IV-98, X-98), E. guineensis (IV-98), Syagrus sp. (IV-98, X-98) e S. romanzoffiana (VI-98, X-98); Piracicaba, Acrocomia aculeata (III-98, IX-98), Aiphanes aculeata (III-98, IX-98), A. cunninghamii (III-98, IX-98), A. phalerata (III-98, IX-98), Attalea sp. (III-98, IX-98), B. gasipaes (III-98), B. eriospatha (III-98, IX-98), C. mitis (III-98, IX-98), C. urens (III-98, IX-98), C. humilis (III-98, IX-98), C. nucifera (III-98, IX-98), C. nana (III-98), L. chinensis (III-98, IX-98), R. oleraceae (III-98, IX- 
98), $P$. dactylifera (III-98, LX-98), P. reclinata (III-98, IX-98), P. roebelenii (III-98, IX98), P. caudescens (III-98, IX-98), P. macarthurii (III-98, IX-98), S. romanzoffiana (III98, IX-98).

OBSERVAÇÕES: Foram medidas 4 fêmeas de Pernambuco e 8 de São Paulo. Um indivíduo em Pernambuco apresentou as setas $\mathrm{Z5}, \mathrm{s} 4 \mathrm{e}$ as macrosetas consideravelmente menores (33\%) que os outros indivíduos, embora o escudo dorsal fosse aproximadamente do mesmo tamanho dos demais. Os indivíduos de Pernambuco apresentaram Z5, SgIV e StiIV cerca de $20 \%$ maiores que os indivíduos de São Paulo. A mesma tendência foi verificada por A.C. Lofego (informação pessoal) ao comparar indivíduos do nordeste e do sudeste. A média geral obtida neste trabalho está muito próxima das medições de Aponte \& McMurtry (1995). Esta espécie foi a que apresentou maior distribuição e abundância entre os locais e plantas amostradas.

Neoseiulus anonymus (Chant \& Baker)

Amblyseius anonymus Chant \& Baker, 1965: 21; McMurtry, 1983: 254; Schicha \& Elshafie, 1980: 32; Moraes \& Mesa, 1988: 76.

Neoseiulus anonymus Denmark \& Muma, 1973: 265; Kreiter \& Moraes, 1997: 378.

DISTRIBUIÇÃO: Brasil, Colômbia, Guatemala e Honduras; Cuba, México e Peru (Moraes et al., 1991); Guadalupe e Martinica (Kreiter \& Moraes, 1997).

ESPÉCIMES EXAMINADOS: São Paulo: Pariquera-açu, S. romanzoffiana (IV-98); Piracicaba, C. nucifera (IX-98).

OBSERVAÇÕES: O comprimento do cérvix da espermateca (18) dos indivíduos coletados é $50 \%$ maior que o verificado por Schicha \& Elshafie (1980) e Kreiter \& Moraes (1997), e 30\% maior que o verificado por Moraes \& Mesa (1988).

Neoseiulus recifensis Gondim Jr. \& Moraes, sp. $\mathrm{n}$.

(Figs. 28-32)

DIAGNOSE: Difere de Neoseiulus californicus (McGregor, 1954) por apresentar 
as setas j4, J2, Z1, Z5, S4 e S5 menores; de Neoseiulus bellinus (Womersley, 1954) por apresentar o escudo dorsal menos estriado, o cérvix da espermateca menor, além das setas j4, J2, Z1, Z5, S4 e S5 menores.

FÊMEA ( $\mathrm{n}=8)$

Dorso: Placa dorsal com poucas estriações nas margens e latero-posteriormente a J2, com 279 (268-291) de comprimento, 143 (142-145) de largura, j1 21 (19-22), j3 33 (32-35), j4 16 (15-18), j5 16 (15-18), j6 20 (19-23), J2 22 (21-24), J5 7 (6-7), z2 33 (3035), z4 34 (32-36), z5 17 (16-19), Z1 24 (22-26), Z4 47 (44-49), Z5 50 (47-53), s4 45 (43-47), S2 42 (41-44), S4 21 (21-24), S5 21 (19-23), r3 31 (30-34), R1 28 (26-30).

Todas as setas lisas, exceto Z4 e Z5 que são serreadas. Apresenta o padrão dorsal de setas 10A:9B.

Peritrema: Estendendo-se até o nível de j1.

Ventre: Placa esternal lisa, com 3 pares de setas, 2 pares de poros e margem anterior indistinta. Distância entre ST1-ST3 53 (49-53). A seta ST1 está no escudo, mas em uma porção pouco esclerotizada. ST2-ST2 57 (54-60) e ST5-ST5 58 (57-60). Com 2 placas metapodais. Placa ventrianal em forma de vaso, lisa, com 3 pares de setas préanais e 1 par de poros; comprimento de 92 (89-95), largura ao nível de ZV2 69 (68-72) e ao nível do ânus 62 (59-64).

Espermateca: Cérvix em forma de trombeta, com 13 (12-14) de comprimento. Átrio nodular pouco distinto.

Quelíceras: Dígito fixo com 27 (26-27) de comprimento e 2 dentes subapicais; dígito móvel com 28 (26-29) de comprimento e sem dentes.

Pemas: Macrosetas com extremidades afiladas: SgeIV 21 (19-21), StiIV 17 (1619), StIV 30 (27-32). Quetotaxia do genu II 2;2/0;2/0;1/genu III 1;2/1;2/0;1.

MACHO: Desconhecido.

LOCALIDADE E MATERIAL TIPO: Holótipo fềmea e 3 parátipos fềmeas de C. nucifera ( $8^{\circ} 01^{\prime} 04^{\prime \prime}$ de latitude sul e $34^{\circ} 56^{\prime} 40^{\prime \prime}$ ' de longitude oeste) em Recife em I99; 2 parátipos fêmeas em VI-98. Um parátipo fềmea de C. nucifera $\left(7^{\circ} 41^{\prime} 40^{\prime \prime}\right.$ de latitude sul e 34 $50^{\prime} 40^{\prime \prime}$ de longitude oeste) em Itamaracá em VI-98; 1 parátipo fềmea em I-99. Todos os espécimes coletados em Pernambuco. 


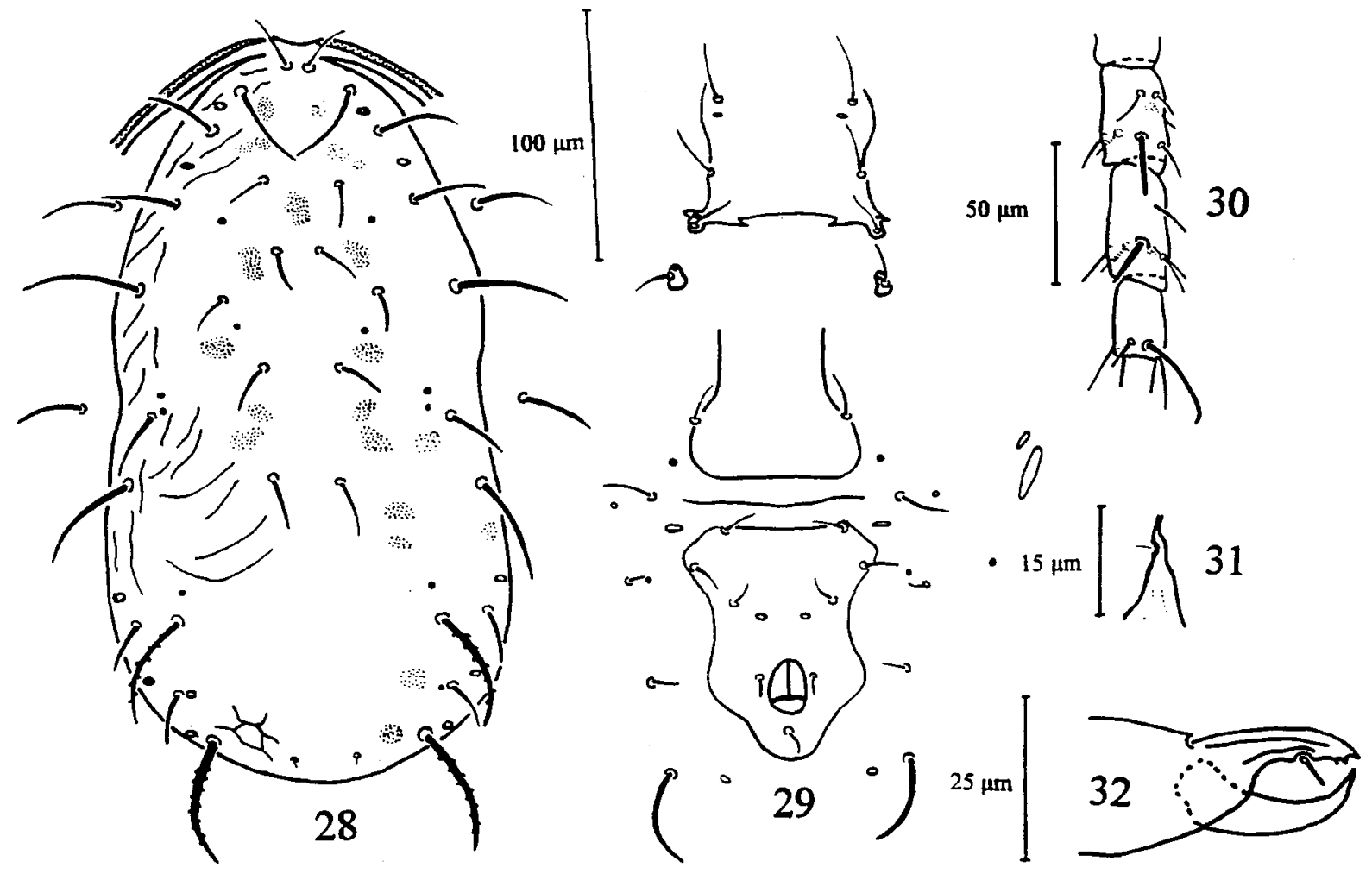

Figuras 28-32. Neoseiulus recifensis sp. n. 28, placa dorsal; 29, placas ventrais; 30, genu, tíbia e pré-tarso da perna IV; 31 , cérvix da espermateca; 32 , quelícera. 
ETIMOLOGIA: recifensis, referente ao local onde o ácaro foi encontrado.

Neoseiulus veigai Gondim Jr. \& Moraes, sp. $\mathbf{n}$.

(Figs. 33-36)

DIAGNOSE: Esta espécie difere de Neoseiulus atsak (Chant \& Hansell, 1971) e Neoseiulus constrictatus (El-Benhawy, 1984) por não apresentar macrosetas na perna IV e apresentar a seta Z5 plumosa.

Fêmea $(n=2)$

Dorso: Placa dorsal reticulada, com 327 (325-328) de comprimento, 195 (180210) de largura, j1 20 (19-20), j3 16 (15-16), j4 13, j5 14, j6 16 (15-16), J2 19, J5 11, z2 16 (15-16), z4 16 (15-16), z5 13, Z1 20 (19-20), Z4 26 (25-27), Z5 48 (47-48), s4 20 (19-20), S2 23 (22-23), S4 22 (21-22), S5 21 (20-21), r3 16, R1 17. Todas as setas são lisas, exceto $\mathrm{Z5}$ que é plumosa e $\mathrm{Z4}$ que é serreada. O padrão da quetotaxia dorsal é 10A:9B.

Peritrema: estendendo-se até o nível de $\mathrm{j} 1$.

Ventre: Placa esternal com margens bem delimitadas, liso, com 3 pares de setas e 2 pares de poros. Distância entre ST1-ST3 59, ST2-ST2 53, ST5-ST5 61 (58-63). Placa ventrianal em forma de escudo, com reticulações contornando o ânus, 3 pares de setas pré-anais e 1 par de poros mesais em relação a JV2, com 114 (111-116) de comprimento, 113 (107-118) de largura ao nível de ZV2. Com 2 pares de placas metapodais.

Espermateca: Cérvix tubular com leve constrição mediana, com 18 de comprimento e átrio nodular distinto.

Pernas: Sem macrosetas. Quetotaxia do genu II $2 ; 2 / 0 ; 2 / 0 ; 1 /$ genu III $1 ; 2 / 1 ; 2 / 0 ; 1$.

MACHO: Desconhecido.

LOCALIDADE E MATERIAL TIPO: Holótipo fêmea e 1 parátipo fềmea de $E$. edulis ( $24^{\circ} 36^{\prime} 43^{\prime \prime}$ de latitude sul e $47^{\circ} 53^{\prime} 11^{\prime \prime}$ 'de longitude oeste). Todos os espécimes coletados em Cananéia (São Paulo) em X-98.

ETIMOLOGIA: veigai, em homenagem a Antônio Fernando de Souza Leão 


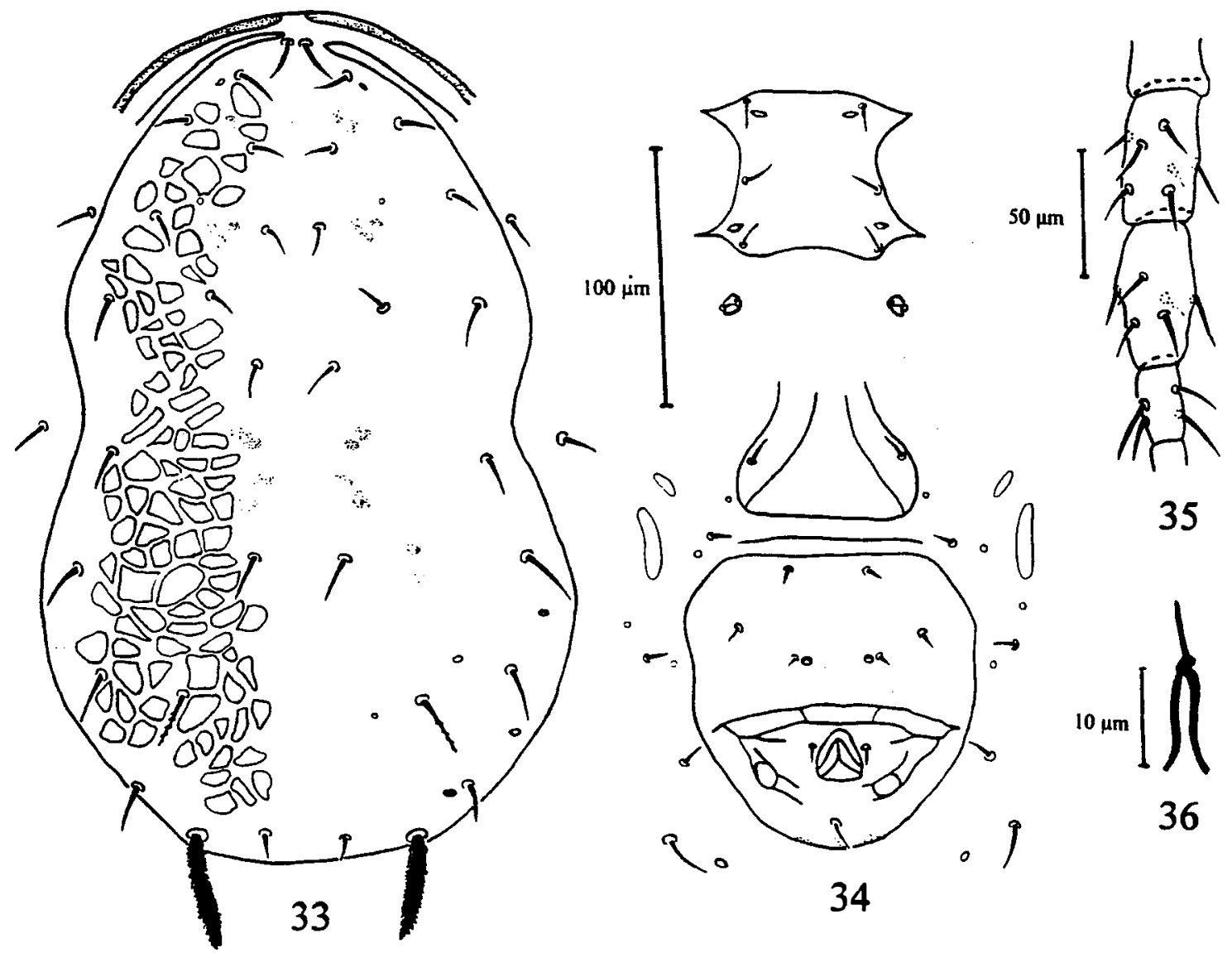

Figuras 33-36. Neoseiulus veigai sp. n. 33, placa dorsal; 34, placas ventrais; 35 , genu, tíbia e pré-tarso da perna IV; 36 , cérvix da espermateca. 
Veiga, eminente entomologista da Universidade Federal Rural de Pernambuco.

Paraamblyseius multicircularis Gondim Jr. \& Moraes, sp. n.

(Figs. 37-40)

DIAGNOSE: Esta espécie difere de Paraamblyseius lunatus Muma, 1962 por apresentar a maioria das setas dorsais e cérvix da espermateca de 2 a 3 vezes maiores e s4 menor; de Paraamblyseius ogdeni DeLeon, 1966 por apresentar as setas z2, z4, S2, $\mathrm{S} 4$ e Z4 maiores e s4 menor.

FÊMEA $(n=5)$

Dorso: Placa dorsal com ornamentações circulares, com 263 de comprimento, 210 de largura, j1 13 (12-13), j3 24 (23-25), j4 32 (29-34), j5 36 (34-38), j6 35 (33-36), J2 38, J5 12 (10-13), z2 26 (26-27), z4 37 (34-39), z5 30, Z1 44 (42-45), Z4 44 (42-47), Z5 25 (24-26), s4 43 (41-45), S2 34 (33-35), S4 33 (32-34), S5 24 (23-25), r3 14 (1315), R1 17 (16-18). Todas as setas lisas, exceto $Z 5$ que é serreada. $O$ padrão de setas dorsal desta espécie é 10A:9B.

Peritrema: Estendendo-se até o nível de j1.

Ventre: Placa external com poucas estriações laterais, 3 pares de setas e 2 pares de poros. Distância entre ST1-ST3 28 (27-32), ST2-ST2 63 (62-65) e ST5-ST5 100 (98101). Placa genital com ornamentações circulares. Placa ventrianal ampla, reticulada e com ornamentações circulares, com 3 pares de setas pré-anais e um par de poros, com 100 (96-109) de comprimento e 188 (184-191) de largura ao nível de ZV2. Com um par de placas metapodais, providas de omamentações circulares.

Espermateca: Cérvix tubular, levemente dilatado na região proximal, com 18 (17-19) de comprimento; átrio indistinto.

Quelícera: Dígito fixo com 19 de comprimento e 5 dentes; dígito móvel com 19 de comprimento e 2 dentes.

Pernas: Sem macrosetas. Quetotaxia do genu II 1;2/0;2/0;1/genu III 1;2/0;2/0;1. MACHO: Desconhecido.

LOCALIDADE E MATERIAL TIPO: Holótipo fêmea e 2 parátipos fềmeas de 

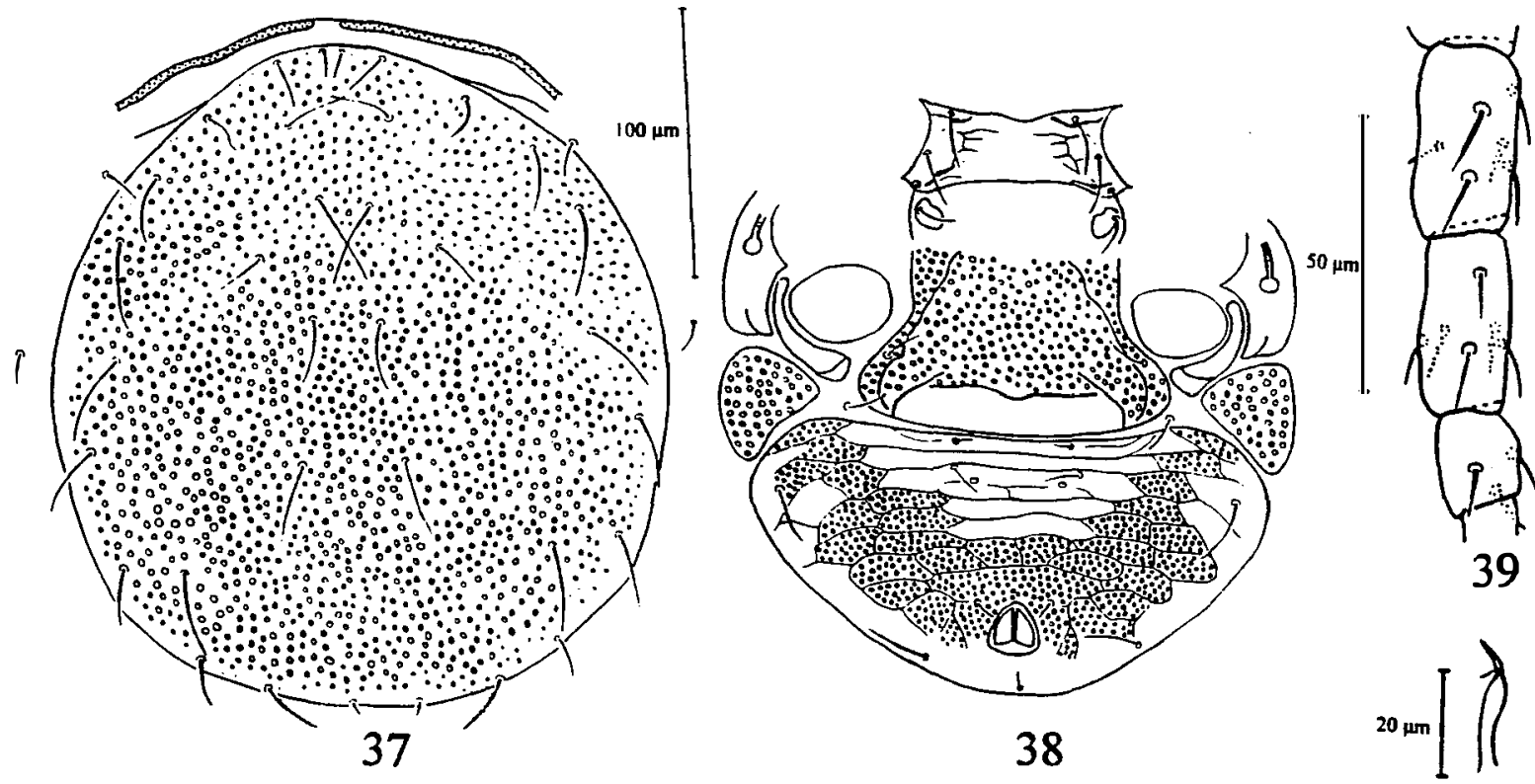

40

Figuras 37-40. Paraamblyseius multicircularis sp. n. 37, placa dorsal; 38, placas ventrais; 39, genu. tíbia e pré-tarso da perna IV; 40, cérvix da espermateca. 
G. pohliana ( $24^{\circ} 36^{\prime} 51^{\prime \prime}$ de latitude sul e $47^{\circ} 52^{\prime} 58^{\prime \prime}$ de longitude oeste) em IV-98; 2 parátipos fêmeas em VII-99. Todos os espécimes coletados em Pariquera-açu (São Paulo).

ETIMOLOGIA: multicirculares, referente as ornamentações encontradas nos escudos desses ácaros.

Phytoscutus sexpilis Muma

Phytoscutus sexpilis Muma, 1961: 275; DeLeon, 1967:17; Muma \& Denmark, 1970: 24; Yoshida-Shaul \& Chant, 1997: 234.

Typhlodromus sexpilis, Hirschmann, 1962: 17.

Amblyseius sexpilis, van der Merwe, 1968: 161.

DISTRIBUIÇÃO: Cuba, EUA e Trinidad-Tobago.

ESPÉCIMES EXAMINADOS: Pernambuco: Recife, Euterpe sp. (VI-98); São Paulo: Piracicaba, A cunninghamii (IX-98) e A. phalerata (IX-98); Pariquera-açu: E. guineensis (IV-98).

MEDIÇÕES (6 fềmeas de São Paulo): comprimento da placa dorsal 329 (310-352), largura 285 (263-300), j1 20 (19-21), j3 36 (34-38), j4 12, j6 13 (12-13), J5 10 (8-12), z2 16, z4 26, z5 10 (8-11), Zl 17 (16-18), Z4 171 (161-183), Z5 231 (213-247), s4 175 (161-194), S4 14 (11-16), S5 12 (11-14), r3 15, R1 16, ST1-ST3 46 (44-48), ST2-ST2 63 (60-65), ST5-ST5 95 (84-105), comprimento da placa ventrianal 135 (124-143), largura ao nível de ZV2 171 (163-180), comprimento do cérvix da espermateca 15 (1317), SgeIV 74 (69-83), StiIV 66 (59-70), StIV 13 (11-16).

OBSERVAÇÕES: Os valores obtidos estão próximos dos registrados para o holótipo e apresentados por Yoshida-Shaul \& Chant (1997). Entretanto a seta Zl é 35\% menor e as setas $\mathrm{z} 2$ e r3 $50 \%$ maiores que os valores observados por aqueles autores.

Phytoseiulus macropilis (Banks)

Laelaps macropilis Banks, 1905: 139. 
Hypoaspis macropilis, Banks, 1915: 85.

Phytoseiulus speyeri Evans, 1952: 398 (sinonímia, de acordo com Kennett, 1958: 477)

Phytoseiulus chanti Ehara, 1966: 135 (sinonímia, de acordo com Denmark \& Muma, 1973: 236)

Phytoseiulus macropilis, Muma \& Denmark, 1970: 30; McMurtry, 1983: 259; Denmark \& Schicha, 1983: 31; Kreiter \& Moraes, 1997: 378.

DISTRIBUIÇÃO: Angola, Brasil, Canadá, Cuba, EUA, Guatemala, Havai, Ilhas Canárias, Ilhas Cook, Ilhas Figi, Jamaica, Nova Caledônia, Panamá, Peru, Polônia, Portugal e Porto Rico; Colômbia (Moraes \& Mesa, 1988); México (Moraes et al., 1991); Guadalupe (Kreiter \& Moraes, 1997); Costa Rica (Denmark et al., 1999).

ESPÉCIMES EXAMINADOS: São Paulo: Pariquera-açu, $C$. nucifera (IV-98) e $S$. romanzoffiana (IV-98); Piracicaba, L. chinensis (IX-98) e P. reclinata (IX-98).

OBSERVAÇÕES: Foram medidas 5 fêmeas, observando-se que z4 variou de 51-63, enquanto que no material tipo o comprimento desta seta varia de 34-49 (Denmark \& Schicha, 1983).

Proprioseiopsis dominigos (El-Banhawy), n. comb.

Amblyseius dominigos El-Benhawy, 1984: 130; McMurtry \& Moraes, 1989: 185; Moraes et al., 1991: 126; Feres \& Moraes, 1998: 126.

DISTRIBUIÇÃO: Brasil; Peru (McMurtry \& Moraes, 1989); Colômbia (Moraes et al., 1991).

ESPÉCIMES EXAMINADOS: São Paulo: Cananéia, B. setosa (X-98); Pariquera-açu, A. dubia (IV-98), E. guineensis (IV-98, X-98), E. edulis (IV-98, X-98) e G. gamiova (IV-98); Piracicaba, Acrocomia aculeata (III-98), C. mitis (IX-98), P. macarthurii (III98, IX-98) e $P$. reclinata (III-98).

OBSERVAÇÕES: Foram medidas 4 fêmeas de Pariquera-açu e 2 de Piracicaba. Os espécimes coletados em Pariquera-açu estão mais próximos das medições da descrição original. Os espécimes de Piracicaba apresentaram as setas $\mathrm{z} 4$ e a maioria das macrosetas até 30\% maiores que os de Pariquera-açu. 
Proprioseiopsis neotropicus (Ehara), n. comb.

Amblyseius neotropicus Ehara, 1966: 133; Moraes \& Mesa, 1988: 79; Moraes et al., 1991: 127.

DISTRIBUIÇÃO: Brasil; Colômbia (Moraes \& Mesa, 1988); Equador (Moraes et al., 1991).

ESPÉCIMES EXAMINADOS: Pernambuco: Igarassu, Euterpe sp. (VI-98); São Paulo: Pariquera-açu, B. gasipaes (IV-98, X-98), B. setosa (IV-98), C. nucifera (X-98), Syagrus sp. (X-98), S. romanzoffiana (IV-98).

OBSERVAÇÕES: Os valores obtidos nas medições dos exemplares coletados se mostraram próximos àqueles da descrição original, exceto por $\mathrm{j} 3$ e r3 que foram $50 \%$ maiores. Isto também foi observado por Moraes \& Mesa (1988) para espécimes da Colômbia.

\section{Proprioseiopsis ovatus (Garman)}

Amblyseiopsis ovatus Garman, 1958: 78.

Amblyseius ovatus, Moraes \& McMurtry, 1983: 133; Moraes et al., 1991: 127.

Typhlodromus (Amblyseius) ovatus, Chant, 1959: 90.

Proprioseiopsis ovatus, Denmark \& Muma, 1973: 237.

DISTRIBUIÇÃO: Brasil, Costa Rica, Equador, EUA, Havai, Honduras e Porto Rico; Filipinas (Moraes et al., 1989).

ESPÉCIMES EXAMINADOS: São Paulo: Piracicaba, $A$. phalerata (III-98), $P$. reclinata (III-98) e S. romanzoffiana (III-98).

MEDIÇÕES (3 fêmeas): comprimento da placa dorsal 342 (337-347), largura 316 (300331), j1 31 (30-32), j3 81 (78-83), j4 6 (5-7), j5 6 (5-6), j6 9, J5 6 (6-7), z2 47 (43-50), z4 27 (25-29), z5 6 (5-6), Z1 19 (16-21), Z4 105, Z5 89, s4 108 (100-110), S2 11, S4 8 (7-8), S5 8 (7-8), r3 21 (20-22), R1 (não observado), ST1-ST3 51 (48-53), ST2-ST2 78, ST5-ST5 111 (108-116), comprimento da placa ventrianal 102, largura ao nível de ZV2 107 (106-108), ao nível do ânus 109 (108-110), comprimento do cérvix da espermateca 
19 (18-20), dígito fixo da quelícera com 34 (32-35) de comprimento e 4 dentes, dígito móvel com 35 (34-36) de comprimento e 2 dentes, SgeIV 57 (54-59), StiIV 40 (38-43), StIV 76 (73-81),

OBSERVAÇÕES: O resultado das medições mostrou que a seta s4 é $25 \%$ maior que a do holótipo, medido por Moraes \& McMurtry (1983). Já as setas S2, S4 e S5 apresentam aproximadamente metade do comprimento mostrado por aqueles autores.

Typhlodromalus manihoti (Moraes), n. comb.

Amblyseius manihoti Moraes et al., 1994: 211.

DISTRIBUIÇÃO: Bolívia, Brasil, Colômbia, Cuba, Equador, Nicaragua, Paraguai, Peru, Suriname, Trinidad-Tobago, Venezuela (Moraes et al., 1994).

ESPÉCIMES EXAMINADOS: Pernambuco: Igarassu, B. ferruginea (VI-98, I-99).

OBSERVAÇÕES: As medições dos exemplares coletados estão de acordo com a descrição original (Moraes et al., 1994). Esta espécie é bastante comum em mandioca (Manihot esculenta Crantz) e raramente encontrada em outras espécies de plantas, tendo chamado atenção o fato de ter sido encontrada, neste trabalho, em uma mesma planta em duas épocas distintas (estações seca e chuvosa). Isto sugere que esta planta pode ser um hospedeiro regular deste ácaro.

Typhlodromips ariri Gondim Jr. \& Moraes, sp. $\mathbf{n}$.

(Figs. 41-45)

DIAGNOSE: Esta espécie difere de Typhlodromips gonzalezi Moraes et al., 1991 por apresentar j6, J2 e Z1 maiores, escudo dorsal menos estriado, cérvix da espermateca e StiIV menor e poro pré-anal próximo de JV2; difere de Typhlodromips bhoraii DeLeon, 1967 por apresentar as setas z2, z4, s4, S2 maiores e StiIV e o cérvix da espermateca menor.

Fêmea: $(n=4)$

Dorso: Placa dorsal com estriações laterais e anteriores a $\mathrm{Zl}$ e com reticulações 


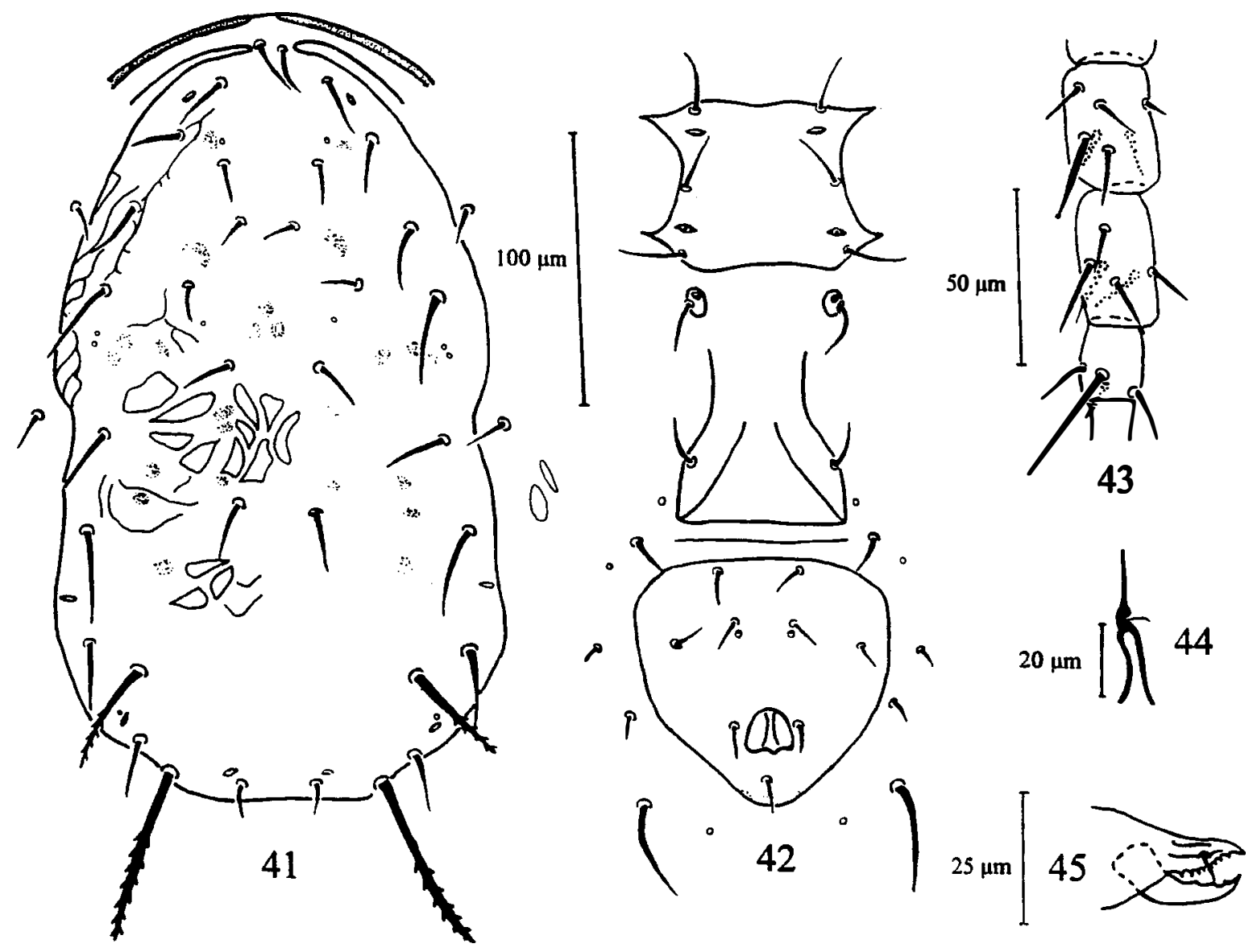

Figuras 41-45. Typhlodromips ariri sp. n. 41, placa dorsal; 42, placas ventrais; 43, genu, tíbia e pré-tarso; 44 , cérvix da espermateca; 45 , quelícera. 
ao longo do centro da placa, 278 (266-285) de comprimento, 163 (161-169) de largura, j1 17 (16-18), j3 21 (21-22), j4 16 (14-17), j5 16 (15-17), j6 18 (17-19), J2 22 (21-23), J5 11, z2 21 (20-22), z4 24 (23-25), z5 15 (14-16), Z1 24 (23-26), Z4 44 (42-48), Z5 74 (69-80), s4 35 (33-37), S2 34 (33-35), S4 24 (22-27), S5 18 (17-20), r3 14 (13-16), R1 16 (15-17). Todas as setas lisas, exceto $\mathrm{Z4}$ e $\mathrm{Z5}$ que são serreadas. O padrão da quetotaxia dorsal é 10A:9B.

Peritrema: Estendendo-se até o nível de $\mathrm{j} 1$.

Ventre: Placa esternal bem delimitada, lisa, 3 pares de setas e 2 pares de poros. Distância entre ST1-ST3 55 (54-57), ST2-ST2 57 (56-59), ST5-ST5 56 (55-57). Placa ventrianal em forma de escudo, lisa, com 3 pares de setas e um par de poros pré-anais, setas JV2 inseridas anteriormente às setas ZV2. Poros pré-anais muito próximos às setas ZV2. Placa com 98 (92-103) de comprimento, 98 (95-100) de largura ao nível de ZV2 e 82 (75-87) ao nivel do ânus. Com 2 pares de placas metapodais.

Espermateca: Cérvix tubular, com leve constrição mediana, com 12 (11-14) de comprimento; átrio nodular distinto.

Quelíceras: Dígito fixo com 20 (19-20) de comprimento e 8 dentes; dígito móvel com 24 (23-25) de comprimento e 3 dentes.

Pernas: Macroseta com extremidade robusta: SgeIII 16 (15-17), StiIII 16 (15-16), SgeIV 23 (22-24), StiIV 22 (20-24), StIV 38 (37-39). Quetotaxia do genu II 2;2/0;2/0;1 e genu III $1 ; 2 / 1 ; 2 / 0 ; 1$.

MACHO: Desconhecido.

LOCALIDADE E MATERIAL TIPO: Holótipo fêmea, de $G$. schottiana (245' $45^{\prime \prime}$ de latitude sul e $47^{\circ} 51^{\prime} 51^{\prime \prime}$ de longitude oeste); 1 parátipo fêmea, de $A$. aculeatissimum nas mesmas coordenadas, 1 parátipo fêmea, de $G$. schottiana; 1 parátipo fêmea, de E. edulis ( $24^{\circ} 54^{\prime} 08^{\prime \prime}$ ' de latitude sul e $47^{\circ} 50^{\prime} 38^{\prime \prime}$ ' de longitude oeste). Todos os espécimes coletados em Cananéia (São Paulo-Brasil) em X-98.

ETIMOLOGIA: ariri, referente ao nome indígena da palmeira $A$. aculeatissimum, um dos hospedeiros deste ácaro. 
Typhlodromips cananeiensis Gondim Jr. \& Moraes, sp. n.

(Figs. 46-52)

DIAGNOSE: Esta espécie difere de Typhlodromips mangleae DeLeon (1967) por apresentar as extremidades das macrosetas clavadas, s4 e Z4 menores; difere de Typhlodromips pederosus El-Benhawy (1978) por apresentar s4, Z4 e Z5 menores e S2, S4 e S5 maiores, assim como as extremidades das macrosetas clavadas.

Fêmea: (Figs. 33-37) $(\mathrm{n}=8)$

Dorso: Placa dorsal reticulada lateralmente na parte anterior e totalmente na posterior, 301 (289-312) de comprimento, 198 (191-204) de largura, j1 18 (16-19), j3 17 (15-18), j4 11 (11-12), j5 11 (11-12), j6 13 (11-14), J2 14 (13-16), J5 9 (7-11), z2 14 (13-16), z4 14 (12-15), z5 12 (11-12), Z1 14 (13-16), Z4 26 (24-29), Z5 63 (58-68), s4 17 (15-18), S2 16 (15-18), S4 15 (14-17), S5 15 (13-16), r3 13 (12-14), R1 14 (12-15). Todas as setas lisas, exceto Z4 e Z5, que são serreadas. O padrão da quetotaxia dorsal é 10A:9B.

Peritrema: Estendendo-se até o nível de $\mathrm{j} 1$.

Ventre: Placa esternal com margens bem delimitadas, lisa, com 3 pares de setas e 2 pares de poros. Distância entre ST1-ST3 56 (55-58), ST2-ST2 62 (60-63), ST5-ST5 60 (57-64). Placa ventrianal em forma de escudo, com estriações transversais entre os poros pré-anais e o ânus, com 3 pares de setas pré-anais e um par de poros, com 102 (100-105) de comprimento, 95 (90-102) de largura ao nivel de ZV2 e 82 (79-86) ao nível do ânus. Com 2 pares de placas metapodais.

Espermateca: Cérvix pocular, com 6 (4-8) de comprimento; átrio distinto.

Quelíceras: Dígito fixo com 24 (24-25) de comprimento e 9-10 dentes; dígito móvel com 20 de comprimento e 3 dentes.

Pernas: Macrosetas da perna III com extremidade afilada; macrosetas da perna IV

clavadas. SgeIII 16 (15-17), StiIII 15 (14-16), SgeIV 24 (23-26), StiIV 18 (15-20), StIV 34 (32-36). Quetotaxia do genu II 2; 2/0; 2/0; 1/genu III 1; 2/1; 2/0; 1.

MACHO: (Figs. 38-39) (3 espécimes) 

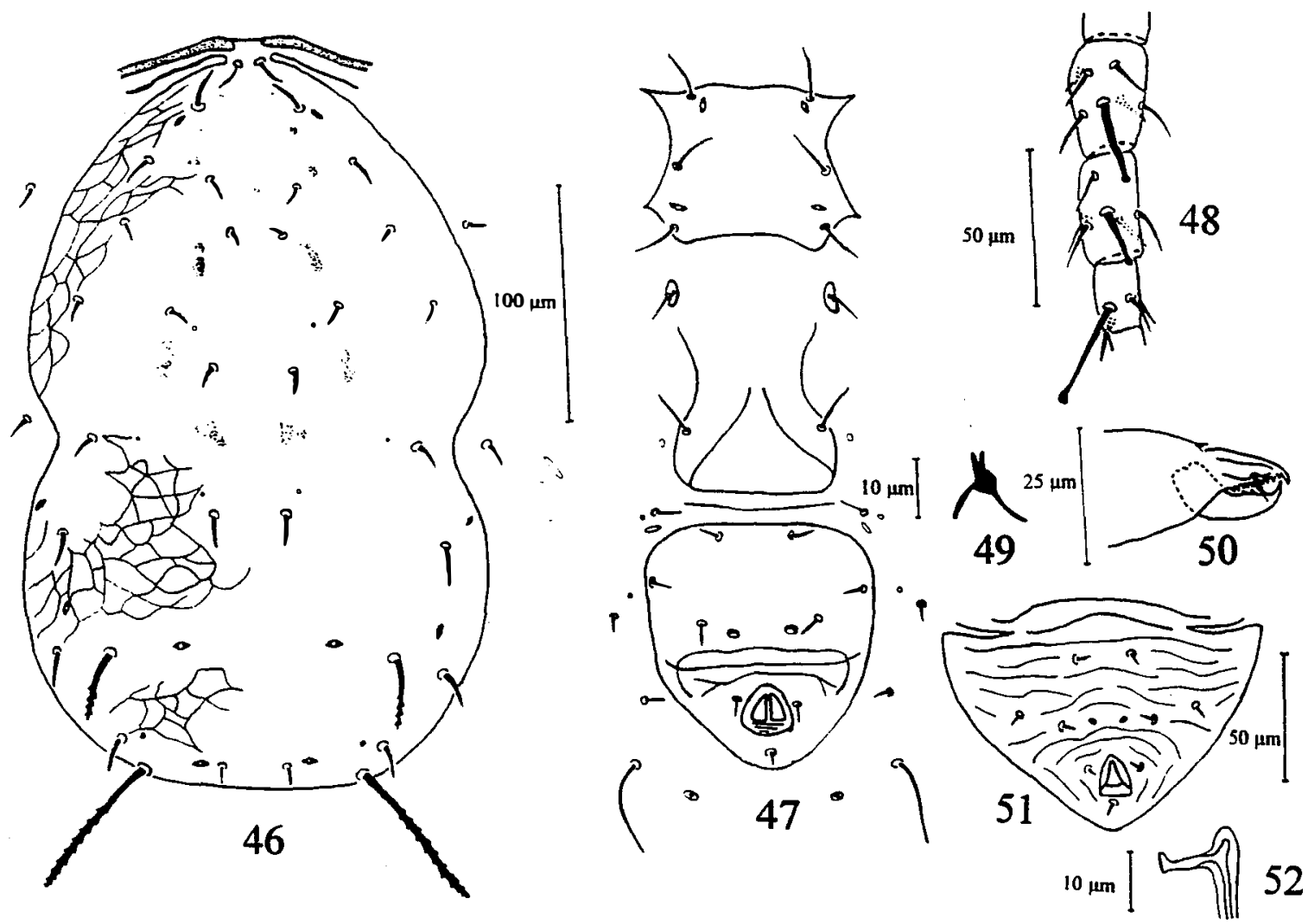

Figuras 46-52. Typhlodromips cananeiensis sp. n. 46, placa dorsal da fềmea; 47 , placas ventrais da fềmea: 48 , genu, tỉbia e pré-tarso da fềmea; 49 , cérvix da espermateca; 50 , quelícera da fềmea; 51 , placa ventrianal do macho; 52 , espermadáctilo. 
Dorso: Placa dorsal totalmente reticulada, 238 (226-245) de comprimento, 159 (153-164) de largura, j1 15 (15-16), j3 18, j4 7 (6-8), j5 8 (7-8), j6 9 (8-11), J2 10 (811), J5 7 (6-7), z2 11 (11-12), z4 11 (11-12), z5 9 (8-9), Z1 12 (11-13), Z4 21, Z5 41 (39-43), s4 15 (14-16), S2 13 (12-13), S4 12 (12-13), S5 12 (11-13), r3 11 (11-12), R1 11 (11-12). Todas as setas lisas, exceto Z4 e Z5 que são serreadas. Setas r3 e R1 no escudo dorsal.

Peritrema: Atingindo o nível de j1.

Ventre: Placa ventrianal subtriangular, estriada, com 3 pares de setas e 1 par de poros pré-anais, com 99 (95-102) de comprimento e 127 (124-130) de largura ao nivel dos ângulos anteriores.

Quelíceras: Espermadáctilo com 17 de comprimento.

Pernas: Macrosetas das perna III com extremidade afilada; macrosetas da perna IV clavadas. SgeIII 13 (13-14), StiIII 13, SgeIV 17 (16-18), StiIV 16 (15-16), StIV 26 (25-26). Quetotaxia do genu II 2; 2/0; 2/0; 1/genu III $1 ; 2 / 1 ; 2 / 0 ; 1$.

LOCALIDADE E MATERIAL TIPO: Holótipo fêmea e 1 parátipo fềmea de $B$. setosa ( $24^{\circ} 54^{\prime} 09^{\prime \prime}$ de latiude sul e $47^{\circ} 50^{\prime} 39^{\prime \prime}$ ' de longitude oeste) em X-98; 2 parátipos

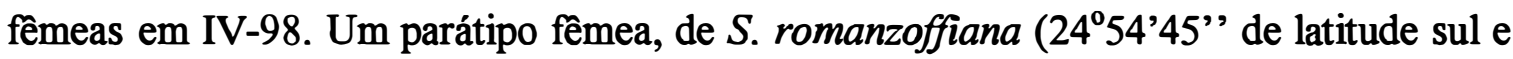
$47^{\circ} 51^{\prime} 51$ " de longitude oeste) em IV-98. Três parátipos fêmeas de G. schottiana ( $24^{\circ} 54^{\prime} 45^{\prime \prime}$ de latitude sul e $47^{\circ} 51^{\prime} 51^{\prime \prime}$ de longitude oeste) em IV-98. Alótipo macho de $B$. setosa em X-98; 2 parátipos machos em IV-98. Todos os espécimes coletados em Cananéia (São Paulo).

ETIMOLOGIA: cananeiensis, referente ao local tipo da espécie aqui descrita (Cananéia, SP).

Typhlodromips jucara Gondim Jr. \& Moraes, sp. n.

(Figs. 53-57)

DIAGNOSE: Difere de Typhlodromips caribbeanus (DeLeon, 1965b) por apresentar a seta Z5 maior, cérvix da espermateca menor, macroseta do genu IV maior, escudo dorsal mais estriado e poros do escudo ventrianal mais próximos. Difere de 
Typhlodromips auratus DeLeon, 1966 por apresentar Z5 maior, escudo dorsal mais estriado e poros do escudo ventrianal mais próximos. Difere de Typhlodromips mangleae DeLeon, 1967 por apresentar as setas Z4 e 44 menores e macrosetas da perna IV menores.

Fêmea: $(n=4)$

Dorso: Placa dorsal estriada lateralmente na parte anterior e posterior, 301 (296304) de comprimento, 197 (191-207) de largura, j1 18 (17-19), j3 18 (16-19), j4 12 (1112), j5 12 (12-13), j6 13 (13-14), J2 15, J2 9 (8-9), z2 12 (11-12), z4 15 (14-15), z5 10 (9-11), Z1 15 (14-16), Z4 24 (24-25), Z5 40 (39-40), s4 18, S2 18 (17-18), S4 16 (1517), S5 13 (12-13), r3 14 (13-14), R1 14 (13-14). Todas as setas lisas, exceto Z5 que é serreada. O padrão dorsal das setas é 10A:9B.

Peritrema: Estendendo-se até o nível de j1.

Ventre: Placa esternal lisa, margens bem delimitadas, 3 pares de setas pré-anais e 2 pares de poros. Distância entre ST1-ST3 61 (60-63), ST2-ST2 66 (65-68) e ST5-ST5 65 (63-67). Placa ventrianal com estriações transversais entre os poros pré-anais e 0 ânus, 3 pares de setas pré-anais e um par de poros adjacentes e imediatamente mesoposteriores a JV2. Placa com 92 (90-95) de comprimento, 85 (84-86) de largura ao nível de ZV2 e 77 (75-78) ao nível do ânus. Com 2 pares de placas metapodais.

Espermateca: Cérvix campanulado, com 13 (12-14) de comprimento; átrio indistinto.

Quelíceras: Dígito fixo com 35 de comprimento e 16 dentes; dígito móvel com 38 de comprimento e 3 dentes.

Pemas: Macrosetas com extremidade afilada: SgeIII 12 (11-12), StillI 12 (1113), SgeIV 8 (8-9), StiIV 15 (14-15), StIV 26 (25-27). Quetotaxia do genu II 2;2/0;2/0;1/genu III $1 ; 2 / 1 ; 2 / 0 ; 1$.

MACHO: Desconhecido.

LOCALIDADE E MATERIAL TIPO: Holótipo fêmea e 3 parátipos fêmeas de Euterpe sp. ( $7^{\circ} 53^{\prime} 27^{\prime \prime}$ de latitude sul e $34^{\circ} 58^{\prime} 36^{\prime \prime}$ de longitude oeste). Todos os espécimes coletados em Igarassu (Pernambuco) em I-99.

ETIMOLOGIA: jucara, referente ao nome indígena do palmiteiro (juçara), 


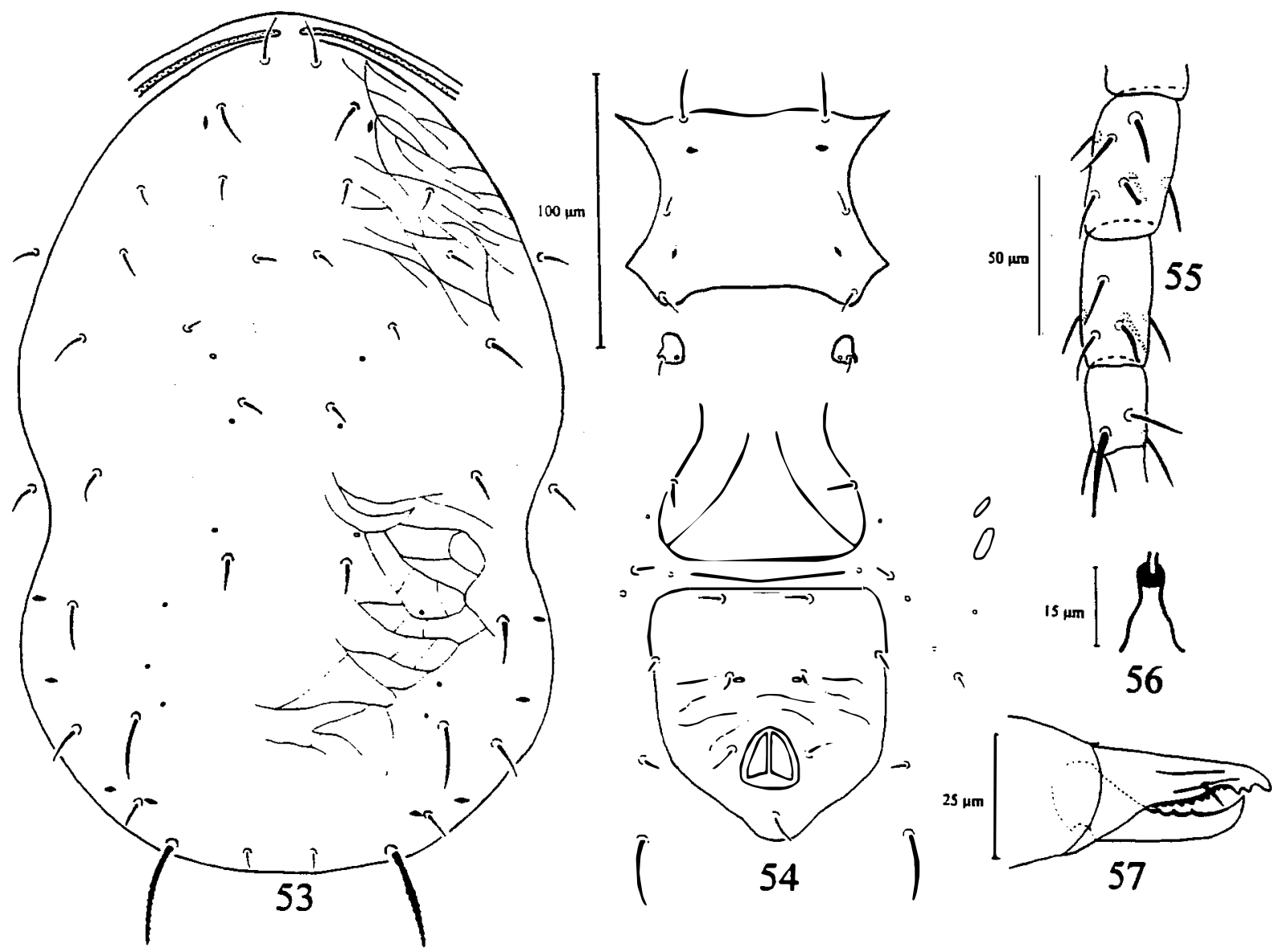

Figuras 53-57. Typhlodromips jucara sp. n. 53, placa dorsal; 54, placas ventrais; 55, genu, tíbia e pré-tarso da perna IV; 56, cérvix da espermateca; 57, quelícera. 
planta encontrada na Mata Atlântica do Brasil e sobre a qual o ácaro foi coletado.

\section{Typhlodromips linharis El-Benhawy}

Typhlodromips linharis El-Benhawy, 1984: 136.

DISTRIBUIÇÃO: Brasil.

ESPÉCIMES EXAMINADOS: São Paulo: Pariquera-açu, A. aculeatissimum (IV-98, X98), A. dubia (X-98), E. guineensis (X-98), E edulis (X-98), G. gamiova (IV-98, X-98), G. pohliana (X-98).

MEDIÇÕES (4 fềmeas): comprimento da placa dorsal 296 (289-310), largura 209 (199218), j1 22 (22-23), j3 26 (25-27), j4 9 (8-10), j5 9 (8-10), j6 13 (12-13), J2 14 (13-15), J5 7 (7-8), z2 13 (12-13), z4 19 (18-20), z5 8 (7-8), Z1 17 (16-18), Z4 53 (49-55), Z5 61 (58-64), s4 27 (25-28), S2 20 (19-21), S4 14 (13-15), S5 11, r3 13 (12-13), R1 9, ST1ST3 58 (56-60), ST2-ST2 71 (68-72), ST5-ST5 70 (68-72), comprimento da placa ventrianal 91 (89-94), largura ao nível de ZV2 97 (95-98), comprimento do cérvix da espermateca 7 (7-8), dígito fixo da quelícera com 35 de comprimento e 14 dentes, dígito móvel com 35 (34-36) de comprimento e 3 dentes, SgeI 15 (15-16), SgeII 16 (15-16), SgeIII 16 (16-17), StiIII 14 (14-15), SgeIV 32 (30-34), StiIV 16 (15-17), StIV 28.

OBSERVAÇÕES: As medições estão de acordo com a descrição original, exceto S2 (20) que é cerca de $40 \%$ maior que o verificado por El-Benhawy (1984).

\section{Typhlodromips mangleae DeLeon}

Typhlodromips mangleae DeLeon, 1967: 28.

Amblyseius mangleae, Moraes \& Mesa, 1988: 75; Moraes et al., 1991: 124.

DISTRIBUIÇÃO: Brasil, Porto Rico e Trinidad-Tobago; Colômbia (Moraes \& Mesa, 1988).

ESPÉCIMES EXAMINADOS: Pernambuco: Igarassu, B. ferruginea (VI-98, I-99), $C$. nucifera (VI-98, I-99); Itambé, A. intumescens (VI-98), C. nucifera (VI-98), Syagrus sp. (VI-98); Recife, C. nucifera (VI-98). 
MEDIÇÕES (4 fêmeas): comprimento da placa dorsal 333 (310-358), largura 219 (210231), j1 17 (15-19), j3 20 (17-21), j4 10 (9-11), j5 10 (9-11), j6 11, J2 12 (12-13), J5 9 (8-9), z2 12 (11-12), z4 12 (11-12), z5 9 (8-9), Zl 13 (12-14), Z4 35 (31-37), Z5 69 (6770), s4 22 (20-23), S2 12 (11-12), S4 8 (7-9), S5 7 (6-8), R3 15 (14-16), rl 13 (12-14), ST1-ST3 55 (54-56), ST2-ST2 62 (60-63), ST5-ST5 62 (59-65), comprimento da placa ventrianal 110 (105-118), largura ao nível de ZV2 88 (85-91), ao nível do ânus 80 (7787), comprimento do cérvix da espermateca 5 , dígito fixo da quelícera com 25 (23-27) de comprimento e 8 dentes e dígito móvel com 26 (25-26) de comprimento e 3 dentes, SgeI 27 (25-28), SgeII 26 (24-27), SgeIII 30 (28-31), StilII 26 (24-28), SgeIV 45 (4149), StiIV 38 (35-43), StIV 55 (51-58).

OBSERVAÇÕES: As medições concordam com a descrição original, entretanto o comprimento do cérvix da espermateca (5) é $40 \%$ menor que relatado para o holótipo. A.C. Lofego (informação pessoal) encontrou valores semelhantes ao verificado neste trabalho, para exemplares coletados nos Estados de São Paulo e Pernambuco.

\section{Phytoseius guianensis DeLeon}

Phytoseius guianensis DeLeon, 1965b: 18; Denmark, 1966: 23; Denmark \& Muma, 1973: 269; Moraes \& McMurtry, 1983: 144.

DISTRIBUIÇÃO: Brasil e Guiana.

ESPÉCIMES EXAMINADOS: Pernambuco: Itambé, S. schizopylla (VI-98).

OBSERVAÇÕES: Apenas uma fêmea foi encontrada e medida. As dimensões desta concordam com a descrição original.

\section{Phytoseius woodburyi DeLeon}

Phytoseius (Phytoseius) woodburyi DeLeon, 1965b: 130.

Phytoseius (Dubininellus) woodburyi, Denmark, 1966: 64.

Phytoseius (Phytoseius) woodburyi, Muma \& Denmark, 1968: 236; Moraes et al., 1991: 133; Kreiter \& Moraes, 1997: 380. 
DISTRIBUIÇÃO: Havai, Índia, Jamaica, Porto Rico e Trinidad-Tobago; Colômbia (Moraes et al., 1991); Martinica (Kreiter \& Moraes, 1997).

ESPÉCIMES EXAMINADOS: São Paulo: Piracicaba, B. eriospatha (IX-98), L. weddellianum (III-98), P. caudescens (IX-98) e S. romanzoffiana (IX-98).

MEDIÇÕES (4 fêmeas): comprimento da placa dorsal 280 (279-284), largura 149 (145151), j1 33 (32-34), j3 36 (33-38), j4 6 (5-6), j5 6 (5-6), j6 7 (6-7), J5 8 (7-9), z2 15 (1416), z3 36 (34-37), z4 14 (13-15), z5 7 (6-8), Z4 94 (91-97), Z5 80 (79-81), s4 130 (126137), s6 82 (79-85), r3 46 (43-47), ST1-ST3 54 (53-57), ST2-ST2 61 (59-63), ST5-ST5 61 (59-62), comprimento da placa ventrianal 53 (50-58), largura ao nível de ZV2 37 (3637) e ao nível do ânus 49 (48-50), comprimento do cérvix da espermateca 5 , SgeIV 8 , StiIV 53 (50-55), StIV 28 (26-30).

OBSERVAÇÕES: Os exemplares medidos são muito próximos aos relatados por Kreiter \& Moraes (1997).

Cocoseius elsalvador Denmark \& Andrews

Cocoseius elsalvador Denmark \& Andrews, 1981: 155.

DISTRIBUIÇÃO: El Salvador e EUA.

ESPÉCIMES EXAMINADOS: Pernambuco: Itambé, $A$. intumescens (I-99); Igarassu, $A$. intumescens (I-99), C. nucifera (I-99) e Euterpe sp. (VI-98, I-99).

MEDIÇÕES (4 fêmeas): comprimento da placa dorsal 278 (254-288), largura 150 (145159), j1 25 (24-26), j3 56 (54-59), j4 35 (34-38), j5 55 (53-55), j6 67 (62-70), J2 66 (6270), J5 24 (23-26), z2 27 (25-29), z3 32 (30-33), z4 70 (68-74), z5 32 (30-34), z6 90 (8594), Z4 72 (69-76), Z5 74 (71-78), s4 78 (76-80), S4 72 (68-75), r3 39 (37-41), R1 76 (75-77), ST1-ST3 55 (51-57), ST2-ST2 58 (55-61), ST5-ST5 56 (55-59), comprimento do cérvix da espermateca 19, dígito fixo com 26 (25-26) de comprimento, dígito móvel com 26 (25-26) de comprimento, SgeIV 44 (41-47), StiIV 31 (25-37), StIV 66 (62-70). OBSERVAÇÕES: As medições dos exemplares coletados concordam com as medições da descrição original. $O$ peritrema das fêmeas coletadas atinge o nível de $\mathbf{z} 3$, enquanto que no material tipo, atinge o nível de s4 (Denmark \& Andrews, 1981). 
Leonseius regularis (DeLeon)

Typhloseiopsis regularis DeLeon, 1965a: 122; Moraes et al., 1991: 136.

Diadromus regularis, DeLeon, 1966: 100.

Chanteius regularis, DeLeon, 1967: 16.

Typhlodromus regularis, Chant \& Yoshida-Shaul, 1983a: 1034; El-Benhawy, 1984: 139. DISTRIBUIÇÃO: Brasil, Colômbia, Guiana, Porto Rico e Trinidad-Tobago. ESPÉCIMES EXAMINADOS: Pernambuco: Recife, E. guineensis (VI-98, I-99). São Paulo: Cananéia, C. nucifera (X-98); Pariquera-açu, C. nucifera (X-98) e E. guineensis (IV-98).

OBSERVAÇÕES: Os espécimes de São Paulo (3fềmeas) apresentam as macrosetas da perna IV 20 a $40 \%$ maiores que os de Pernambuco (4 fêmeas); o escudo dorsal e ventrianal dos espécimes de São Paulo também são maiores que os de Pernambuco. A média geral das medições está muito próxima das medições de El-Benhawy (1984) obtida para espécimes de São Paulo. As setas Z4 (101), Z5 (276), SgeI (53), SgeIV (119), Stilv (63) e StIV (49) são menores que observado por Moraes et al. (1991) para espécimes coletados da Colômbia. $O$ comprimento do cérvix da espermateca dos exemplares coletados é cerca de $30 \%$ menor que relatado para o material tipo (DeLeon, 1965a).

\section{Typhlodromina subtropica (Muma \& Denmark)}

Typhlodromina subtropica Muma \& Denmark, 1969: 412; Muma \& Denmark, 1970:

132; Chant \& Yoshida-Shaul, 1983b: 1046; Moraes \& McMurtry, 1983: 142.

DISTRIBUIÇÃO: Antigua, Brasil, Costa Rica, EUA, Galápagos, Jamaica, México e Nicaragua; Colômbia (Moraes \& Mesa, 1988).

ESPÉCIMES EXAMINADOS: Pernambuco: Itamaracá, $P$. pacifica (VI-98); Recife, $E$. guineensis (VI-98, I-99). São Paulo: Piracicaba, C. humilis (IX-98).

OBSERVAÇÕES: Foram medidas 3 fềmeas de Pernambuco e 2 de São Paulo. As medições dos ácaros coletados estão de acordo com as observações de Chant \& 
Yoshida-Shaul (1983b) e Moraes \& McMurtry (1983), exceto j4 (35) que é 50\% maior que verificado por Moraes \& McMurtry (1983) (22).

\section{Typhlodromus annectens DeLeon}

Typhlodromus annectens DeLeon, 1958: 75; Chant \& Yoshida-Shaul, 1984: 1868; Moraes \& McMurtry, 1983: 142; Moraes \& Mesa, 1988: 82; Moraes et al., 1991: 134; Feres \& Moraes, 1998: 128.

Galendromus annectens, Muma, 1961: 298; 1963: 30; Muma \& Denmark, 1970: 135;

Denmark \& Muma, 1973: 274; Denmark, 1982: 142; Moraes et al., 1982: 21.

DISTRIBUIÇÃO: Brasil, Canadá, Colômbia, EUA, Galápagos, Honduras, México e Porto Rico; Costa Rica e El Salvador (Denmark et al., 1999).

ESPÉCIMES EXAMINADOS: São Paulo: Piracicaba, $A$. phalerata (III-98) e $A$. cunninghamii (DX-98).

OBSERVAÇÕES: Os valores observados são semelhantes aos verificados por Moraes $\&$ Mesa (1988), que são maiores que as medidas observadas do material tipo (Denmark, 1982). O peritrema atinge o nível entre $\mathrm{z} 3$ e $\mathrm{z} 4$ e a distância entre os poros pré-anais é semelhante a distância entre as setas JV2, como verificado por Moraes \& Mesa (1988).

\section{Typhlodromus camelliae Chant \& Yoshida-Shaul}

Typhlodromus camelliae Chant \& Yoshida-Shaul, 1983b: 1053; Feres \& Moraes, 1998: 130.

DISTRIBUIÇÃO: Uruguai; Brasil (Feres \& Moraes, 1998).

ESPÉCIMES EXAMINADOS: São Paulo: Piracicaba, Attalea sp. (IX-98), C. urens (III98), C. nucifera (III-98, LX-98).

MEDIÇÕES (4 fềmeas): comprimento da placa dorsal 326 (316-337), largura 179 (175183), j1 22 (21-23), j3 22 (21-23), j4 16 (15-17), j5 17 (16-17), j6 18 (17-19), J2 22 (2122), J5 12 (11-13), z2 18 (17-19), z3 21 (20-23), z4 21 (20-22), z5 17 (16-18), Z4 35 (33-35), Z5 43 (40-45), s4 24 (23-25), s6 24 (23-26), S5 20 (18-21), r3 20 (19-21), R1 
24 (23-26), ST1-ST3 57 (56-58), ST2-ST2 55 (53-58), ST5-ST5 61 (59-63), comprimento da placa ventrianal 107 (103-110), largura ao nível de ZV2 71 (69-72) e ao nível do ânus 70 (67-72), comprimento do cérvix da espermateca 17 (16-18), dígito fixo com 22 de comprimento, dígito móvel com 26 de comprimento.

Typhlodromus ornatus (Denmark \& Muma), n. comb.

Amblydromella ornata Denmark \& Muma, 1973: 270.

DISTRIBUIÇÃO: Brasil

ESPÉCIMES EXAMINADOS: São Paulo: Piracicaba, C. nucifera (III-98, IX-98). MEDIÇÕES (4 fêmeas): comprimento da placa dorsal 346 (337-358), largura 185 (180191), j1 22 (21-23), j3 17, j4 12 (11-13), j5 12 (11-12), j6 14 (13-15), J2 16 (15-16), J5 11 (10-11), z2 13 (12-14), z3 14 (13-15), z4 15 (14-16), z5 13 (12-14), Z4 22, Z5 40 (38-40), s4 17 (16-18), s6 20 (19-20), S2 20 (20-21), S4 21 (20-21), S5 22 (21-22), r3 16, R1 18 (17-19), ST1-ST3 67 (66-68), ST2-ST2 61 (60-62), ST5-ST5 59 (57-60), comprimento da placa ventrianal 116 (110-121), largura ao nível de ZV2 92 (86-97) e ao nível do ânus 82 (81-83), comprimento do cérvix da espermateca 26 (26-27).

\section{Typhlodromus transvaalensis (Nesbit)}

Kampimodromus transvaalensis Nesbit, 1951: 55.

Neoseiulus transvaalensis, Muma, 1961: 295.

Clavidromus transvaalensis, Muma \& Denmark, 1968: 238; Muma \& Denmark, 1970: 128.

Typhlodromus transvaalensis, Chant \& Baker, 1965: 5; Schicha, 1981: 36; Moraes \& Mesa, 1988: 83.

Typhlodromus jackmickleyi DeLeon, 1958: 75 (sinonímia, de acordo com Muma \& Denmark, 1968: 238).

Typhlodromus pectinatus Athias-Henriot, 1958:179 (sinonímia, de acordo com Muma \& Denmark, 1968: 238). 
DISTRIBUIÇÃO: África do Sul, Argélia, Brasil, Egito, EUA, Guiné, Havai, Indonésia, Israel, Nova Caledônia, Panamá e Rússia; Colômbia (Moraes \& Mesa, 1988); Costa Rica (Denmark et al., 1999).

ESPÉCIMES EXAMINADOS: São Paulo: Piracicaba, $P$. reclinata (III-98), $P$. caudescens (III-98).

OBSERVAÇÕES: As medições dos espécimes encontrados concordam com aqueles citados por Moraes \& Mesa (1988) para espécimes da Colômbia.

Até o presente momento, apenas 5 espécies de fitoseídeos eram conhecidas em Arecáceas no Brasil, sendo elas: P. elliptica coletado sobre $C$. nucifera em PiracicabaSão Paulo (Flechtmann, 1967); A. chiapensis coletado sobre Attalea speciosa em Timon/Maranhão; A. herbicolus coletado sobre S. romanzoffiana em Arapoti-Paraná; $E$. alatus coletado sobre $C$. nucifera em Aracaju-Sergipe; $E$. citrifolius coletado sobre $R$. oleraceae em Sete Lagoas/Minas Gerais (Santana \& Flechtmann, 1998). Dentre todos os fitoseídeos coletados neste trabalho, os mais frequentemente encontrados nas matas nativas pertencem aos gêneros Amblyseius e Typhlodromips, enquanto que nas áreas alteradas os gêneros mais frequentemente encontrados foram Amblyseius, Euseius e Iphiseiodes.

\subsection{CONCLUSÕES}

1) Phytoseiidae é o grupo de ácaros predadores que apresenta maior diversidade de espécies nas arecáceas amostradas.

2) I. zuluagai é de ocorrência comum nas arecáceas amostradas, e a espécie mais abundante entre as espécies coletadas. 


\section{DESCRIÇÃO DE UMA NOVA ESPÉCIE DO GÊNERO Cocoseius (ACARI: PHYTOSEIIDAE) E REDESCRIÇÃO DO GÊNERO}

\section{RESUMO}

Uma espécie nova de fitoseídeo, Cocoseius palmarum Gondim Jr., Moraes \& McMurtry sp.n. é descrita a partir de ácaros coletados de Arecaceae no Nordeste do Brasil. Apenas Cocoseius elsalvador Denmark \& Andrews era conhecido neste gênero até o momento, coletado em Cocos nucifera L. e Sabal palmetto (Walt.), plantas da familia Arecaceae. $\mathrm{O}$ gênero Cocoseius é redescrito. 
DESCRIPTION OF A NEW SPECIES OF GENUS Cocoseius (ACARI: PHYTOSEIIDAE) AND REDESCRIPTIONS OF GENUS

\section{SUMMARY}

A new species of phytoseiid, Cocoseius palmarum Gondim Jr., Moraes \& McMurtry n. sp. is described from specimens collected on Arecaceae in northeastern Brazil. Only Cocoseius elsalvador Denmark and Andrews was known in this genus until now, collected from the Arecaceae Cocos nucifera L. and Sabal palmetto (Walt.), plants of the family Arecaceae. The genus Cocoseius is redefined. 


\subsection{INTRODUÇÃO}

O gênero Cocoseius foi descrito com base em Cocoseius elsalvador Denmark \& Andrews, única espécie do gênero conhecida até o momento. Esta espécie foi descrita de uma fêmea (holótipo) coletada de Cocos nucifera L. em Tonacatapeque (El Salvador), e outra fêmea (parátipo) coletada de Sabal palmetto (Walt.) na Florida (E.U.A) (Denmark \& Andrews, 1981). Uma nova espécie deste gênero, Cocoseius palmarum Gondim Jr., Moraes \& McMurtry sp. n., é descrita com base em espécimes de diferentes estágios de desenvolvimento. $\mathrm{O}$ gênero Cocoseius foi redefinido para abrigar as duas espécies.

\subsection{MATERIAL E MÉTODOS}

Folhas de palmeiras foram coletadas no município de Igarassu, acondicionadas em sacos de papel, sendo estes colocados dentro de sacos plásticos e conduzidas ao laboratório dentro de caixa de isopor refrigerada. No laboratório, as folhas foram examinadas com auxilio de um microscópio estereoscópico, coletando-se os ácaros e montando-os em lâminas para microscopia com meio de Hoyer. Os ácaros pertencentes à espécie nova do gênero Cocoseius foram medidos e ilustrados para sua descrição.

A nomenclatura utilizada foi a proposta por Rowell et al. (1978) para as setas da superfície dorsal e a proposta por Chant \& Yoshida-Shaul (1991) para as setas da superfície ventral do idiossoma. As medições são indicadas em micrômetros. Todos os

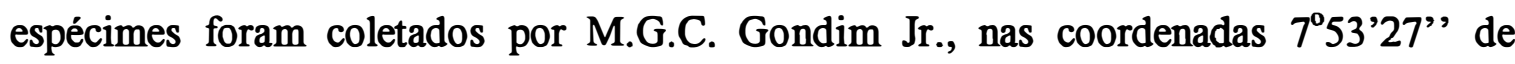
latitude sul e $34^{\circ} 58^{\prime} 36^{\prime \prime}$ 'de longitude oeste.

\subsection{RESULTADOS E DISCUSSÃO}

Denmark \& Andrews (1981) afirmaram que $C$. elsalvador, espécie tipo do gênero Cocoseius, têm 8 setas "L" (laterais), incluindo a seta inserida entre j6 e R1. Esta seta foi chamada de "L6" por estes autores, correspondendo à seta s6 de acordo com a 
nomenclatura de. Rowell et al. (1978), adotada neste trabalho. Chant \& Yoshida-Shaul (1989) concordaram com Denmark \& Andrews (1981) na identificação da seta s6, apesar de questionarem as interpretações destes autores por causa da posição mesal desta seta em relação a série de setas s-S. Chant \& McMurtry (1994) caracterizaram o gênero Cocoseius pela presença de z3 e z6, e pela ausência de Z1, s6, S2 e S5. A identificação de z6 (e ausência de s6) foi concluída com base na posição mesal da inserção da seta em relação ao solenostoma adjacente.

Chant \& Yoshida-Shaul (1989) afirmaram que a identidade de z6 em Australiseiulus angophorae (Schicha) e Australiseiulus australicus (Womersley) é duvidosa, por causa da posição lateral da seta em comparação com outras espécies onde a presença de $\mathrm{z} 6$ foi considerada inquestionável. Na espécie descrita neste trabalho, em espécimes coletadas no Nordeste do Brasil e identificadas como C. elsalvador, e nos desenhos da descrição original de $C$. elsalvador, a inserção de z6 é quase em linha com a inserção das setas s-S adjacentes.

Chant \& Yoshida-Shaul (1989) mencionaram que a única forma de esclarecer a identificação desta seta (z6 ou s6) seria através do exame do estágio larval. Lindquist \& Evans (1965) afirmaram que z6 aparece primeiro no estágio deutoninfal de Ascidae e famílias relacionadas. O desenho de Ueckerman \& Loots (1988) para Typhlodromus (Anthoseius) querellus Ueckermann \& Loots também sugere que z6 apareça no estágio deutoninfal. Entretanto, Chant \& Yoshida-Shaul (1989) verificaram que z6 pode também aparecer no estágio de protoninfa, citando como exemplo Paraseiulus soleiger (Ribaga), também mostrado por Chant (1958). Outros autores tem observado que em algumas espécies de Typhlodrominae $\mathrm{z} 6$ pode estar ausente no macho mas presente na fềmea adulta (Wainstein, 1962; Chant \& Yoshida-Shaul, 1982 e 1986).

Por outro lado, todas as espécies estudadas por Rowell \& Chant (1979) nas quais s6 foi identificada na fase adulta, como em Metaseiulus pomi (Parrot), Galendromus (Galendromus) longipilus Nesbitt, Typhlodromus (Typhlodromus) pyri Scheuten, Typhlodromus (Anthoseius) bakeri (Garman), Neoseiulella aceri Collyer, Neosiulella tiliarum Oudemans e Typhloseiulus simplex (Chant), a seta s6 está presente no estágio larval, ainda que às vezes representada apenas pela base da seta. 
Denmark \& Andrews (1981) caracterizaram o gênero Cocoseius como sendo semelhante a Paraseiulella (=Metaseiulus, espécies do grupo cornus, sensu Chant \& McMurtry 1994), mas tendo apenas 1 par de setas pré-anais, 3 setas com ápices dilatados na perna IV e 5 pares de setas lateroventrais (mencionam 4 pares, mas provavelmente JV5 não foi considerado). Chant \& McMurtry (1994) redescreveram o gênero Cocoseius com base em C. elsalvador, a única espécie conhecida deste gênero até aquela época, mencionando características que não foram consideradas na descrição original. A nova espécie descrita neste trabalho não se encaixa exatamente na descrição atual do gênero por apresentar 3 pares de setas pré-anais e 2 pares de setas lateroventrais. Deste modo, o conceito de Cocoseius é expandido para acomodar as características desta nova espécie.

Redescrição do Gênero Cocoseius: Este gênero é redefinido para incluir espécies com as seguintes características: seta z3 e z6 presentes; s6, Z1 e S5 ausentes. Fêmea com o padrão de setas 12B:6F/JV-3,4:Zv (ou JV-3,4:ZV-3). Escudo dorsal com a maioria das setas alongadas, setiformes, serreadas; $\mathrm{z} 3$ inserida lateralmente à inserção de z2 e z4; escudo ventrianal reduzido ou não, com apenas um (JV2) ou 3 (JV1, JV2 e ZV2) pares de setas pré-anais; quarto par de pemas com 3 macrosetas longas e com ápices dilatados; demais pernas sem macrosetas; cérvix da espermateca em forma de trombeta; dígito fixo da quelícera com poucos dentes, todos distais; peritrema estendendo-se anteriormente até o nível de z2.

Cocoseius palmarum Gondim Jr., Moraes \& McMurtry sp.n.

(Figs. 58-68)

Diagnose: As fềmeas adultas desta espécie diferem de Cocoseius elsalvador Denmark \& Andrews, 1981 por apresentarem o escudo dorsal escuro, mais curto que largo, com poucas estriações na parte anterolateral; escudo esternal bastante estriado; escudo ventrianal com 3 pares de setas pré-anais e ausência da seta ZV3.

Larva: (Figs. 50-51) $(\mathrm{n}=1)$. Dorso: Escudo podonotal com as seguintes setas e respectivas dimensões: j1 24, j3 24, j4 3, j5 3, j6 62, z2 13, z4 48, z5 3 e s4 54 . A seta z5 
encontra-se em posição usual, posterolateralmente à seta j5. Escudo opistonotal indistinto; seta Z4 105. Peritrema ausente. Ventre: Apresenta as setas ST1, ST2, ST3, JV1, JV2, JV5, para-anais e pós-anais; seta Z5 encontra-se posterior a JV5. Escudo anal indistinto.

Protoninfa: (Figs. 52-53) $(\mathrm{n}=1)$. Dorso: Escudo podonotal com as seguintes setas e respectivas dimensões: j1 19, j3 35, j4 22, j5 46, j6 59, z2 16, z4 54, z5 19 e s4 56. A seta Z5 encontra-se em posição usual. Escudo opistonotal distinto, com as seguintes setas e respectivas dimensões: J5 8, Z4 59, S4 24 e Z5 32. Setas J2 38, z6 64, r3 27 e R1 19 inseridas na membrana. Peritrema: curto, extendendo-se anteriormente até o nível de z6. Ventre: Apresenta as setas ST1, ST2, ST3, JV1, JV2, JV5, pré-anais e pósanais. Escudo anal esclerotizado.

Deutoninfa: (Figs.54-55) $(\mathrm{n}=1)$. Dorso: Escudos podonotal e opistonotal fundidos e com as seguintes setas e respectivas dimensões: $\mathrm{j} 122, \mathrm{j} 338, \mathrm{j} 438, \mathrm{j} 546, \mathrm{j} 6$ 54, J2 56, J5 8, z2 21, z3 28, z4 55, z5 23, z6 75, Z4 66, Z5 45, s4 63, S4 45. Seta z5 localizada no alinhamento de j5 e s4. Setas $\mathrm{r} 338$ e R1 30 inseridas na membrana. Peritrema: estendendo-se anteriormente ao nivel de z2. Ventre: Apresenta as setas ST1, ST2, ST3, ST4, ST5, JV1, JV2, JV5, ZV1, ZV2, pré-anais e pós-anais.

Fêmea: (Figs.56-60) $(\mathrm{n}=8)$. Dorso: Escudo dorsal escuro, liso, exceto pela presença de poucas estriações anterolaterais, com 245 (241-247) de comprimento, 181 (172-191) de largura, j1 25 (24-27), j3 40 (39-43), j4 54 (53-56), j5 58 (56-60), j6 66 (62-68), J2 67 (65-68), J5 10 (9-12), z2 26 (25-28), z3 32 (30-32), z4 67 (65-69), z5 32 (30-34), z6 82 (78-85), Z4 71 (68-74), Z5 66 (63-69), s4 73 (70-76), S4 64 (63-66), r3 59 (55-67), R1 47 (45-50). Como verificado na deutoninfa, z5 encontra-se localizada no alinhamento de j5 e s4. Todas as setas dorsais são serreadas, exceto J5 que é lisa. A seta z6 é lateral ao solenostoma adjacente. Peritrema: estendendo-se anteriormente até 0 nível de j3. Ventre: escudo esternal escuro, reticulado, com 3 pares de setas (ST1, ST2 e ST3) e 2 pares de poros; distância entre ST1-ST3 45 (44-46), ST2-ST2 55 (53-56). Escudo genital escuro, irregularmente estriado; distância entre ST5-ST5 28 (25-29). Dois pares de escudos metapodais presentes. Escudo ventrianal escuro e estriado, 80 (79-81) de comprimento, 63 (57-67) de largura ao nível de ZV2 e 62 (58-67) ao nível do 


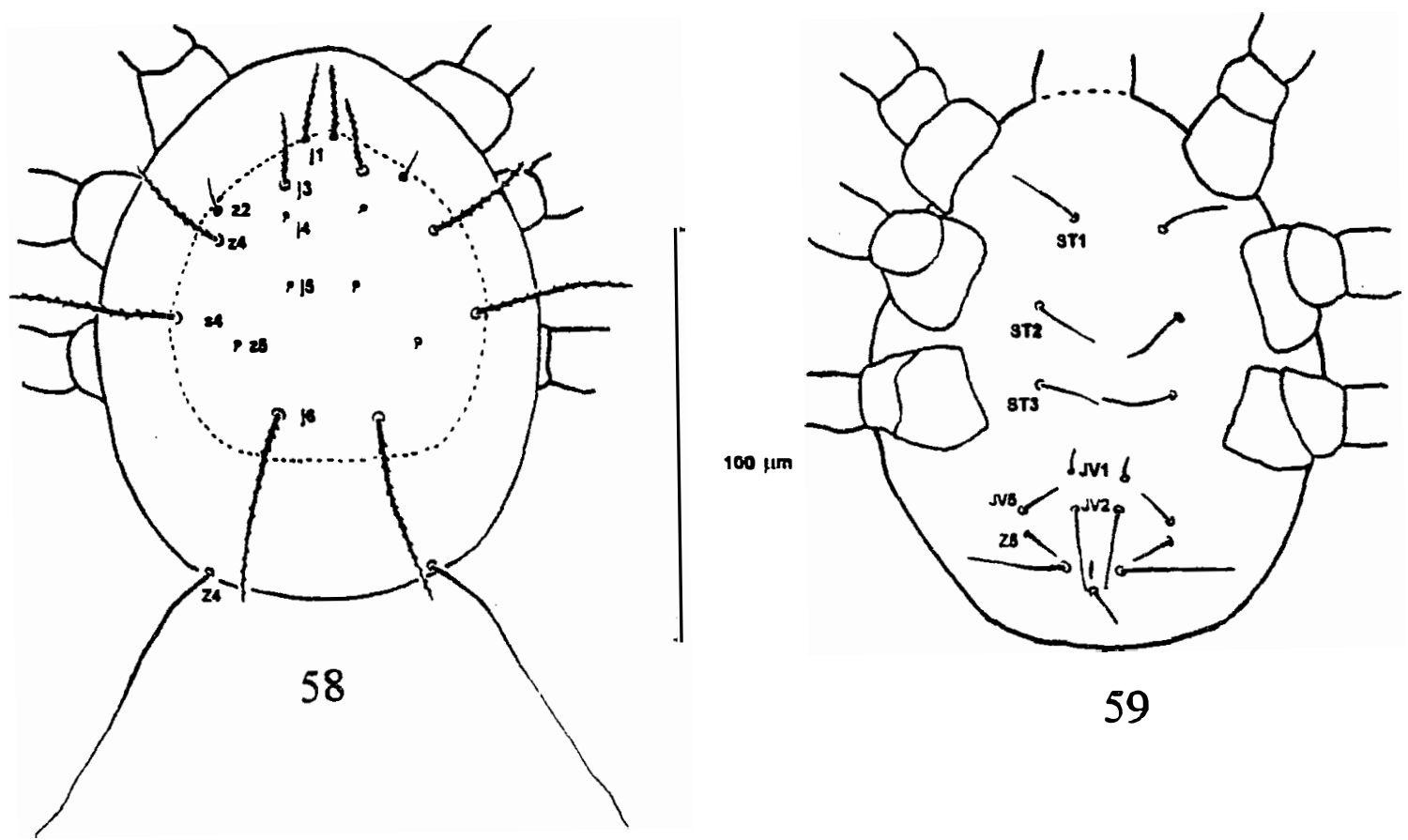

Figura 58-59. Cocoseius palmarum sp. n. (larva). 58, vista dorsal; 59, vista ventral.
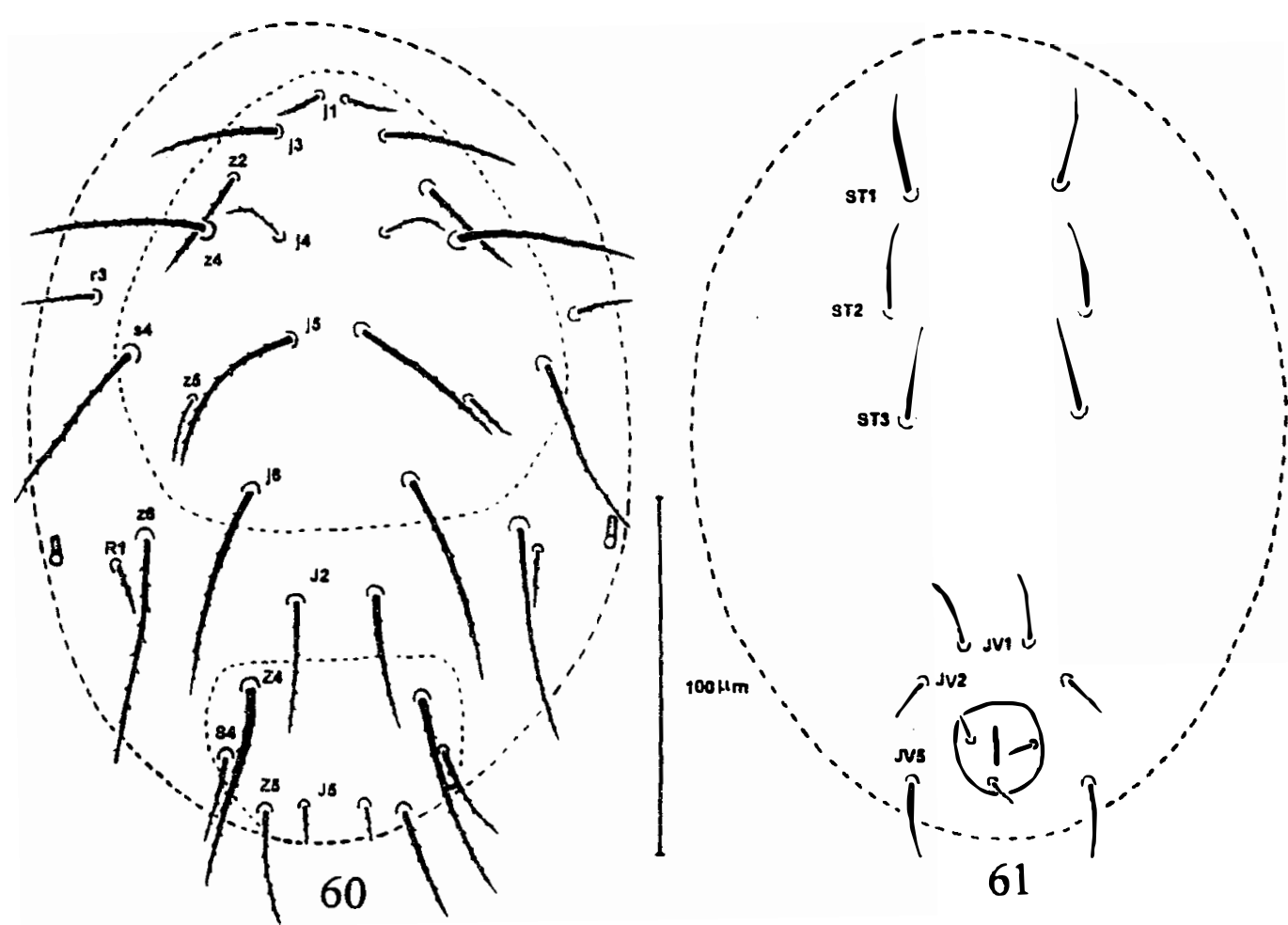

Figura 60-61. Cocoseius palmarum sp. n. (protoninfa). 60. vista dorsal: 61, vista ventral. 

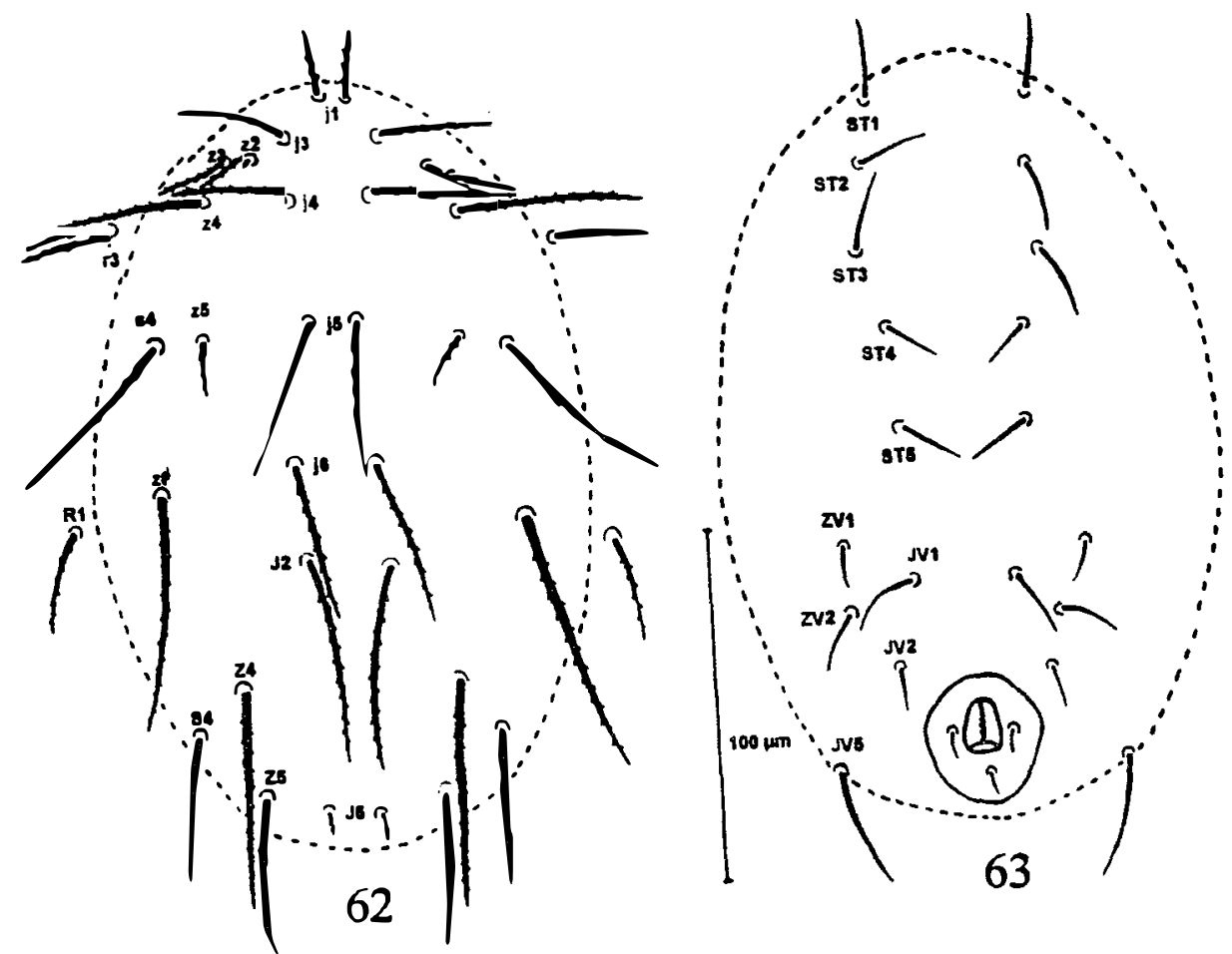

Figura 62-63. Cocoseius palmarum sp. n. (deutoninfa). 62, vista dorsal; 63, vista ventral.
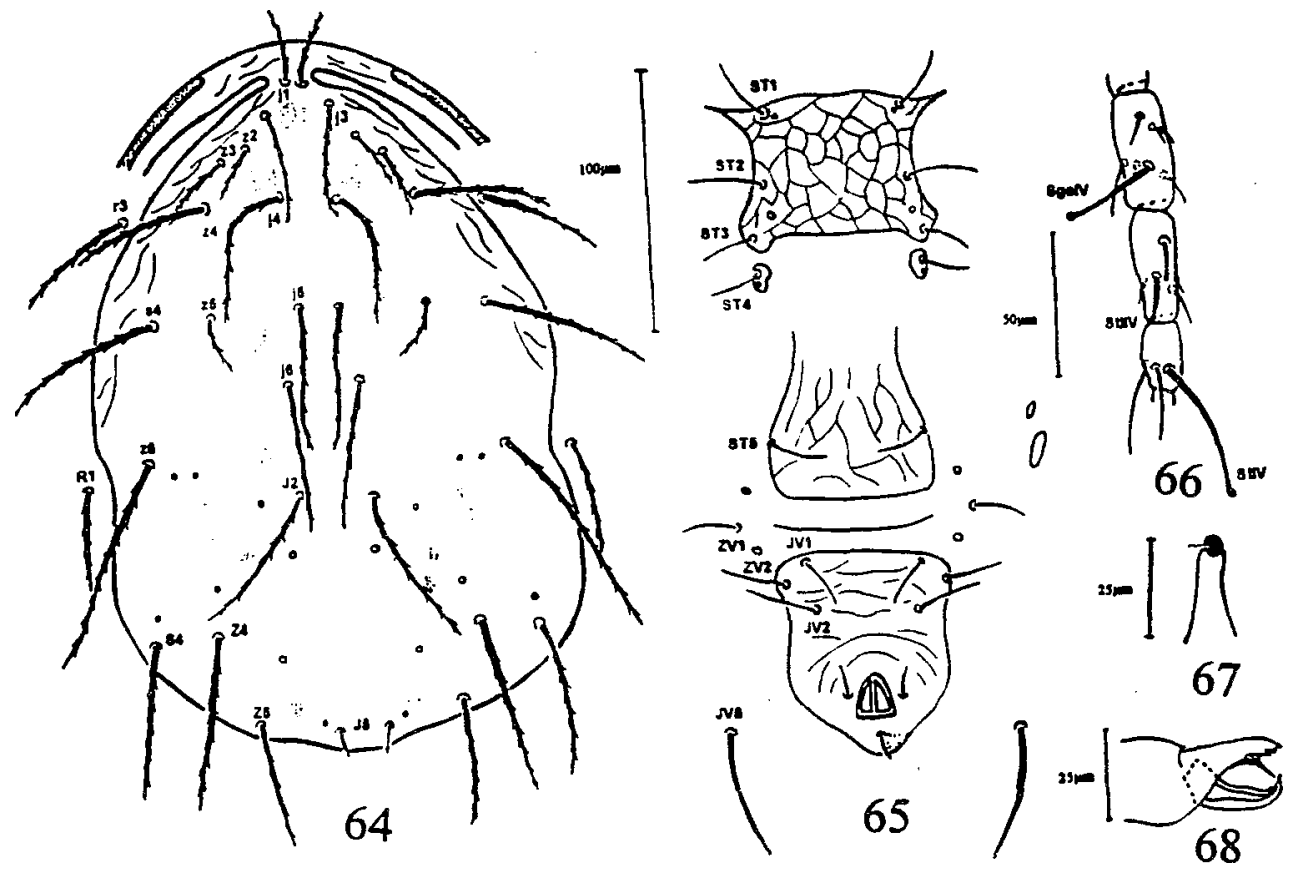

Figura 64-68. Cocoseius palmarum sp. n. (fêmea). 64. vista dorsal; 65, vista ventral; 66, Genu. Tíbia e Tarso da perna IV; 67, espermateca; 68, Quelícera. 
ânus; com 3 pares de setas pré-anais e sem poros. Seta JV3 ausente. Pernas: não apresenta macrosetas nas pernas I-III; macrosetas da perna IV dilatadas na extremidade, com as seguintes dimensões: Sge 35 (34-36), Sti 25 (24-26), St 53 (50-55). Quetotaxia do genu II 2;2/0;2/0;1/genu III 1;2/1;2/0;1. Espermateca: Cérvix em forma de trombeta. Átrio pequeno e nodular. Quelíceras: Dígito fixo com 24 de comprimento e 2 dentes subapicais; digito móvel 24, com 1 dente.

Macho: Desconhecido.

Localidade e Material Tipo: holótipo fềmea e 4 parátipos fềmeas de Euterpe sp. ( $7^{\circ} 53^{\prime} 27^{\prime \prime}$ de latitude sul e $34^{\circ} 58^{\prime} 36^{\prime \prime}$ de longitude oeste) em I-99; 3 parátipos fêmeas em VI-98; 1 parátipo fêmea em V-99. Holótipo e 7 parátipos depositados no setor de zoologia do Departamento de Entomologia, Fitopatologia e Zoologia Agrícola da Escola Superior de Agricultura "Luiz de Queiroz" (ESALQ-USP), Piracicaba-SP; 1 parátipo fêmea depositado no "United States National Museum of Natural History" (USNMNH) em Washington D.C.

Etimologia: palmarum, refere-se às palmeiras, grupo a que pertence a planta sobre a qual este ácaro foi encontrado.

Observações: Conclui-se que z6 está presente e s6 está ausente em C. palmarum sp. n., com base no seguinte: a) a ausência de qualquer seta (ou base da seta) lateral à seta j6 na larva de $C$. palmaram n.sp.; a seta s6 aparece normalmente no estágio larval, como mostrado por Rowell \& Chant (1979) para 7 espécies de Typhlodrominae e por Lindquist \& Evans (1965) para Ascidae; b) a presença de 2 setas laterais a j6 na protoninfa de C. palmarum n. sp. (uma interpretada como R1), e a observação de Chant (1958) que z6 surge na protoninfa de Typhlodrominae ( $P$. soleiger (Ribaga)). Possivelmente, Chant (1958) não notou a presença da base da seta correspondente a s6 na larva de $P$. soleiger e Typhlodromus (Anthoseius) bakeri (Garman), como indicado pela comparação dos desenhos fornecidos por este autor com aqueles mostrados por Rowell e Chant (1979). 


\section{CICLO DE VIDA DE Retracrus johnstoni (ACARI: PHYTOPTIDAE)}

\section{RESUMO}

Os eriofídeos estão comumente associados à palmeiras, contudo muitos deles não causam danos econômicos a estas plantas. Uma exceção é Retracrus johnstoni Keifer, mencionado no Brasil como praga em Bactris gasipaes Kunth, planta usada para produção de palmito. $R$. johnstoni tem sido frequentemente verificado em grande número de arecáceas no Estado de São Paulo. $O$ objetivo deste trabalho foi estudar a biologia deste ácaro sob condições de laboratório. Seções de folhas de Syagrus romanzoffiana (Cham.) Glassman, com cerca de 15 folíolos foram mantidas vivas, submergindo a base em água. Com um pincel de cerdas finas e auxílio de microscópio estereoscópio 20 adultos de $R$. johnstoni foram colocados em cada folíolo para oviposição. Depois de 24 horas, os ácaros foram removidos, deixando-se apenas um ovo por folíolo. Uma vez por dia, os ovos e os estágios subsequentes foram examinados para determinação do ciclo de vida. A duração dos diferentes estágios foram: incubação, $6,9 \pm 0,3$; ninfa I, 7,1 $\pm 0,4$ e ninfa II, $6,5 \pm 0,4$. A duração total dos estágios imaturos foi $20,5 \pm 0,7$ dias. A razão sexual foi de 2 fềmeas para 1 macho. O período de pré-

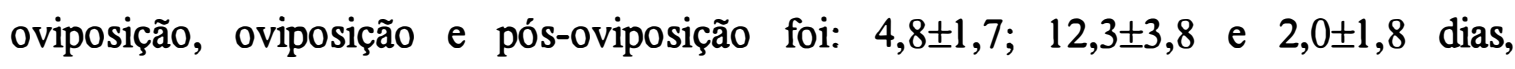
respectivamente, correspondendo a uma longevidade de 19,1 $\pm 3,6$ dias; a longevidade do

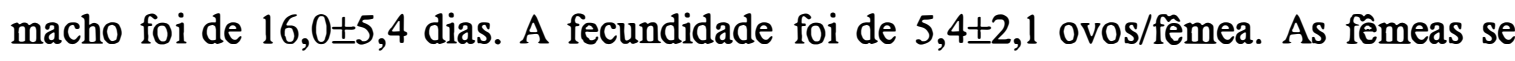
reproduziram por partenogênese arrenótoca. Todos os estágios de desenvolvimento de ambos os sexos são cobertos por cera. O espermatóforo assemelha-se aos de outras espécies da superfamília, constituído por um pé de $6 \mu \mathrm{m}$ de comprimento e cabeça de aproximadamente $6 \mu \mathrm{m} \times 6 \mu \mathrm{m}$. Observações de campo e laboratório indicaram que os 
danos causados às folhas apresentam-se através de manchas escuras na superfície inferior e amarelecimento na região correspondente da superfície superior da folha. As manchas das folhas tomam-se progressivamente maiores e coalescem. 


\section{LIFE CYCLE OF Retracrus johnstoni (ACARI: PHYTOPTIDAE)}

Eriophyid mites are common associates of palm trees, although most of them do not cause economic damage to those plants. One of the exceptions is Retracrus johnstoni Keifer, mentioned in Brazil as a pest of Bactris gasipaes Kunth, a plant used for palm heart production. $R$. jonhstoni has been frequently found in large numbers on Arecaceae in the State of São Paulo, Brazil. The objective of this work was to study the biology of this mite under laboratory condition. Sections of leaves of the palm tree Syagrus romanzoffiana (Cham.) Glassman, with ca. 15 leaflets were maintained alive by submerging their bases in water. With a fine brush and under a stereo microscope 20 adults of $R$. johnstoni were put onto each leaflet for oviposition. After $24 \mathrm{~h}$, mites were removed, leaving only one of the eggs laid. Once a day, the eggs and the subsequent stages were examined to determine the life cycle. The duration of the different stages was: egg, $6,9 \pm 0,3$; nymph I, 7,1 $\pm 0,4$ and nymph II, $6,5 \pm 0,4$. The total duration of the immature phase was $20,5 \pm 0,7$ days. Sex ratio was 2 females to 1 male. Preoviposition, oviposition and post-oviposition periods were: $4,8 \pm 1,7,12,3 \pm 3,8$ and 2,0 $\pm 1,8$ days, respectively, corresponding to a female longevity of $19,1 \pm 3,6$ days; male longevity was $16,0 \pm 5,4$ days. Fecundity was 5,4 $\pm 2,1$ eggs/female. Females reproduced through arrhenotokous parthenogenesis. All developmental stages of both sexes are covered by wax. The spermatophore resembles those of other species in the same superfamily, and consists of a foot ca. $5 \mu \mathrm{m}$ long and a head of ca. $5 \times 5 \mu \mathrm{m}$. Field and laboratory observations indicated that damaged leaflets show dark spots on the upper surface and yellowish spots on the corresponding regions of the lower surface. Leaf spots become progressively larger and coalescent. 


\subsection{INTRODUÇÃO}

Os eriofídeos são ácaros frequentemente associados a palmeiras, embora normalmente não causem danos econômicos. Uma exceção é o gênero Retracrus, composto por 2 espécies, ambas relatadas como pragas. A espécie Retracrus elaeis Keifer, é citada como importante praga de Elaeis guineensis N.J. Jacquin (dendezeiro) na Colômbia (Genty \& Reyes, 1977) e na América Central (Ochoa et al., 1991). Retracrus johnstoni Keifer é citado como "praga de palmeiras" na América Central (Ochoa et al., 1991) e de Bactris gasipaes Kunth (pupunha) no Brasil (Ferreira, 1997). Segundo Amrine \& Stasny (1994), este gênero é bastante específico em relação aos seus hospedeiros, tendo apenas as palmeiras como plantas hospedeiras conhecidas.

$R$. elaeis foi descrito de folhas de $E$. guineensis coletadas na Colômbia, nas quais causa manchas amareladas ou alaranjadas (Keifer, 1975a). R. johnstoni foi descrito de folhas de Chamaedorea sp., coletadas no México, nas quais causa manchas escuras, visíveis em ambas as superficies (Keifer, 1965a). Neste trabalho $R$. johnstoni foi o eriofídeo com maior frequência e abundância em folhas de arecáceas, tendo-se também observado altas infestações deste ácaro em Syagrus romanzoffiana (Cham.) Glassman em Piracicaba, Estado de São Paulo (Capítulo 3).

Pouco se conhece sobre a biologia de espécies de Retracrus. O único trabalho neste sentido foi realizado por Genty \& Reyes (1977), que estudaram a biologia de $R$. elaeis sobre E. guineensis. A biologia de $R$. johnstoni é totalmente desconhecida.

Devido ao considerável aumento da área plantada com arecáceas no sul do país e ao fato deste ter sido o eriofídeo com maior distribuição, abundância e com maior número de plantas hospedeiras neste trabalho (Capítulo 3), considerou-se conveniente estudar sua biologia e alguns aspectos do seu comportamento, como subsídio para uma avaliação do seu potencial como praga. 


\subsection{MATERIAL E MÉTODOS}

A biologia de $R$. johnstoni foi estudada utilizando-se como hospedeiro $S$. romanzoffiana (jerivá), a $25,8 \pm 2,0^{\circ} \mathrm{C} ; 56 \pm 5 \%$ de umidade relativa e 14 horas de fotofase. Para tanto, seções proximais de folhas recém abertas de jerivá foram mantidas vivas, emergindo-se a parte proximal da ráquis em um recipiente com água. Os folíolos foram desbastados, deixando-se em média 15 folíolos por seção de folha nas partes mediana e distal (Figura 69). A água dos recipientes foi semanalmente trocada de forma a proporcionar a boa conservação das folhas. Após 30 dias do início das observações, os ácaros foram transferidos para novas seções de folhas.

Os ácaros utilizados no experimento foram obtidos no campus da ESALQ-USP (Piracicaba-SP), em plantas de $S$. romanzoffiana. Com auxílio de pincel de cerdas finas, foram transferidos 20 adultos de $R$. johnstoni para cada folíolo das ráquis. Após 24 horas, retiraram-se os adultos e parte dos ovos, deixando-se apenas um ovo por folíolo, em um total de 50 ovos. Diariamente, a partir das 14 horas, os indivíduos foram observados ao microscópio estereoscópico para determinação da duração dos estágios de desenvolvimento.

Os ácaros não foram acasalados ao atingirem a fase adulta, devido à dificuldade de manipulação, que provocava a perda de grande parte das repetições. Os adultos também foram observados diariamente às $14 \mathrm{~h}$. Após a morte, os indivíduos foram montados em lâminas para confirmação do sexo.

Dos 50 ovos utilizados para instalação do experimento, apenas 20 indivíduos atingiram a fase adulta e 13 completaram o ciclo total. As perdas dos demais indivíduos foram decorrentes de fuga e manipulação, e portanto não foram utilizados para efeito de cálculo.

Foram feitas observações ao microscópio eletrônico das formas imaturas e adultas dos ácaros, assim como do espermatóforo. A metodologia utilizada foi a mesma descrita no Capítulo 4, utilizando-se apenas a fixação em tetróxido de ósmio e a metalização com ouro. Além disso, os sintomas de ataque de $R$. johnstoni às plantas de S. romanzoffiana foram descritos com base em observações no campo e no laboratório. 


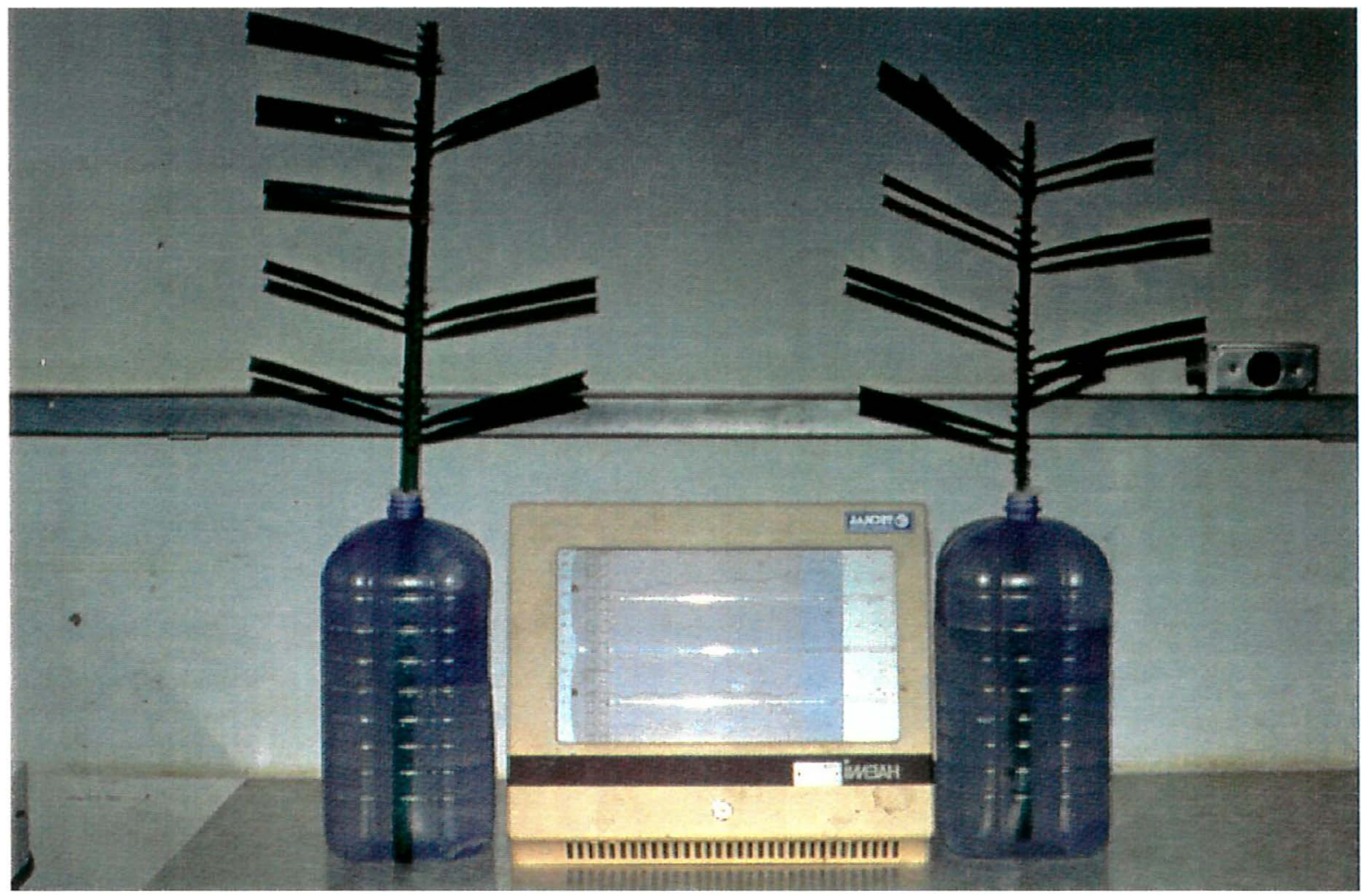

Figura 69. Criação de Retracrus johnstoni em laboratório a $25,8 \pm 2,0^{\circ} \mathrm{C} ; 56 \pm 5 \%$ de umidade relativa e 14 horas de fotofase. 


\subsection{RESULTADOS E DISCUSSÃO}

\section{Biologia}

$R$. johnstoni apresentou durante seu desenvolvimento os estágios de ovo, ninfa I, ninfa II e adulto. Os diferentes estágios de desenvolvimento das fases imaturas tiveram aproximadamente a mesma duração e um período de ovo-adulto de $20,5 \pm 0,7$ dias (Tabela 1).

Tabela 1. Duração dos estágios de desenvolvimento e reprodução, em dias, e fecundidade de Retracrus johnstoni em Syagrus romanzoffiana a $25,8 \pm 2,0^{\circ} \mathrm{C}$; $56 \pm 5 \%$ de umidade relativa e 14 horas de fotofase.

\begin{tabular}{lcccc}
\hline Estágio de Desenvolvimento & $\begin{array}{c}\text { Média } \pm \text { I.C. } \\
(5 \%)^{*}\end{array}$ & \multicolumn{2}{c}{ Valores } & Númimo Máximo de \\
& Imaturos (Fêmeas + Machos) & Observações \\
\hline Incubação & $6,9 \pm 0,3$ & 6 & 9 & 20 \\
Ninfa I & $7,1 \pm 0,4$ & 6 & 8 & 20 \\
Ninfa II & $6,5 \pm 0,4$ & 5 & 8 & 20 \\
Período de ovo-adulto & $20,5 \pm 0,7$ & 18 & 23 & 20 \\
& Adultos (Fêmeas ou Machos) & & \\
Pré-oviposição & $4,8 \pm 1,7$ & 2 & 10 & 9 \\
Oviposição & $12,3 \pm 3,8$ & 4 & 21 & 9 \\
Pós-oviposição & $2,0 \pm 1,8$ & 1 & 8 & 9 \\
Longevidade da fềmea & $19,1 \pm 3,6$ & 14 & 26 & 9 \\
Número de ovos & $5,4 \pm 2,1$ & 3 & 12 & 9 \\
Longevidade do macho & $16,0 \pm 5,4$ & 8 & 25 & 4 \\
\hline
\end{tabular}

* Intervalo de confiança a $5 \%$ de probabilidade.

A razão sexual verificada neste trabalho foi de 2 fềmeas para 1 macho. As 
fêmeas apresentaram um período de pré-oviposição de 4,8 1 ,7; período de oviposição

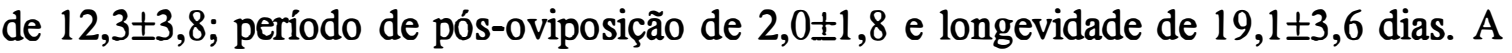
longevidade dos machos foi de $16,0 \pm 5,4$ dias. A fecundidade total foi de pouco mais de 5 ovos/fêmea, que mantidas isoladamente depositaram ovos que deram origem apenas a machos, evidenciando o tipo de reprodução por partenogênese arrenótoca.

Segundo Manson \& Oldfield (1996) os eriofideos podem apresentar 2 formas de desenvolvimento. Uma delas simplificada, comum aos eriofídeos de clima tropical, onde os ácaros se desenvolvem durante todo o ano, apresentando um único formato de fềmea, que passa sucessivamente pelos estágios de ovo, ninfa I, ninfa II e adulto, sem entrar em estado de hibernação ou estivação.

Genty \& Reyes (1977) criaram $R$. elaeis em fragmentos de folíolo de $E$. guineensis, cujas extremidades foram imersas em parafina, e colocados sobre meio de agar-água, para evitar o ressecamento do folíolo, conseguindo uma duração dos fragmentos de 45 dias. Observaram um período de incubação de 11 dias e um ciclo total de 60 a 70 dias.

Os dados obtidos neste trabalho são bastante diferentes dos verificados por Genty \& Reyes (1977), entretanto não é possível se fazer uma comparação entre os resultados, devido ao fato das espécies serem diferentes assim como pela ausência de informações daqueles autores sobre as condições em que o trabalho foi desenvolvido.

$R$. johnstoni apresentou um ciclo longo se comparado a outros eriofídeos, além de uma fecundidade muito baixa. Contudo, não se pode afirmar que este ácaro não oferece potencial para causar danos econômicos às arecáceas. Deve-se levar em consideração que as fêmeas foram submetidas ao isolamento, não podendo coletar espermatóforos e isto pode influenciar sua reprodução.

Apesar de $R$. johnstoni ter um ciclo longo, as folhas das arecáceas não são substituídas ou caem com frequência. As palmeiras mantêm as folhas fixadas ao estipe, normalmente por mais de um ano. Este longo tempo de permanência, pode promover uma exposição maior da planta ao ácaro e consequentemente maior dano. 


\section{Morfologia}

Os diferentes estágios de desenvolvimento de $R$. johnstoni podem ser observados na Figura 70 (A-F). Os ovos são translúcidos e possuem formato arredondado. Aparentemente, são colados na folha, pois não destacam-se quando manipulados com pincel. Medem aproximadamente $50 \mu \mathrm{m}$ de diâmetro e são frequentemente recobertos por cerosidade.

A ninfa I, a ninfa II e o adulto apresentam o corpo recoberto por cerosidade, medindo aproximadamente 100, 120 e $180 \mu \mathrm{m}$ de comprimento, respectivamente. Logo após eclosão da ninfa I, não se verifica a presença da cera. Entretanto, 24 horas após a eclosão, esta é observada recoberta lateralmente e dorsalmente. Após cada ecdise verifica-se que o estágio subsequente apresenta-se quase sem cerosidade, ficando apenas alguns filamentos de cera sobre o escudo prodorsal, enquanto que a exúvia permanece com o restante da cera. Poucas horas após a ecdise, os ácaros começam a secretar nova cerosidade. Observou-se que com a prática é possivel distinguir, através do tamanho do ácaro e do aspecto da cerosidade o estágio de desenvolvimento do ácaro.

O espermatóforo de $R$. johnstoni foi visualizado através de microscopia eletrônica, apresentando uma cabeça subquadrangular, de aproximadamente $6 \mu \mathrm{m}$ de lado. Esta é presa a um pedúnculo, medindo aproximadamente $6 \mu \mathrm{m}$ comprimento, cuja base é fixada no folíolo (Figura 71).

Segundo Genty \& Reyes (1977) R. elaeis apresenta os ovos normalmente recobertos por densa cerosidade. Estes autores afirmaram que após a oviposição as fêmeas desenvolvem movimentos circulares em torno dos ovos, ficando estes cobertos pela cera, presente lateralmente nas fêmeas. Neste trabalho não foi observado este comportamento. Contudo, a grande maioria dos ovos verificados na colônia apresentavam-se cobertos por filamentos de cera semelhantes ao secretado lateralmente pelos adultos. É possível também que o deslocamento dos ácaros dentro da colônia promova este efeito. 


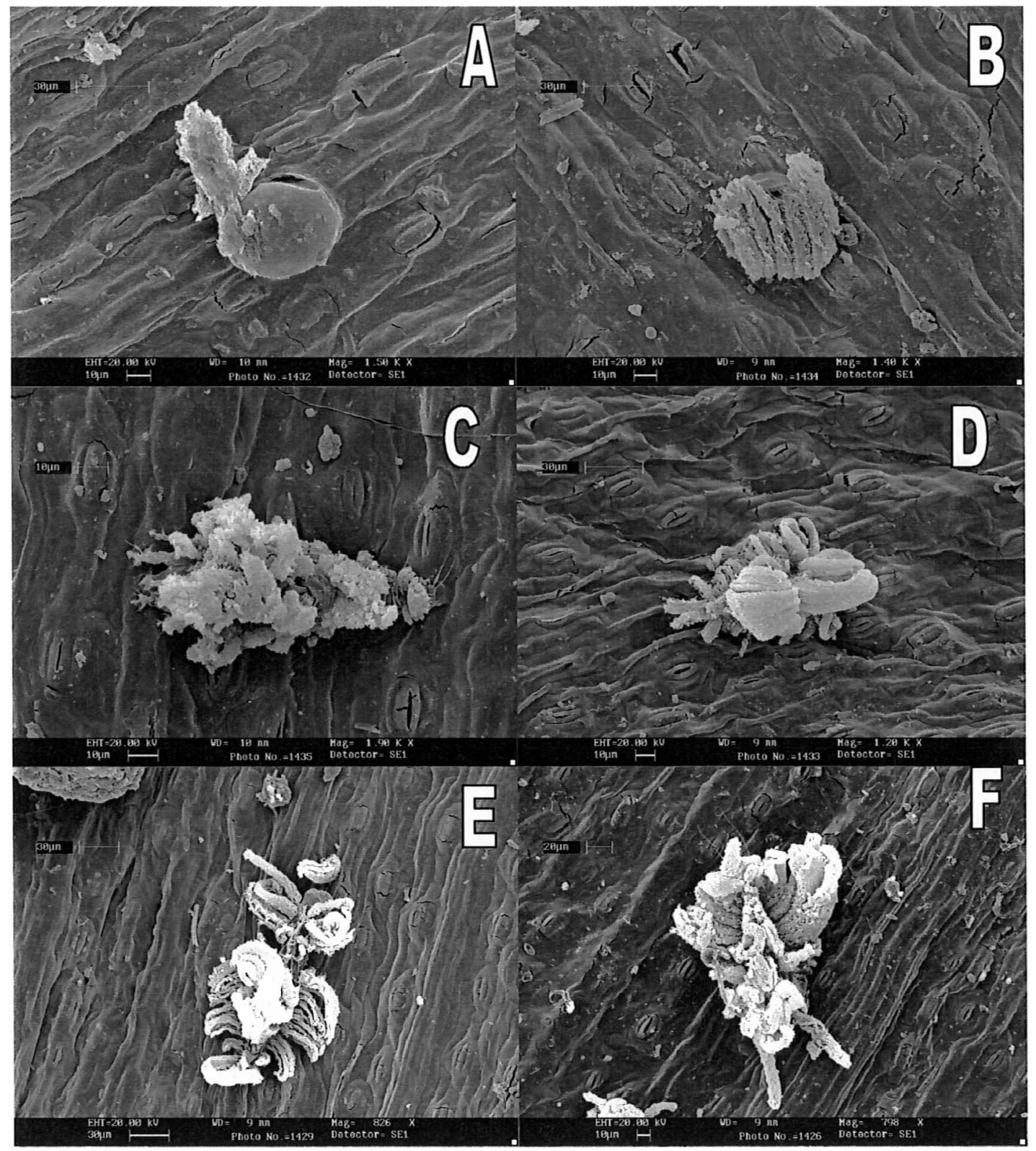

Figura 70. Retracrus johnstoni. A - Ovo sem cera; B - Ovo com cera; C - Ninfa I; D Ninfa II; E - Exúvia; F - Adulto. 


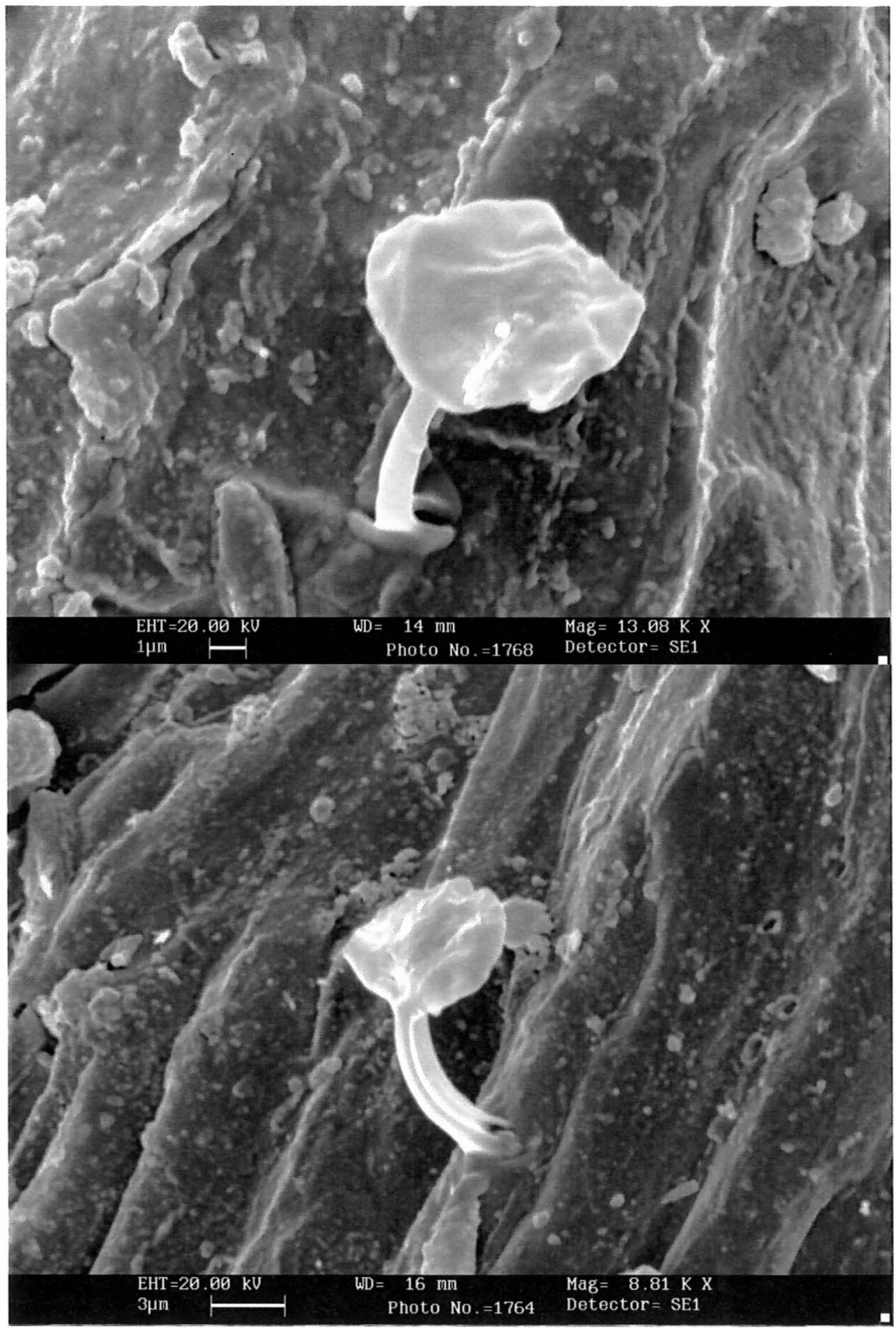

Figura 71. Espermatóforo de Retracrus johnstoni. 
Até o momento, cerca de 20 espécies de eriofídeos tiveram seus espermatóforos estudados. $\mathrm{O}$ espermatóforo apresenta as dimensões da cabeça, pedúnculo, número de espermatozóides por espermatóforo e quantidade depositada por macho variável, conforme a espécie (Oldfield, 1969; Oldfield et al., 1970; Oldfield, 1973; Oldfield \& Newell, 1973a; Oldfield \& Newell, 1973b; Oldfield \& Michalska, 1996).

Os espermatóforos apresentam os espermatozóides sobre a cabeça na forma de um saco (endoespermatóforo) (Oldfield \& Michalska, 1996). Diversos espermatóforos de $R$. johnstoni foram examinados ao microscópio eletrônico, mas não foi possível observar a presença do endoespermatóforo. Talvez, o método de preparação utilizado neste trabalho tenha favorecido a perda desta estrutura durante a manipulação da amostra.

\section{Sintomas de Ataque}

A região da superfície ventral da folha de $S$. romanzoffiana onde se encontram os diferentes estágios de $R$. johnstoni apresenta-se escurecida e com aspecto pulverulento, devido à presença de exúvias dos ácaros. Na superfície superior correspondente, aparecem manchas amareladas, inicialmente claras, que tornavam-se de coloração mais intensa com o decorrer do tempo. Com o desenvolvimento da colônia de ácaros, estas manchas coalescem, provocando um amarelecimento generalizado da folha. Com o passar do tempo, estas secam e caem prematuramente. As figuras 72, 73 e 74 mostram 0 aspecto superior da folha, inferior da folha e pulverulento da colônia, respectivamente.

Genty \& Reyes (1977) estudaram a sintomatologia causada por $R$. elaeis a $E$. guineensis. Observaram manchas nas folhas, inicialmente com aspecto negro, que com 0 tempo tornavam-se amarelo alaranjadas, chagando a coalescer. 


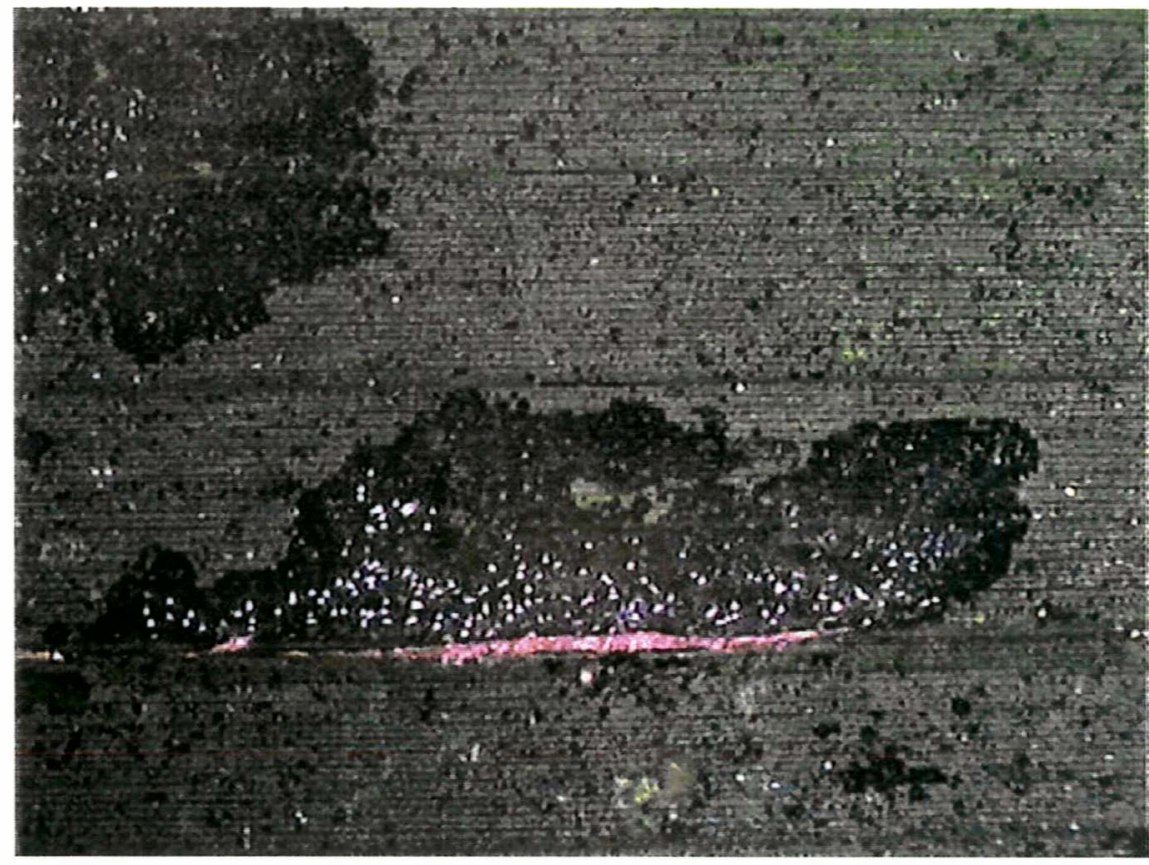

Figura 72. Sintomas provocados por Retracrus johnstoni a face abaxial da folha de Syagris romanzoffiana.

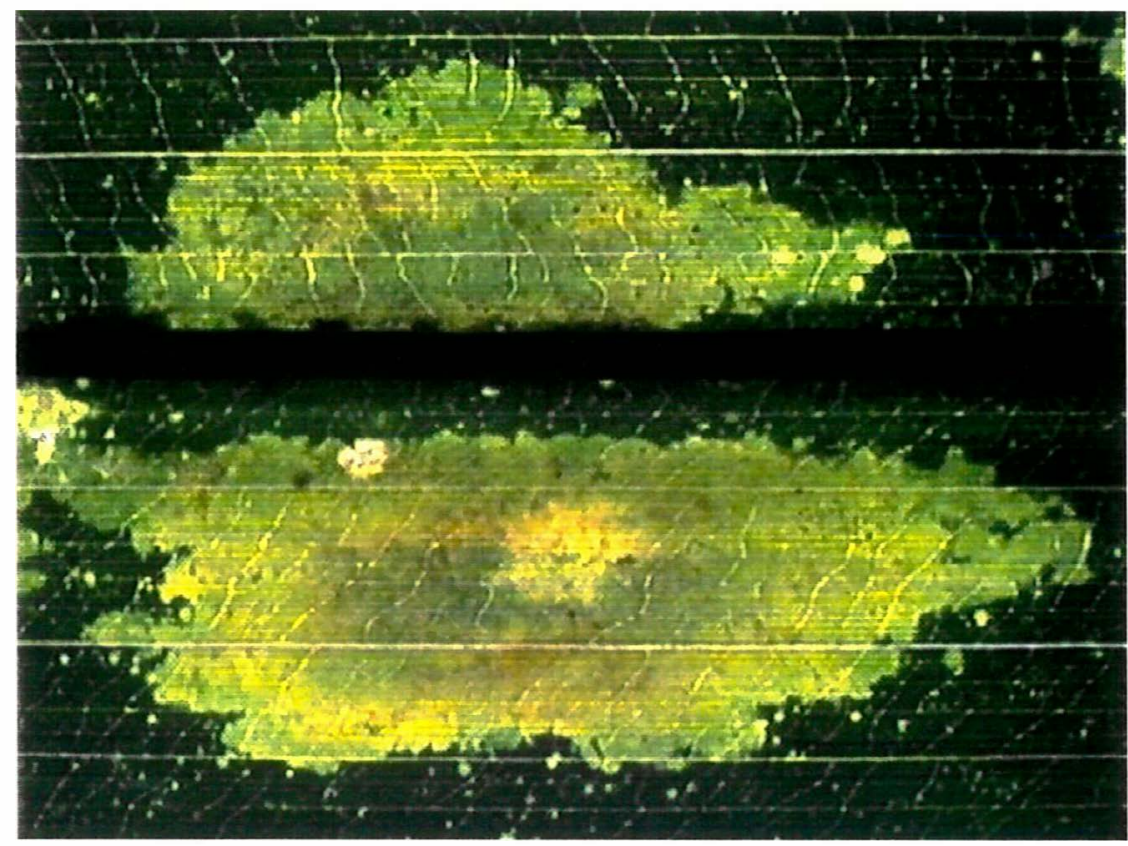

Figura 73. Sintomas provocados por Retracrus johnstoni a face superior da folha de Syagrus romanzoffiana. 


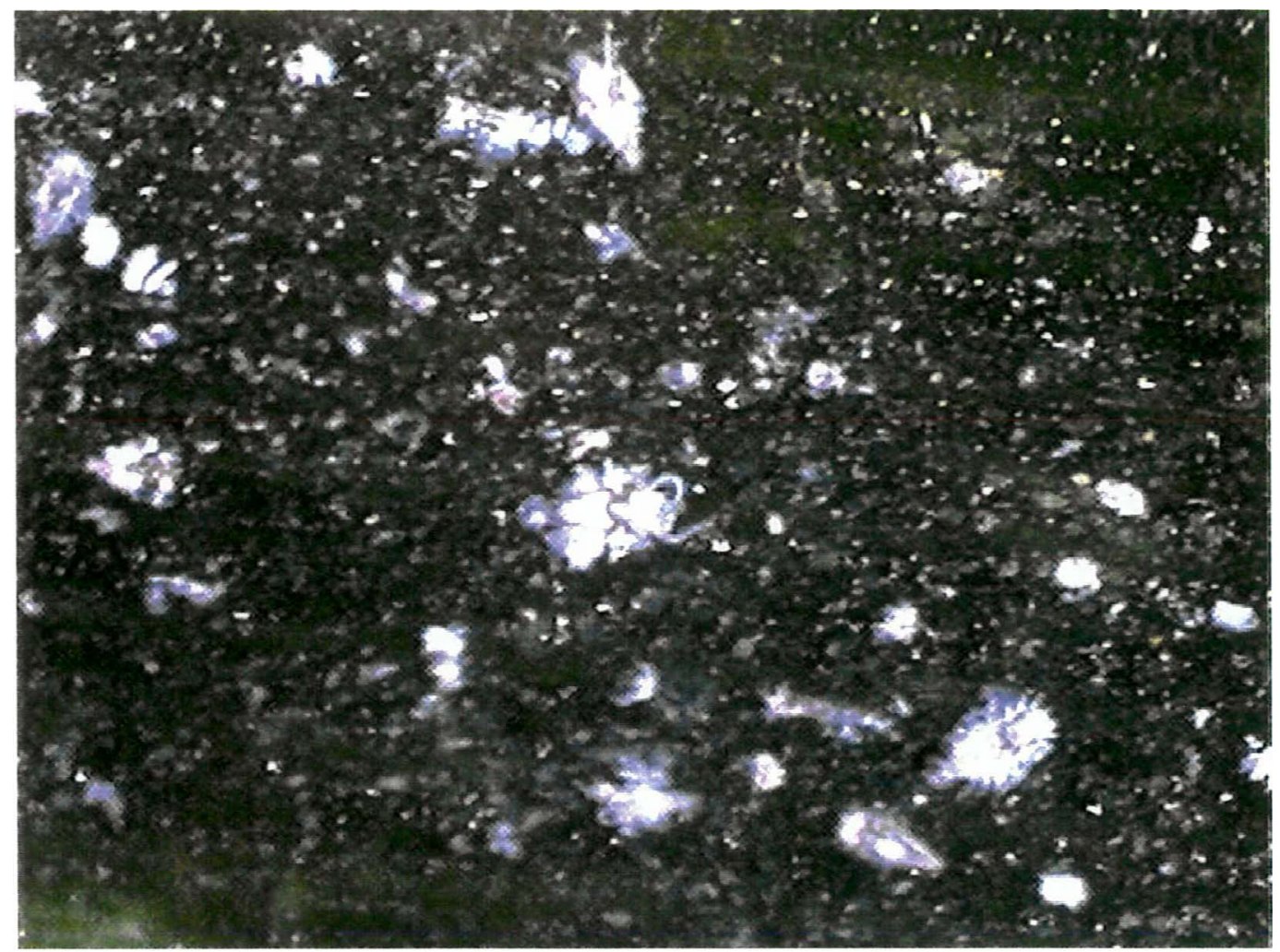

Figura 74. Colônia de Retracrus johnstoni em Syagrus romanzoffiana. 


\subsection{CONCLUSÃO}

1) R. johnstoni apresentou um ciclo longo e baixa fertilidade nas condições estudadas. 


\section{COMPATIBILIDADE REPRODUTIVA DE DUAS POPULAÇÕES DE Iphiseiodes zuluagai (ACARI: PHYTOSEIIDAE)}

\section{RESUMO}

A compatibilidade reprodutiva entre 2 populações identificadas como Iphiseiodes zuluagai Denmark \& Muma foi avaliada, para confirmar se realmente pertenciam à mesma espécie. $\mathrm{O}$ estudo foi conduzido com ácaros de colônias estabelecidas a partir de indivíduos coletados de Citrus sp. em Piracicaba e Syagrus romanzoffiana (Cham.) Glassman em Pariquera-açu, ambas em São Paulo. Estas colônias foram mantidas em laboratório através de uma modificação do método descrito por Zacarias \& Nicolino (1993), a $25 \pm 1^{\circ} \mathrm{C}, 85 \pm 5 \%$ de umidade relativa e 12 horas de fotofase. A compatibilidade reprodutiva foi avaliada através de cruzamentos e retrocruzamentos entre ácaros de cada colônia e observações da fecundidade dos ácaros durante 10 dias. Cruzamentos heterogâmicos e retrocruzamentos produziram descendentes fẻrteis em proporções comparáveis aos cruzamentos homogâmicos. 


\section{REPRODUCVITY COMPATIBILITY BETWEEN TWO POPULATIONS OF Iphiseiodes zuluagai (ACARI: PHYTOSEIIDAE)}

\section{SUMMARY}

The study was done with mites from colonies initiated with individuals collected on Citrus sp. in Piracicaba and Syagrus romanzoffiana (Cham.) Glassman in Pariqueraaçu, both in the state of São Paulo. The colonies were maintained in a laboratory using a modification of the method described by Zacarias \& Nicolino (1993), at $25 \pm 1^{\circ} \mathrm{C}, 85 \pm 5 \%$ of R.H. and $12 \mathrm{~h}$ ligth: $12 \mathrm{~h}$ dark. The reproductive campatibility was evaluated through crosses and back-crosses between mites of each colony and observations on their fecundity during 10 days. The heterogamic crosses and the back-crosses resulted in fertile progeny in proportions comparable to the homogamic crosses. 


\subsection{INTRODUÇÃO}

Os fitoseídeos correspondem à família de ácaros predadores que mais é citada na literatura como inimigos naturais de ácaros fitófagos. Sua importância foi revelada a partir de meados deste século, mediante constatações da influência destes organismos no controle de populações de ácaros fitófagos (McMurtry et al., 1970). Entretanto, as frequentes alterações provocadas pelo homem ao meio ambiente, como desmatamento, monocultivo e uso de agrotóxicos, têm simplificado demasiadamente a diversidade dos ecossistemas. Estas ações implicam frequentemente no desfavorecimento de inimigos naturais como os fitoseídeos.

Essas alterações podem ser minimizadas através de práticas que restaurem a fauna de inimigos naturais em ecossistemas alterados. Neste sentido, as áreas de vegetação nativa, como as matas, representam uma fonte importante de diversidade biológica, podendo fornecer material para ser introduzido em áreas desequilibradas ou através do consorcio de culturas comerciais com plantas nativas exploradas comercialmente. Um exemplo disto, têm sido o plantio comercial de arecáceas nativas do Brasil, como Euterpe edulis Mart. (juçara), Euterpe oleracea Mart. (açai) ou Bactris gasipaes Kunth. (pupunha), com outras culturas perenes.

A taxonomia clássica, utilizada na identificação das espécies, nem sempre consegue solucionar todos os problemas de identificação. Dúvidas que surgem devido à semelhança morfológica entre espécies próximas podem ser melhor esclarecidas através de testes biológicos. Nesse sentido, a biossistemática tem como objetivo elucidar dúvidas entre taxa (Furtado, 1997). No Brasil, suspeita-se que os espécimes identificados como I. zuluagai possam pertencer a mais de uma espécie, devido à grandes variações morfológicas encontradas em espécimes coletados de diferentes regiões (Lofego, 1998).

Diversos trabalhos têm sido realizados com ácaros da família Phytoseiidae para o esclarecimento da incompatibilidade reprodutiva entre populações aparentemente pertencentes à mesma espécie ( Croft, 1970; McMurtry, 1980; Congdon \& McMurtry, 1985). Em alguns casos, verifica-se que as populações estudadas pertencem a espécies 
diferentes (Braun et al., 1993), em outros casos verifica-se que a reprodução é afetada devido a outros fatores como pela presença de microorganismos simbiontes (Hoy \& Cave, 1988).

I. zuluagai foi a espécie mais frequente e abundante nas arecáceas amostradas neste trabalho (Capítulo 5). Esta espécie também é bastante comum em pomares de citros (Gravena, 1990; Chiavegato, 1991), sendo atribuída a ela um importante papel no controle de ácaros fitófagos nessa cultura. Este trabalho foi realizado para verificar se populações identificadas como I. zuluagai, provenientes de pomares de Citrus sp. e de Syagrus romanzoffiana (Cham.) Glassman, ambas do Estado de São Paulo, pertencem a mesma espécie, e assim fornecer subsídios para avaliar se as arecáceas presentes em matas nativas podem servir como reservatório de ácaros predadores para outras culturas comerciais.

\subsection{MATERIAL E MÉTODOS}

Espécimes de 1 . zuluagai foram coletados em plantas de Citrus sp. em Piracicaba e em Syagrus romanzoffiana (Cham.) Glassman em Pariquera-açu, ambas no Estado de São Paulo. Uma colônia com ácaros de cada localidade foi estabelecida em laboratório utilizando-se a metodologia descrita por Zacarias \& Nicolino (1993). A única alteração feita no método foi a substituição das bandejas plásticas por placas de Petri. $\mathrm{O}$ alimento fornecido aos ácaros foi pólen de taboa (Typha angustifolia L.). As colônias foram mantidas em câmaras de criação a $25 \pm 1^{\circ} \mathrm{C}, 85 \pm 5 \%$ de umidade relativa e 12 horas de fotofase.

Uma amostra de 10 fêmeas de cada colônia, foi coletada aleatoriamente, para estudo de morfologia. Os ácaros foram montados em lâmina para microscopia com líquido de Hoyer e observados ao microscópio óptico para medição de caracteres morfológicos relevantes para a identificação da espécie.

Deutoninfas obtidas das colônias foram isoladas em unidades de criação, constituídas por uma caixa plástica de $2,6 \mathrm{~cm}$ de diâmetro e $1,0 \mathrm{~cm}$ de altura, com tampa telada, que permitia a passagem do ar por uma abertura de $1,5 \mathrm{~cm}$ de diâmetro. $O$ fundo 
de cada caixa foi forrado com um disco de papel de filtro umedecido com água destilada, sobre o qual colocou-se um disco de folha de feijão-de-porco (Canavalia ensiformes D.C.) com pólen de taboa. Após a emergência das fêmeas e machos, foram formados 10 casais e sempre que ocomia a morte do macho, este foi substituído. Os ácaros foram transferidos diariamente para novas unidades de criação, observando-se a oviposição diária durante 10 dias.

Em cada cruzamento e retrocruzamento foram utilizados 10 casais. Os ovos obtidos dos cruzamentos foram mantidos isoladamente $\mathrm{e}$ utilizados para os retrocruzamentos e determinação da razão sexual. Utilizou-se sempre que possivel o mesmo número de repetições nos retrocruzamentos.

\subsection{RESULTADOS E DISCUSSĀO}

Os valores das medições dos parâmetros morfológicos de I. zuluagai para as populações de Citrus sp. e Arecaceae e do holótipo (Denmark \& Muma, 1972) são apresentados na Tabela 2. Foram muito pequenas as diferenças entre estas populações em relação aos parâmetros estudados. Também, as diferenças entre as populações avaliadas e do holótipo foram pequenas, indicando que as populações estudadas pertencem à espécie $I$. zuluagai .

Todas as fêmeas dos cruzamentos homogâmicos ovipositaram, e a oviposição média foi próxima de 1,0 ovo/fềmea/dia (Tabela 3). A razão sexual da progênie resultante destes cruzamentos foi $50 \%$ de fềmeas para Citrus sp. e $82 \%$ para fềmeas de Arecaceae. Nos cruzamentos heterogâmicos, a maioria das fềmeas ovipositou e a oviposição média diária foi semelhante aos valores obtidos nos cruzamentos homogâmicos. A razão sexual dos cruzamentos heterogâmicos também apresentou-se semelhante aos cruzamentos homogâmicos ( 42 a $80 \%$ de fềmeas).

Os retrocruzamentos homogâmicos e heterogâmicos sempre resultaram em niveis consideráveis de oviposição. Pelo menos $75 \%$ das fềmeas de cada retrocruzamento ovipositaram, e a oviposição média variou de 1,1 a 1,7 ovos/fêmea/dia. A razão sexual da progenie obtida nos retrocruzamentos foi sempre maior ou igual a $47 \%$ de fềmeas, 
exceto em um caso ( $38 \%$ quando fêmeas resultantes do cruzamento de fềmeas de Citrus sp. e machos de Arecaceae foram cruzadas com machos de Citrus sp.).

Tabela 2. Médias de parâmetros morfológicos, expressos em micrômetros, de fềmeas de 2 populações identificadas como Iphiseiodes zuluagai, coletadas em Citrus sp. e Arecaceae no Estado de São Paulo (1999).

\begin{tabular}{lccc}
\hline \multirow{2}{*}{ Parâmetros } & Holótipo & \multicolumn{2}{c}{ Populações } \\
Morfológicos & (Denmark \& Muma) & Piracicaba & Pariquera-açu \\
& & Citus sp. (n=10) & Arecaceae (n=10) \\
\hline CED & 330 & $353(341-363)$ & $345(336-356)$ \\
LED & 237 & $268(259-286)$ & $271(264-286)$ \\
j1 & 22 & $23(22-24)$ & $23(22-24)$ \\
j3 & 26 & $30(27-32)$ & $30(30-32)$ \\
s4 & 97 & $107(100-111)$ & $108(105-11)$ \\
z5 & 110 & $109(105-113)$ & $112(103-116)$ \\
SgeI & $*$ & $46(43-49)$ & $48(46-49)$ \\
SgeII & $*$ & $31(30-32)$ & $32(30-32)$ \\
SgeIII & $*$ & $47(46-49)$ & $46(43-49)$ \\
StiIII & $*$ & $27(27-27)$ & $26(24-27)$ \\
SgeIV & 95 & $87(84-95)$ & $87(84-92)$ \\
StiIV & 55 & $51(49-54)$ & $54(51-54)$ \\
StIV & 35 & $36(32-38)$ & 34 \\
\hline
\end{tabular}

* Medidas não fornecidas pelos autores.

A presença de ovos deformados só foi verificada em um cruzamento, mesmo assim com uma percentagem muito baixa ( $4 \%$ de ovos deformados).

Os níveis de oviposição média diária verificados neste trabalho foram muito semelhantes àqueles obtidos por Yamamoto \& Gravena (1996) para uma população de I. zuluagai de Jaboticabal, Estado de São Paulo, sob condições climáticas próximas às empregadas neste trabalho. Foram, entretanto, maiores que aqueles obtidos por Reis et al. (1998), sob aproximadamente as mesmas condições, para uma população de $I$. 
Tabela 3. Cruzamentos e retrocruzamentos entre duas populações identificadas como Iphiseiodes zuluagai, coletadas em Citrus sp. e Arecaceae no Estado de São Paulo (1999).

\begin{tabular}{lcccccc}
\hline Cruzamentos & Número de & $\%$ de fềmeas & Número total & Número de & $\%$ de ovos & Razão Sexual \\
Fêmea X macho & Casais & (oviposição) & de ovos & Ovos/fémea/dia* & deformados & (fềmeas \%)
\end{tabular}

Homogâmico (Piracicaba)

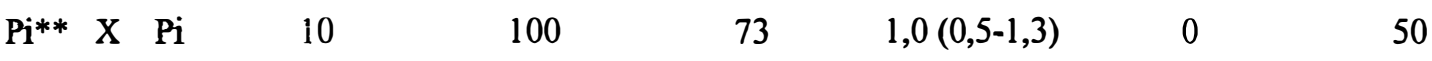

Retrocruzamentos

$\begin{array}{lllllll}\text { PiPi X Pi } & 8 & 100 & 71 & 1,4(0,6-1,5) & 0 & 52 \\ \text { Pi X PiPi } & 8 & 78 & 40 & 1,1(0,9-1,4) & 0 & 48\end{array}$

Homogâmico (Pariquera-açu)

$\mathrm{Pa}^{* * * X} \mathrm{~Pa} \quad 10$

$81 \quad 1,2(0,7-1,6) \quad 0 \quad 82$

Retrocruzamento

$\mathrm{PaPa} X \mathrm{~Pa} \quad 10$

$\mathrm{Pa} \mathrm{X} \mathrm{PaPa}$

$10 \quad 90$

100

74

$1,2(1,0-1,5)$

88

Heterogâmico

Pi X Pa

10

70

61

$1,2(0,8-1,7)$

94

Retrocruzamentos

$\mathrm{PiPa} \times \mathrm{Pi} \quad 3$

$\begin{array}{llll}P i P a & X & P a & 5\end{array}$

100

36

$1,4(1,1-1,9)$

38

$\mathrm{Pi} \quad \mathrm{X}$ PiPa 7

100

67

$1,6(1,4-1,7)$

80

$\mathrm{Pa} X \mathrm{PiPa} \quad 7$

86

23

$1,0(0,6-1,7)$

47

100

62

$1,4(1,0-1,7)$

56

Heterogâmico

\section{Pa X Pi 10}

100

82

$1,2(0,9-1,6)$

80

\section{Retrocruzamentos}

\begin{tabular}{lllll}
$\mathrm{PaPi}$ & $\mathrm{X}$ & $\mathrm{Pi}$ & 6 & 100 \\
$\mathrm{PaPi}$ & $\mathrm{X}$ & $\mathrm{Pa}$ & 10 & 100 \\
$\mathrm{Pi}$ & $\mathrm{X} \mathrm{PaPi}$ & 4 & 75 \\
$\mathrm{~Pa}$ & $\mathrm{X} \mathrm{PaPi}$ & 4 & 75 \\
\hline
\end{tabular}

100

$82 \quad 1,7(1,6-2,0)$

54

00

100

$1,4(1,1-1,8)$

76

75

16

$1,1(0,8-1,5)$

58

* média ( valor mínimo-valor máximo); **Pi (Piracicaba); ***Pa (Pariquera-açu). 
zuluagai de Lavras, Estado de Minas Gerais.

Embora as populações utilizadas para este estudo sejam oriundas de locais e ecossistemas bastante diferentes, os resultados obtidos mostram não ter havido incompatibilidade reprodutiva entre os ácaros destas populações, sendo estas pertencentes a uma mesma espécie. Este é um indicativo de que as populações nativas de I. zuluagai podem ser manejadas de modo a serem utilizadas no controle de ácaros em plantios de espécies nativas de arecáceas e de outras culturas.

\subsection{CONCLUSÃO}

1) As populações de fitoseídeos oriundas de plantios de Citrus sp. de Piracicaba e de Syagrus romanzoffiana de Pariquera-açu pertencem à mesma espécie, identificadas como I. zuluagai. 


\section{REFERÊNCIAS BIBLIOGRÁFICAS}

ALTIERE, M.A. Biodiversity and pest managemente in agroecosystems. New York: Food Products Press, 1994. 185p.

AMARAL, V. Notas sobre ácaros nasais com a descrição de duas novas espécies: Ptilonyssus zeferinoi $\mathrm{n}$.sp. e Sternostoma clementei $\mathrm{n} . \mathrm{sp}$. (Acarina: Rhinonyssidae). Lista das espécies descritas no Brasil e seus hospedeiros. Arquivos do Instituto Biológico, v.35. p.107-126, 1968.

AMRINE JR.; MANSON, D.M.C. Preparation, mouting and description study of Eriophyọid mites. In: LINDQUIST. E.E.; SABELIS, M.W.; BRUIN, J. (Ed.). Eriophyoid mites: their biology, natural enemies and control. Amsterdan: Elsevier, 1996. p.383-396.

AMRINE, J.W. Jr.; STASNY, T.A. Catalog of the Eriophyoidea (Acarina: Prostigmata) of the World. Michigan: Indira Publishing House, 1994. 798p.

ANDRÉ, H.M. A generic revision of the family Tydeidae (Acari: Actinedida). IV. Generic descriptions, keys and conclusions. Bulletin et Annales de la Societe Royale Belge d'Entomologie, v.116, p. 103-168, 1980.

APONTE, O.; McMURTRY, J.A. Revision of the genus Iphiseiodes DeLeon (Acari: Phytoseiidae). International Journal of Acarology, v.21, n.3, p.165-183, 1995. 
AQUINO, M.L.N.; ARRUDA, G.P. O agente causal da "necrose do olho do coqueiro" em Pernambuco. Recife: IPA, 1967. 33p.

ARAGÃO, H.B. Ixodidas brasileiros e de alguns países limítrofes. Memórias do Instituto Oswaldo Cruz, v.31, p.759-843, 1936.

ATHIAS-HENRIOT, C. Contribution a la connaissance du genre Typhlodromus Scheuten (Acariens Parasitiformes, Phytoseiidae). Description de deux especies nouvelles dÁlgerie et cle des especies du groupe finlandicus. Reveu De Pathologie Vegetale Et D'Entomologie Agricole De France, v.37, n.2, p.179-186, 1958.

BAKER, E.W. A review of the mites of the family Cheyletidae in the United States National Museum. Proceedings of the United States National Museum, v.99, p.267-320, 1949.

BAKER, E.W. A reviw of the genera of the family Tydeidae. Advances in Acarology Cornell University Press, v.2, p.95-133, 1965.

BAKER, E.W.; TUTTLE, D.M. The false spider mites of México (Tenuipalpidae: Acari). Thecnical Bulletin, v.1706, p.1-237, 1987

BANKS, N. Descriptions of some new mites. Proceedings Entomological Society of Washington, v.7, p.133-142, 1905.

BANKS, N. The Acarina or mites. A review of the group for the use of economic entomologist. United States Department of Agriculture, v.108, p.1-153, 1915.

BARBOSA, A.M.M. Pupunha (Bactris gasipaes). In: ENCONTRO SOBRE PRODUÇÃO DE PALMITO, Piracicaba, 1983. Piracicaba: Calq, 1993. p.8-11. 
BLOMMERS, L. Species of the genus Amblyseius Berlese, 1914, from Tamatave, east Madagascar (Acarina: Phytoseiidae). Bulletin Zoologisch Museum Universiteit Van Amsterdam, v.3, p.143-155, 1974.

BOLLAND, H.R.; GUTIERREZ, J.; FLECHIMANN, C.H.W. World catalog of the spider mites family (Acari: Tetranychidae). Boston: Brill, 1998. 392p.

BRAUN, A.R.; MESA, N.C.; CUELLAR, M.E.; MELO, E.L.; MORAES, G.J. de. Biosystematics of phytoseiid mites (Acari: Phytoseiidae) associated with cassava. Experimental and Applied Acarology, v.17, p.205-213, 1993.

CANESTRINI, G.; FANZAGO, F. Nuovi acari italiani (ser. 2). Atti Societá VenetoTrentina Scienze Naturali. v.5, n.1, p.99-111, 1876.

CANIZO, J.A. del. Palmeras. Madri: Mundi-Prensa, 1991. 289p.

CASTRO, M.P. Reestruturação genérica da família Rhinonyssidae Vitzthum, 1935 (Acari: Mesostigmata, Gamasides) e descrição de algumas espécies novas. Arquivos do Instituto Biológico, v.18, p.253-284, 1948.

CHANT, D.A. Immature and adult stages of some British Phytoseiidae BERL., 1916 (Acarina). Journal of the Linneaun Society of London, Zoology, v.43, p.599$643,1958$.

CHANT, D.A. Phytoseiid mites (Acarina: Phytoseiidae). Part I. Bionomics of seven species in southeastern England. Part II. A taxonomic review of the family Phytoseiidae, with descriptions of thirty-eight new species. Canadian Entomologist, Suppl. 12, p.1-166, 1959. 
CHANT, D.A.; BAKER, E.W. The Phytoseiidae (Acarina) of Central America. Memoirs of the Entomological Society of Canada, v.41, p.1-56, 1965.

CHANT, D.A.; HANSELL, R.I.C. The genus Amblyseius (Acarina: Phytoseiidae) in Canada and Alaska. Canadian Journal of Zoology, v.49, n.5, p.703-758, 1971.

CHANT, D.A.; McMURTRY, J.A. A review of the subfamilies Phytoseiidae and Typhlodrominae and Typhlodrominae (Acari: Phytoseiidae). International Journal of Acarology, v.20, n.4, p.223-310, 1994.

CHANT, D. A.; YOSHIDA-SHAUL, E. A world review of the soleiger species group in the genus Typhlodromus Scheuten (Acari: Phytoseiidae). Canadian Journal of Zoology, v.60, p.3021-3032, 1982.

CHANT, D.A.; YOSHIDA-SHAUL, E. A world review of five similar species groups in the genus Typhlodromus Scheuten: Part I. The regularis and theodoliticus groups (Acarina: Phytoseiidae). Canadian Journal of Zoology, v.61, p.1032-1040, 1983a.

CHANT, D.A.; YOSHIDA-SHAUL, E. A world review of five similar species groups in the genus Typhlodromus Scheuten. Part II. The conspicuus and cornus groups (Acarina: Phytoseiidae. Canadian Journal of Zoology, v.61, p.1041- 1057, 1983 b.

CHANT, D.A.; YOSHIDA-SHAUL, E. A world review of the occidentalis species group in the genus Typhlodromus Scheuten (Acarina: Phytoseiidae). Canadian Journal of Zoology, v.62, p.1860- 1871, 1984.

CHANT, D. A.; YOSHIDA-SHAUL, E. A world review of the ecclesiasicus species group in the genus Typhlodromus Scheuten (Acarina: Phytoseiidae). Canadian Journal of Zoology, v.64, p.447-466, 1986. 
CHANT, D.A.; YOSHIDA-SHAUL, E. Adult dorsal setal pattems in the family Phytoseiidae (Acari: Gamasina). International Journal of Acarology, v.15, p. 219-233, 1989.

CHANT, D.A.; YOSHIDA-SHAUL. E. Adult ventral setal pattems in the family Phytoseiidae (Acari: Gamasina). Internaltional Journal of Acarology, v.17, n.3, p.187, 1991.

CHAUDHRI, W.M. Six new species of mites of the genus Amblyseius (Phytoseiidae) from Pakistan. Acarologia, v.10, p.550-562, 1968.

CHIAVEGATO, L.G. Ácaros da cultura dos citros. In: RODRIGUES, O. (Ed.) Citricultura brasileira. Campinas: Fundação Cargil, 1991, v.2., p.469-491.

CONGDON, B.D., McMURTRY, J.A. Biosystematics of Euseius on Califomia citrus and avocado with the description of a new species (Acari: Phytoseiidae). International Journal of Acarology, v.11, p.23-30, 1985.

CROFT, B.A. Comparative studies on four strains of Typhlodromus occidentalis (Acarina: Phytoseiidae). I. Hybridization and reproductive isolation studies. Annals of the Entomological Society of America, v.63, n.6, p.1559-1563, 1970.

CUENCA, M.A.G. Importância econômica do Coqueiro. In: FERREIRA, J.M.S.; WARWICK, D.R.N.; SIQUEIRA, L.A. (Ed.). Cultura do coqueiro no Brasil. Aracaju: EMBRAPA, 1994. p. 1-65.

DANESHVAR, H.; DENMARK, H.A. Phytoseiids of Iran (Acarina: Phytoseiidae). International Journal of Acarology, v.8, p.3-14, 1982. 
DeLEON, D. Four new acarina in the family Tarsonemidae. The Florida Entomologist, v.39, p.105-112, 1956.

DeLEON, D. The genus Tenuipalpus in Mexico (Acarina: Tenuipalpidae). The Florida Entomologist, v.40, p.81-93, 1957.

DeLEON, D. Four new Typhlodromus from southern Florida (Acarina: Phytoseiidae). The Florida Entomologist, v.41, p.73-76, 1958.

DeLEON, D. Eight new Amblyseius from Mexico with collection notes on two other species (Acarina: Phytoseiidae). The Florida Entomologist, v.44, n.2, p.85-91, 1961.

DeLEON, D. The cervix of some Phytoseiid type specimes (Acarina: Phytoseiidae). Acarologia, v.4, p.174-176, 1962.

DeLEON, D. Phytoseiid mites from Puerto Rico with descriptions of new species (Acarina: Mesostigmata). The Florida Entomologist, v.48, n.2, p.121-131, 1965a.

DeLEON, D. Ten new species of Phytoseius (Pennaseius) from Mexico, Trinidad, and British Guiana with a key to species Acari: Phytoseiidae). Entomological News, v.76, n.1, p.11-21, 1965 b.

DeLEON, D. Phytoseiidae of British Guyana with keys to species (Acarina: Mesostigmata). Studies on the Fauna of Suriname and other Guyanas, v.8, p.81-102, 1966.

DeLEON, D. Some mites of the Caribbean Area. Part I. Acarina on plants im Trinidad, West Indies. Kansas: Allen Press, 1967. 66p. 
DENMARK, H.A. Revision of the genus Phytoseius Ribaga, 1904 (Acarina: Phytoseiidae). Florida Department Agriculture Bulletin, v.6, p.1-105, 1966.

DENMARK, H.A. Revision of Galendromus Muma, 1961 (Acarina: Phytoseiidae). International Journal of Acarology, v.8, p.133-167, 1982.

DENMARK, H.A.; ANDREWS, K.L. Plant associated Phytoseiidae of El Salvador, Central America (Acarina: Mesostigmata). The Florida Entomologist. v.64, n.1, p.147-158, 1981 .

DENMARK, H.A.; EVANS, G.A.; AGUILAR, H.; VARGAS, C.; OCHOA, R. Phytoseiidae of Central America (Acari: Mesostigmata). Michigan: Indira Publishing House, 1999. 125p.

DENMARK, H.A.; MUMA, M.H. Some phytoseiid mites of Paraguay (Phytoseiidae: Acarina). The Florida Entomologist, v.53, n.4, p.219-227, 1970.

DENMARK, H.A.; MUMA, M.H. Some Phytoseiidae of Colômbia (Acarina: Phytoseiidae). The Florida Entomologist, v.55, n.1, p.19-29, 1972.

DENMARK, H.A.; MUMA, M.H. Phytoseiid mites of Brazil (Acarina: Phytoseiidae). Revista Brasileira de Biologia, v.33, p.235-276, 1973.

DENMARK, H.A.; MUMA, M.H. Phytoseiidae of Jamaica, an annotated list (Acari: Mesostigmata). International Journal of Acarology, v.41, n.1, p.1-22, 1978.

DENMARK, H.A.; MUMA, M.H. A revision of the genus Amblyseius Berlese, 1914 (Acari: Phytoseiidae). Ocasional Papers of the Florida State Collection of Arthropods, v.4, p.1-149, 1989. 
DENMARK, H.A.; SCHICHA, E. Revision of the genus Phytoseiulus Evans (Acarina: Phytoseiidae). International Journal of Acarology, v.9, p.27-35, 1983.

EHARA, S. Some predatory mites of the genera Typhlodromus and Amblyseius from Japan (Phytoseiidae). Acarologia, v.1, p.285-295, 1959.

EHARA, S. Some mites associated with plants in the state of São Paulo, Brazil, with a list of plant mites of South America. Japanese Journal of Zoology, v.15, n.2, p.129-150, 1966.

El-BENHAWY, E.M. Description of some unknown phytoseiid mites from Brazil (Mesostigmata: Phytoseiidae). Acarologia, v.20, n.4, p.477-484, 1978.

El-BENHAWY, E.M. Description of some phytoseiidae mites from Brazil (Acarina: Phytoseiidae). Acarologia, v.25, p.125-144, 1984.

EVANS, G.O. On a new predatory mite of economic importance. Bulletin Entomological Research, v.43, p.397-401, 1952.

EVANS, R.J. Systematics of Cryosophila (Palmae). Systematic Botanic Monography, v. 46, p.1-70, 1995.

FERES, R.J.F.; MORAES, G.J. Phytoseiid mites (Acari: Phytoseiidae) from woody areas in the State of São Paulo, Brazil. Systematic and Applied Acarology, v.3, p.125-132, 1998.

FERREIRA, L.G. S. Pupunha (Bactris gasipaes H.B.K.) In: COORDENADORIA DE ASSISTÊNCIA TÉCNICA INTEGRAL. Manual técnico das culturas. Campinas, 1997. p.317-331. 
FLECHTMANN, C.H.W. Phytoseiidae do Estado de São Paulo (Acarina: Mesostigmata). Anais da Escola Superior de Agricultura "Luiz de Queiroz", v.24, p.247-248, 1967.

FLEChTMANN, C.H.W. Elementos de acarologia. São Paulo: Nobel, 1975. 344p.

FLEChTMANN, C.H.W. Ácaros de importância agrícola. São Paulo: Nobel, 1983. $189 \mathrm{p}$.

FLECHTMANN, C.H.W. Cocos weddelliana Wendl. (Palmae: Arecaceae), a new host plant for Eriophyes guerreronis (Keifer, 1965) (Acari: Eriophyidae) in Brazil. International Journal of Acarology, v.15, p.241, 1989.

FLECHTMANN, C.H.W. Amrineus cocofolius n.g., n.sp. (Acari: Eriophyidae) from Brazil. International Journal of Acarology, v.20, n.1, p.57-59, 1994.

FLECHTMANN, C.H.W. Mite (Arthropoda: Acari) associates of palms (Arecaceae) in Brasil. II. Redescription of Amrineus cocofolius Flechtmann, 1994 (Acari: Eriophyiodae). International Journal of Acarology, v.23, p.195-197, 1997 a.

FLECHTMANN, C.H.W. Mite (Arthropoda: Acari) associates of palms (Arecaceae) in Brazil. III. Eutetranychus nomurai n.sp. (Tetranychidae) from Attalea phalerata Mart. International Journal of Acarology, v.23, p.269-273, 1997b.

FLECHTMANN, C.H.W. Mite (Arthropoda: Acari) associats of palms (Arecaceae) in Brasil. IV. Description of two new species in the family eriophyidae. International Journal of Acarology, v.24, n.2, p.113-117, 1998. 
FLECHTMANN, C.H.W.; MORAES, G.J. de. Biodiversidade de ácaros no Estado de São Paulo. In: BRANDÃO, R.F.; CANCELLO, E.M. (Ed.). Biodiversidade do Estado de São Paulo, Brasil: síntese do conhecimento ao final do século XX, 5: invertebrados terrestres. São Paulo: FAPESP, 1999. Cap.5, p.58-63.

FLECHTMANN, C.H.W.; SANTANA, D.L.Q. Ocorrência de Notostrix attenuata Keifer (Acari: Eriophyidae) em coqueiros no Brasil. In: CONGRESSO BRASILEIRO DE ENTOMOLOGIA, 16., Salvador, 1997. Resumos. Salvador: SEB, 1997. p.40.

FURIA, L.R.R. Características e usos de juçara (Euterpe edulis). In: ENCONTRO SOBRE PRODUÇÃO DE PALMITO, Piracicaba, 1993. Piracicaba: Calq, 1993. p.1-3.

FURTADO, I.P. Biossistemática e biologia de espécies de Euseius (Acari: Phytoseiidae) associados à mandioca. Piracicaba, 1997. 105p. Dissẹtação (mestrado) - Escola Superior de Agricultura "Luiz de Queiroz", Universidade de São Paulo.

GARMAN, P. New species belonging to the genera Amblyseius and Amblyseiopsis with keys to Amblyseius, Amblyseiopsis, and Phytoseiulus. Annals of the Entomological Society of America, v.51, p.69-79, 1958.

GASTON, K.J. What is biodiversity. In: GASTON, K.J. (Ed.). Biodiversity: a biology of numbers and difference. Massachussetts: Blackwell Science, 1996. p.1-9.

GEIJSKES, D.C. Beiträge zur Kenntnis der europäischen Spinnmilben (Acari, Tetranychidae), mit besonderer Berücksichtigung der niederländischen. Arten. Meded. LanbHoogesch. Wageningen, v.42, n.4, p.1-68, 1939. 
GEMTCHUJNICOV, I.D. Manual de taxonomia vegetal. São Paulo: Ceres, 1976. 368 p.

GENTY, P; REYES, E. Un nouvel acarien du palmier à huile: 1'Eriophyidae "Retracrus elaeis Keifer”. Oléagineux, v.32, n.6, p.255-260, 1977.

GOMELAURI, L.A. New phytoseiid mites of the family Phytoseiidae (Berlese) from East Georgia. Bulletin Academic Science Georgian Soviet Socialist Republic Zoology, v.49, n.3, p.701-706, 1968.

GONZALES, R.H. Revision of the Brevipalpus phoenicis "Complex" with descriptions of new species from Chile and Thailand (Acarina: Tenuipalpidae). Acarologia, v.17, p.81-91, 1975.

GRAVENA, S. Manejo de pragas dos citros na atualidade. In: FERNANDES, O.A.; BORTOLI, S.A. de; CORREIA, A.C.B. Manejo integrado de Pragas e nematóides. Jaboticabal: FUNEP, 1990. 253p.

HARRIES, H.C. The evolution, dissemination and classification of Cocos nucifera L. The Botanical Review, v.44, n.3, p.265-307, 1978.

HENDERSON, A.; GALEANO, G.; BERNAL, R. Field guide to the palms of the Americas. Princeton: Princeton University Press, 1995. 352p.

HIRSCHMANN, W. Gangsystematik der Parasitiformes. Acarologie Schriftenreihe fur vergleichende Milbenkunde, Hirschmann-Verlag, Furth/Bay. v.5, p.1-80, 1962. 
HONG, X.Y. Knorella Thailandica, a new name for Knorella bambusae Chandrapatya and a key to world species of Knorella (Acari: Eriophyidae). Systematic and Applied Acarology, v.1, p.205-206, 1996.

HOY, M.A.; CAVE, F.E. Premating and postmating isolation among populations of Metaseiulus occidentalis (Nesbit) (Acarina: Phytoseiidae). Hilgardia, v.56, p.1-20, 1988.

JARDIM, M.A.G.; ANDERSON, A.B. Manejo de populações nativas de açaizeiro no estuário amazônico. Boletim de Pesquisa Florestal, v.15, p.1-8, 1987.

JEPPSON, L.R; KEIFER, H.H.; BAKER, E.W. Mites injurious to economic plants. Berkeley: University of California Press, 1975. 614p.

KAZMIERSKI, A. A revision of the subfamilies Pretydeinae and Tydeinae (Acari: Actinedida: Tydeidae). Part II. The subfamily Pretydeinae Andre, 1979 - new taxa, species review, key and considerations. Mitteilungen aus dem Hamburgischen Zoologischen Museum und Institut, v.93, p.171-198, 1996.

KEIFER, H.H. Eriophyd studies B-9. Sacramento: California Bureau of Entomology, 1963. 20p. (Special Publications).

KEIFER, H.H. Eriophyd Studies B-14. Sacramento: California Bureau of Entomology, 1965a. 20p. (Special Publications).

KEIFER, H.H. Eriophyd Studies B-16. Sacramento: California Bureau of Entomology, 1965b. 20p. (Special Publications).

KEIFER, H.H. Eriophyid Studies C-4. California: United States Department of Agriculture, 1970. 24p. (Special Publications). 
KEIFER, H.H. Eriophyd Studies C-10. California: United States Department of Agriculture, 1975a. 24p. (Special Publication).

KEIFER, H.H. Eriophyid Studies C-11. California: United States Department of Agriculture, 1975b. 24p. (Special Publications).

KENNETT, C.E. Some predacious mites of the subfamilies phytoseiinae and Aceosejinae (Acarina: Phytoseiidae, Aceosejidae) from Central California with description of new species. Annals of the Entomological Society of America, v.51, p.471-479, 1958.

KRANTZ, G.W. A manual of acarology. Oregon: O.S.U. Book Stores, 1970. 335p.

KREITER, S.; MORAES, G.J. Phytoseiid mites (Acari: Phytoseiidae) from Guadaloupe and Martinique. The Florida Entomologist, v.80, p.376-382, 1997.

KUANG, H.Y.; FENG, Y.B. Description of a new genus and three new species of Phyllocoptinae from China (Acariformes: Eriophyidae). Acta Zootaxonomica Sinica, v.14, p.37-41, 1989.

LINDQUIST, E.E.; EVANS, G.O. Taxonomic concepts in the Ascidae, with a modified setal nomenclature for the idiosoma of the Gamasina (Acarina: Mesostigmata). Memories of the Entomological Society of Canadian, v.47, p.1-59, 1965.

LOFEGO, A.C. Caracterização morfológica e distribuição geográfica das espécies de Amblyseiinae (Acari: Phytoseiidae) no Brasil, 1998. 167p. Dissertação (mestrado) Escola Superior de Agricultura "Luiz de Quairoz", Universidade de São Paulo. 
LORENZI, H. Árvores brasileiras - manual de Identificação e cultivo de plantas arbóreas nativas do Brasil. Nova Odessa: Plantarum, 1993. 384p.

LORENZI, H. Palmeiras no Brasil: nativas e exóticas. Nova Odessa: Editora Plantarum, 1996. 303p.

MACARTO, A.C. A família Palmae na cadeia do espinhaço em Minas Gerais. São Paulo, 1999. 86p. Dissertação (mestrado) - Instituto de Biociências, Universidade de São Paulo.

MANSON, D.C.M.; OLDFIELD, G.N. Spermatophore deposition, mating behavior and population mating structure. In: LINDQUIST, E.E.; SABELIS, M.W.; BRUIN, J. (Ed.). Eriophyoid mites: their biology, natural enemies and control. Amsterdan: Elsevier, 1996. p.185-198.

MATTHYSSE, J.G.; DENMARK H.A. Some phytoseiids of Nigeria (Acarina: Phytoseiidae). The Florida Entomologist, v.64, p.340-357, 1981.

MAYR, E. Populations, species, and evolution. Cambridge: Harvard University Press, 1977. 453p.

McGREGOR, E.A. Four new tetranychids. Annual of Entomological Society of America, v.7, p.354-364, 1914.

McGREGOR, E.A. Mites of the family Tetranychidae. Americam Middland Naturalist, v.44, p.142-144, 1950.

McGREGOR, E.A. Two new mites in the genus Typhlodromus (Acarina: Phytoseiidae). Bulletin Society California Academy of Sciences, v.53, p.89-92, 1954. 
McMURTRY, J.A. Biosystematics of threee taxa $\mathrm{n}$ the Amblyseius finlandicus group from South Africa, with comparative life history studies (Acarina: Phytoseiidae). International Journal of Acarology, v.6, n.2, p.147-156, 1980.

McMURTRY, J.A. Phytoseiid mites from Guatemala, with descriptions of two new species and redefinitions of the genera Euseius, Typhlodromus and the Typhlodromus occidentalis species group (Acari: Mesostigmata). International Journal of Entomology, v.25, p.249-272, 1983.

McMURTRY, J.A.; HUFFAKER, C.B.; van de VRIE, M. Ecology of tetranychid mites and their natural enemies: a review. I. Tetranychid enemies: their biological characteres and the impact of spray pratices. Hilgardia, v.40, n.11, p.331-390, 1970.

McMURTRY, J.A.; MORAES, G.J. Some phytoseiid mites from the South Pacific, with descriptions of new species and a definition of the Amblyseius largoensis species group. International Journal of Acarology, v.10, p.27-37, 1984.

McMURTRY, J.A.; MORAES, G.J. Some phytoseiid mites from Peru with descriptions of four new species (Acari: Phytoseiidae). International Journal of Acarology, v.15, n.3, p.179-188, 1989.

MIJUSKOVIC, M.; TOMASEVIC, B. The mites on the citrus trees on the Yugoslav littoral. Society for Science and Art of Montenegro, Monographs, v. 1, p.1-203, 1975.

MOHANASUNDARAM, M. Four new species of phyllocoptinae mites (Eriophyidae: Acarina) from Tamil Nadu, India. Entomon, v.7, p.23-30, 1982. 
MOORE, D.; HOWARD, F.W. Coconuts. In: LINDQUIST, E.E.; SABELIS, M.W. BRUIN, J. (Ed.). Eriophyid mites: their biology, natural enemies and control. Amsterdan: Elsevier, 1996. p. 561-570.

MORAES, G.J. de. Controle biológico de ácaros fitófagos. Informe Agropecuário, v.15, p.53-55, 1991.

MORAES, G.J.; DENMARK, H.A.; GUERRERO, J.M. Phytoseiid mites of Colômbia (Acarina: Phytoseiidae). International Journal of Acarology, v.8, n.1, p.15-22, 1982.

MORAES, G.J. de; McMURTRY, J.A. Phytoseiid mites (Acari) of Northeastern Brazil with descritions of four new species. International Journal of Acarology, v.9, n.3, p.131-148, 1983.

MORAES, G.J. de; McMURTRY, J.A.; DENMARK, H.A. A catalog of the family Phytoseiidae: refereces to taxonomy, synonymy, distribution and habitat. Brasília: EMBRAPA, 1986.353p.

MORAES, G.J.; MESA, N.C. Mites of the family Phytoseiidae (Acari) in Colômbia, with descriptions of three new species. International Journal of Acarology, v.14, n.2, p.71-88, 1988.

MORAES, G.J.; MESA, N.C.; BRAUN, A. Some phytoseiid mites of Latin America (Acari: Phytoseiidae). International Journal of Acarology, v.17, n.2, p.117-139, 1991.

MORAES, G.J.; MESA, N.C.; BRAUN, A.; MELO, E.L. Definition of the Amblyseius limonicus species group (Acari: Phytoseiidae), with descriptions of two new species and new records. International Journal of Acarology, v.20, n.3, p.209-217, 1994. 
MORAES, G.J.; OLIVEIRA, J.V. Phytoseiidae mites of costal Pernambuco in Northeastern Brazil. Acarologia, v.23, n.4, p.315-318, 1982.

MUMA, M.H. Phytoseiidae (Acarina) associeted with citrus in Florida. Annals of the Entomological Society of America, v.48, p.262-272, 1955.

MUMA, M.H. Subfamiles, genera, and species of Phytoseiidae (Acarina: Mesostigmata). Florida State Museum Bulletin Biology Sciences, v.5, p.267-302, 1961.

MUMA, M.H. New Phytoseiidae (Acarina: Mesostigmata) from Florida. The Florida Entomologist, v.45, p.1-10, 1962.

MUMA, M.H. The genus Galendromus Muma, 1961 (Acarina: Phytoseiidae). The Florida Entomologist, Suppl. 1, p.15-41, 1963.

MUMA, M.H.; DENMARK, H.A. Some generic descriptions and name changes in the family Phytoseiidae (Acarina: Mesostigmata). The Florida Entomologist, v.51, p.229-240, 1968.

MUMA, M.H.; DENMARK, H.A. The conspicua species-group of Typhlodromina Muma, 1961. Annals of the Entomological Society of America, v.62, p.406-413, 1969.

MUMA, M.H.; DENMARK, H.A. Phytoseiidae of Florida. Arthropods of Florida and neighboring land areas. Gainnesville: Florida Department Agriculture Cons. Serv., Div. Plant Ind., 1970. 150p. 
NESBITT, H.H.J. A taxonomic study of the Phytoseinae (Family: Laelaptidae) predaceous upon Tetranychidae of economic importance. Zoologische verhandelingen vitgegeven door het Rijksmuseum van Natuurlijke Historie te Leiden. v.12, p.1-64, 1951.

OCHOA, R.; AGUILAR, H.; VARGAS, C. Ácaros fitofagos de America Central: guia ilustrada. Turrialba: CATIE. 1991. 251p.

OLDFIELD, G.N. The biology and morphology of Eriophyes emarginatae, a prunus finger gall mite, and notes on E. prunidemissae. Annals of the Entomological Society of America, 62, n.2, p.269-277, 1969.

OLDFIELD, G.N. Sperm storage in female Eriophyoidea (Acarina). Annals of the Entomological Society of America, v.66, n.5, p.1089-1092, 1973.

OLDFIELD, G.N. Diversity and host plant specificity. In: LINDQUIST. E.E.; SABELIS, M.W.; BRUIN, J. (Ed.). Eriophyoid mites: their biology, natural enemies and control. Amsterdan: Elsevier, 1996. p. 199-216.

OLDFIELD, G.N.; HOBZA, R.F.; WILSON, N.S. Discovery and characterization od spermatiphores in the Eriophyoidea (Acari). Annals of the Entomological Society of America, v.63, n.2, p.520-526, 1970.

OLDFIELD, G.N.; MICHALSKA, K. Spermatophore deposition, mating behavior and population mating structure. In: LINDQUIST, E.E.; SABELIS, M.W.; BRUIN, J. (Eds.). Eriophyoid mites: their biology, natural enemies and control. Amsterdan: Elsevier, 1996. p.185-198. 
OLDFIELD, G.N.; NEWELL, I.M. The spermatophore as the source of sperm for deutogynes of Aculus cornutus (Acari: Eriophyidae). Annals of the Entomological Society of America, v.66; n.1, p.223-225, 1973a.

OLDFIELD, G.N.; NEWELL, I.M. The role of the spermatophore in the reprodutive biology of protogynes of Aculus cornutus (Acarina: Eriophyidae). Annals of the Entomological society of America., v.66, n.1, p.160-163, 1973b.

PEREZ-INIGO, C.; BAGGIO, D. Oribates 'daphiques du Brésil (VIII). Oribates de l'état de São Paulo (Cinquienu Partie). Acarologia, v.35, p.181-198, 1994.

PEREZ-INIGO, C.; BAGGIO, D. Oribates édaphiques du Brésil (IX). Oribates de l'état de Minas Gerais (Premiere Partie). Acarologia, v.37, p.61-72, 1996.

PEREZ-INIGO, C.; BAGGIO, D. Oribates édaphiques du Brésil (X): Qualques oribates de l'état de Pará. Acarologia, v.38, p.403-413, 1997.

PRITCHARD, A.E.; BAKER, E.W. A revision of the spider mite family Tetranychidae. San Francisco: The Pacific Coast Entomological Society, 1955. $472 \mathrm{p}$.

REIS, P.R.; CHIAVEGATO, L.G.; ALVES, E.B. Biologia de Iphiseiodes zuluagai Denmark \& Muma (Acari: Phytoseiidae). Anais da Sociedade Entomológica do Brasil, v.27, n.2, p.185-191, 1998.

ROBBS, C.F.; PERACCHI, A.L. Sobre a ocorrência de um ácaro prejudicial ao coqueiro (Cocos nucifera L.). In: REUNIĀO FITOSSANITÁRIA, Rio de Janeiro, 1965. Anais. Rio de Janeiro: 1965. p.65-70. 
RODRIGUES, R.R. Trilha do parque da ESALQ: Palmeiras. Piracicaba: FEALQ, 1994. 31p.

ROWELL, H.J.; CHANT, D.A. Observations on the ontogeny of setae in the family Phytoseiidae (Acarina: Gamasina). Canadian Journal of Zoology. v.57, n.3, p.670-681, 1979.

ROWELL, H.J.; CHANT, D.A.; HANSELL, I.C. The determination of setal homologies and setal patterns on the dorsal shield in the family Phytoseiidae (Acarina: Mesostigmata). Canadian Entomologist. v.110, p.859-876, 1978.

SANTANA, D.L.Q.; FLECHTMANN, C.H.W. Mite (Artbropoda: Acari) associates of palms (Arecaceae) in Brazil. I. Present status and new records. Revista Brasileira de Zoologia, v.15, n.4, p.959-963, 1998.

SANTANA, D.L. de Q.; FLECHTMANN, C.H.W.; LIMA, M.F. Novos ácaros do coqueiro no Brasil. Aracaju: EMBRAPA/CNPCO, 1994. 4p.

SATHIAMMA, B. World distribution of acarine fauna on the coconut palm. Indian Coconut Journal, v.26, p.7-11, 1995.

SCHICHA, E. Five known and five new species. of phytoseiid mites from Australia and the South Pacific. General and Applied Entomology. v.13, p.29-46, 1981.

SCHICHA, E.; ELSHAFIE, M. Four new species of phytoseiid mites from Australia, and three species from America redescribed (Acari: Phytoseiidae). Journal Australian of Entomological Society, v.19, p.27-36, 1980.

SMILEY, R.L. The predador mite family Cunaxidae (Acari) of the world with a new classification. Michigan: Indira Publishing House, 1992. 356p. 
SPECHT, H.B.; RASMY, A.H. A new phytoseiid (Acarina: Mesostigmata) from applean Nova Scotia. Canadian Entomologist, v.102, p.1022-1024, 1970.

SUMMERS, F.M.; PRICE, D.W. A review of the mite Cheyletidae. University of California Publications in Entomology, v.61, p.1-153, 1970.

TONET, R.M.; FERREIRA, L.G. de S.; OTOBONI, J.L. de M. Levantamento e situação da cultura da pupunha no Estado de São Paulo. Campinas, 1999, 9p.

TSENG, Y.H. Systematics of the mite family Phytoseiidae from Taiwan, with a revised key to genera of the world (II). Journal Agriculture Association of China. New Series, v.94, p.85-128, 1976.

UECKERMANN, E.A.; LOOTS, G.C. The African species of the subgenera Anthoseius DeLeon and Amblyseius Berlese (Acari: Phytoseiidae). Entomology Memoir Department of Agriculture and Water Suppl., v.73. p.1-168, 1988.

UHL, N.W.; DRANSFIELD, J. Genera Palmarum: a classificastion of palms based on the work of Harold E. Moore Jr. Kansas: Allen Press, 1987. 610p.

Van der MERWE, G.G. A taxonomic study of the family Phytoseiidae (Acari) in South Africa with contributions to the biology of two species. South Africa Department of Agriculture Technology Services, Entomol. Mem, v.18, p.1-198, 1968.

WAINSTEIN, B.A. Some new predatory mites of the family Phytoseiidae (Parasitiformes) of the USSR fauna. Entomological Review, v.41, p.139-146, 1962. 
WAINSTEIN, B.A.; VARTAPETOV, S.C. A new species of the genus Amblyseius Berlese (Parasitiformes, Phytoseiidae). Zoological Journal, v.52, n.7, p.10851086, 1973.

WERREN, J.H. Biology of Wolbachia. Annual Review of Entomology, v.42, p.587609, 1997.

WISNIEWSKI, J. DIE UROPODIDEN DER ERDE NACH ZOOGEOGRAPHISCHEN REGIONEN UND SUBREGIONEN GEORDNET. Acarologie, v.40, p.221-291, 1993.

WOMERSLEY, H. Species of the subfamily Phytoseiinae (Acarina: Laelaptidae) from Australia. Australian Journal of Zoology, v.2, p.169-191, 1954.

YAMAMOTO, P.C.; GRAVENA, S. Influência da temperatura e fontes de alimento no desenvolvimento e oviposição de Iphiseiodes zuluagai Denmark \& Muma (Acari: Phytoseiidae). Anais da Sociedade Entomológica do Brasil, v.25, n.1, p.109-115, 1996.

YOSHIDA-SHAUL, E.; CHANT, D.A. A world review of the genus Phytoscutus Muma (Phytoseiidae: Acari). Acarologia, v.38, p.219-238, 1997.

ZACARIAS, M.S.; NICOLINO, C.A.C. Nova técnica de criação de ácaros. In: CONGRESSO DA PÓS-GRADUAÇÃO NA ESAL, 6., Lavras, 1993. Resumos. Lavras: ESAL, 1993. p.79. 